\title{
Sistemas de Informação Cientes de Processos, Robustos e Confiáveis
}

\author{
André Luis Schwerz \\ TESE APRESENTADA \\ $\mathrm{AO}$ \\ Instituto DE MATEMÁticA E EstatísticA \\ DA \\ UNIVERSIDADE DE SÃo PAUlO \\ PARA \\ OBTENÇÃO DO TÍTULO \\ DE \\ DOUTOR EM CIÊNCIAS
}

Programa: Pós-Graduação em Ciência da Computação

Orientador: Prof. Dr. João Eduardo Ferreira

Durante o desenvolvimento deste trabalho o autor recebeu auxílio financeiro da Fundação Araucária - Projeto DINTER - Doutorado Interinstitucional UTFPR/USP

São Paulo, Novembro de 2016 


\section{Sistemas de Informação Cientes de Processos, Robustos e Confiáveis}

Esta versão da tese contém as correções e alterações sugeridas pela Comissão Julgadora durante a defesa da versão original do trabalho, realizada em 08/12/2016. Uma cópia da versão original está disponível no Instituto de Matemática e Estatística da Universidade de São Paulo.

Comissão Julgadora:

- Prof. Dr. João Eduardo Ferreira (orientador) - IME-USP

- Prof. Dr. Marcelo Finger - IME-USP

- Prof. Dr. Márcio Katsumi Oikawa - UFABC

- Prof. Dr. Duncan Dugubras Alcoba Ruiz - PUC-RS

- Prof. Dr. Javam de Castro Machado - UFC 


\section{Agradecimentos}

Agradeço ao meu orientador Prof. João Eduardo Ferreira pela paciência, dedicação, atenção e parceria durante todos esses anos. Muito obrigado por sempre ter me motivado e apoiado. Espero que em algum dia eu seja capaz de retribuir todo seu esforço para tornar este trabalho uma realidade.

Agradeço também ao Prof. Calton Pu pelas suas importantes sugestões para melhoria deste trabalho e, em conjunto com seus alunos, por me receberem na Georgia Tech. Também agradeço ao Programa Ciências sem Fronteiras pelo financiamento do período sanduíche em Atlanta-USA.

Agradeço a Fundação Araucária pelo financiamento do Projeto de Doutorado Interinstitucional (DINTER) que possibilitou este trabalho de doutorado. Agradeço aos professores Fabio Kon e Carlos Eduardo Ferreira do IME-USP e aos professores Luiz Nakamura e Reginaldo Ré da UTFPR pelo empenho e apoio para que o DINTER IME/USP - UTFPR tenha sido realizado. Agradeço aos professores Alfredo Goldman, Fabio Kon, Marco Gerosa, João Eduardo e Carlos Ferreira que se dispuseram a ministrar suas disciplinas em Campo Mourão-PR enfrentando vários transtornos devido aos seus deslocamentos. Agradeço também aos professores Marcelo Finger, Marco Casanova e Fábio Porto por suas contribuições no exame de qualificação.

Agradeço ao Rafael Liberato, não apenas pela inúmeras figuras que produziu para este trabalho, mas, principalmente, pelo seu companheirismo e amizade dos últimos anos. Agradeço aos meus companheiros de DINTER, Ivanilton Polato, Igor Wiese, Rafael Liberato, Igor Steinmacher, Marcos Silvano, Wellington Previero, Luiz Arthur, Rodrigo Campiolo, Francisco Pereira, Lúcio Valentin, Rogério Gonçalves, André Kawamoto, Alessandro Kraemer e Frank Helbert por dividirem o escasso espaço do laboratório E-104 durante o período de créditos e pelo companheirismo durante todos esses anos. Agradeço ao pessoal do Grupo DATA, Bruno Padilha, Mina Cintho, Pedro Takecian, Osvaldo Takai, Marcela Ortega e Pedro Paulo, pelo recebimento no IME-USP e pela importante ajuda prestada em várias situações. Agradeço aos meus alunos da UTFPR que, por muitas vezes, tiveram seus horários alterados para se adaptarem as minhas constantes ausências. Agradeço ao Departamento de Computação e aos funcionários da UTFPR e do IME-USP pelo apoio em várias situações.

Agradeço a toda minha família por compreender minhas ausências e me incentivar nos momentos mais difíceis. Agradeço especialmente aos meus pais Egon e Leonice, meu avô Kurt, minha irmã Lissandra, minha sobrinha Larissa e ao meu cunhado Marcelo por reduzirem a distância entre nós com mensagens de apoio, incentivo e carinho e por me permitirem, mesmo que a distância, participar de suas vidas. Agradeço a minha amada esposa Roseli por seu amor incondicional, por dividir as minhas alegrias e preocupações e por aceitar minhas constantes ausências durante esses anos. O seu companheirismo e amor foram fundamentais nesta jornada. Por fim, gostaria de agradecer a pequena Heloísa por iluminar os nossos corações com o seu maravilho sorriso todas as manhãs. 


\section{Resumo}

\section{SCHWERZ, A. L. Sistemas de Informação Cientes de Processos, Robustos e Confiáveis.}

2016. 103 f. Tese (Doutorado) - Instituto de Matemática e Estatística, Universidade de São Paulo, São Paulo, 2016.

Atualmente, diversas empresas e organizações estão cada vez mais empreendendo esforços para transformar rapidamente as suas potenciais ideias em produtos e serviços. Esses esforços também têm estimulado a evolução dos sistemas de informação que passaram a ser apoiados por modelos de alto nível de abstração para descrever a lógica do processo. Neste contexto, destaca-se o sucesso dos Sistemas de Informação cientes de Processos (PAIS, do inglês Process-Aware Information Systems) para o gerenciamento de processos de negócios e automação de processos científicos de larga escala (e-Science). Grande parte do sucesso dos PAIS é devido à capacidade de prover funcionalidades genéricas para modelagem, execução e monitoramento dos processos. Essas características são bemsucedidas quando os modelos de processos têm um caminho bem-comportado no sentido de atingir os seus objetivos. No entanto, situações anômalas que desviam a execução desse caminho bemcomportado ainda representam um significativo desafio para os PAIS. Por causa dos vários tipos de falhas que desviam a execução do comportamento esperado, prover uma execução robusta e confiável é uma tarefa complexa para os atuais PAIS, uma vez que nem todas as situações de falha podem ser eficientemente descritas dentro da estrutura do fluxo tradicional. Como consequência, o tratamento de tais situações geralmente envolve intervenções manuais nos sistemas por operadores humanos, o que resulta em custos adicionais e significativos para as empresas. Neste trabalho é introduzido um método de composição para recuperação ciente de custos e benefícios que é capaz de encontrar e seguir caminhos alternativos que reduzam os prejuízos financeiros do tratamento de exceções. Do ponto de vista prático, esse método provê o tratamento de exceção automatizado e otimizado ao calcular os custos e benefícios de cada caminho de recuperação e escolher o caminho com a melhor relação custo-benefício disponível. Mais especificamente, o método de recuperação proposto estende a abordagem WED-flow (Workflow, Event processing and Data-flow) para permitir a composição ciente de custos e benefícios de passos de recuperação transacionais backward e forward. Por fim, os experimentos mostram que esse método de recuperação pode ser adequadamente incorporado para manipular exceções em uma ampla variedade de processos.

Palavras-chave: Sistemas de Informação cientes de Processos, Confiabilidade, Robustez, WEDflow, Tratamento de Exceção. 


\section{Abstract}

SCHWERZ, A. L. Robust and Reliable Process-Aware Information Systems. 2016. 103 f. Tese(Doutorado) - Instituto de Matemática e Estatística, Universidade de São Paulo, São Paulo, 2016.

Nowadays, many corporations and organizations are increasingly making efforts to transform quickly and effectively their potential ideas into products and services. These efforts have also stimulated the evolution of information systems that are now supported by higher-level abstract models to describe the process logic. In this context, several sophisticated Process-Aware Information Systems (PAIS) have successfully been proposed for managing business processes and automating largescale scientific (e-Science) processes. Much of this success is due to their ability to provide generic functionality for modeling, execution and monitoring processes. These functionalities work well when process models have a well-behaved path towards achieving their objectives. However, anomalous situations that fall outside of the well-behaved execution path still pose a significant challenge to PAIS. Because of the many types of failures that may deviate execution away from expected behaviors, provision of robust and reliable execution is a complex task for current PAIS, since not all failure situations can be efficiently modeled within the traditional flow structure. As a consequence, the treatment for such situations usually involves interventions in systems by human operators, which result in significant additional cost for businesses. In this work, we introduce a cost/benefitaware recovery composition method that is able to find and follow alternative paths to reduce the financial side effects of exception handling. From a practical point of view, this method provides the automated and optimized exception handling, by calculating the cost and benefits of each recovery path, and choosing the recovery path with the best cost/benefits available. More specifically, our recovery method extends the WED-flow (Workflow, Event processing and Data-flow) approach for enabling cost/benefit-aware composition of forward and/or backward transactional recovery steps. Finally, the experiments point out that this recovery method can be suitably incorporated into exception handling within a wide variety of processes.

Keywords: Process-Aware Information Systems, Reliability, Robustness, WED-flow, Exception Handling. 


\section{Sumário}

Lista de Abreviaturas $\quad$ vi

Lista de Figuras $\quad$ vii

$\begin{array}{lc}\text { Lista de Tabelas } & \text { ix }\end{array}$

1 Introdução $\quad 1$

1.1 Caracterização do problema . . . . . . . . . . . . . . . . . 2

1.2 Questão de Pesquisa . . . . . . . . . . . . . . . . . . . . . 3

1.3 Trabalhos Relacionados . . . . . . . . . . . . . . . . . . . . 3

1.4 Hipótese e sua Justificativa . . . . . . . . . . . . . . . . . . . . . 5

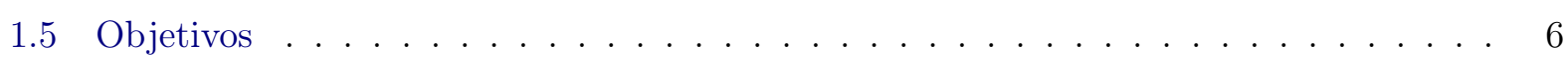

1.6 Publicações . . . . . . . . . . . . . . . . . . . . . . . . 6

1.7 Organização da Tese . . . . . . . . . . . . . . . . 7

2 Sistemas de Informação cientes de Processos $\quad 8$

2.1 Modelos de Processos Tradicionais . . . . . . . . . . . . . . . . . . . . . . . 9

2.1 .1 Redes de Petri . . . . . . . . . . . . . . . . . . . . . 9 9

2.1.2 Modelos de Processos baseados em Grafos . . . . . . . . . . . . . . . . . . 11

2.1 .3 Álgebra de Processos . . . . . . . . . . . . . . . . . . . . . . . . . 12

2.2 Modelos Declarativos . . . . . . . . . . . . . . . . . . . . . . . 14

2.2 .1 Abordagem baseada em regras . . . . . . . . . . . . . . 15

2.2.2 Abordagens baseadas em restrições . . . . . . . . . . . . . . . . . . . . 16

2.3 Considerações Finais ． . . . . . . . . . . . . . . . . . . . . 18

3 Modelos Transacionais $\quad 20$

3.1 Abordagens que estendem a seriação . . . . . . . . . . . . . . . . . 23

3.1 .1 Modelo Transacional Hierárquico . . . . . . . . . . . . . . . . . . . 23

3.1 .2 Bloqueio Altruísta . . . . . . . . . . . . . . . . . . . 25

3.1.3 Transações Emaranhadas . . . . . . . . . . . . . . . . . . . 27

3.2 Abordagens que flexibilizam a seriação . . . . . . . . . . . . . . . . . . . 30

3.2 .1 Modelo SAGAS . . . . . . . . . . . . . . . . . . . . . 31

3.2.2 Modelo Transacional Hierárquico Aberto . . . . . . . . . . . . . . . . . . . . . 32

3.3 Abordagens que substituem a seriação . . . . . . . . . . . . . . . . . 35

3.3 .1 Modelo ConTract . . . . . . . . . . . . . . . . . . . . . 35

3.3 .2 Consistência Linear . . . . . . . . . . . . . . . . . . . . . . . . . . . . . . . . . 41 
3.4 Considerações Finais . . . . . . . . . . . . . . . . . . . . . . . . 44

4 A Abordagem WED-flow $\quad 46$

4.1 Definições da abordagem WED-flow . . . . . . . . . . . . . . . . 47

4.2 Modelagem de processos na abordagem WED-flow . . . . . . . . . . . . 48

4.3 Expressividade da abordagem WED-flow . . . . . . . . . . . . . . 51

4.4 Consistência da aplicação . . . . . . . . . . . . . . . . . 54

4.5 Métodos de Recuperação . . . . . . . . . . . . . . . . . . . . . . 56

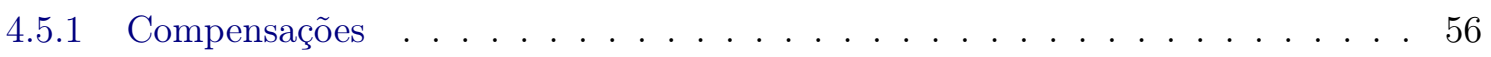

4.5.2 Exceções previstas . . . . . . . . . . . . . . . . . . . 57

4.5 .3 Exceções imprevistas . . . . . . . . . . . . . . . . . . 60

4.6 Propriedades de consistência . . . . . . . . . . . . . . . . . . . 62

4.7 Considerações Finais . . . . . . . . . . . . . . . . . . . . . . . . . . . 64

5 Método de Composição para Recuperação ciente de Custos e Benefícios $\quad 65$

5.1 Considerações para Recuperação da AWIC-Consistência . . . . . . . . . . . . . . . 65

5.2 Apoio WED-flow para o Cálculo do Lucro Estimado . . . . . . . . . . . . . . . . . . . . . . 66

5.3 Composição Automática para Recuperação WED-flow . . . . . . . . . . . . . . . 68

5.4 Exemplos de Caminhos Secundários obtidos pela Recuperação . . . . . . . . . . . . . 71

5.5 Algoritmo de Otimização . . . . . . . . . . . . . . . . . . . . . . . . . . . . . 74

6 Resultados Experimentais $\quad 78$

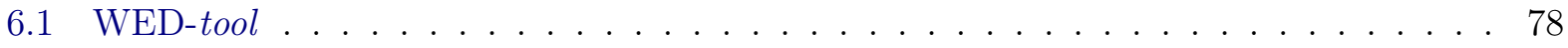

6.2 Configuração dos Experimentos . . . . . . . . . . . . . . . . . . . . 79

6.3 Resultados . . . . . . . . . . . . . . . . . . . 80

6.4 Discussão . . . . . . . . . . . . . . . . . . . . . . . . . 80

7 Conclusão $\quad 82$

7.1 Considerações finais . . . . . . . . . . . . . . . . . . . . . 82

7.2 Sugestões para Pesquisas Futuras . . . . . . . . . . . . . . . . . 83

$\begin{array}{ll}\text { Referências Bibliográficas } & 85\end{array}$ 


\section{Lista de Abreviaturas}

$\begin{array}{ll}\text { ACID } & \text { Atomicidade, Consistência, Isolamento e Durabilidade } \\ \text { AWIC } & \text { Application-Wide Integrity Constraint } \\ \text { BPA } & \text { Basic Process Algebra } \\ \text { DATA } & \text { Database Modeling, Transactions, and Data Analysis } \\ \text { ECA } & \text { Evento, Condição e Ação } \\ \text { ETM } & \text { Extended Transaction Models } \\ \text { FIFO } & \text { First In, First Out } \\ \text { LLT } & \text { Long-lived Transactions } \\ \text { LTL } & \text { Lógica Temporal Linear } \\ \text { PAIS } & \text { Process-aware Infomation Systems } \\ \text { SGBD } & \text { Sistemas de Gerenciamento de Banco de Dados } \\ \text { TAD } & \text { Tipo Abstrato de Dados } \\ \text { XML } & \text { Extensible Markup Language } \\ \text { WED-flow } & \text { Workflow, Event processing and Data-flow }\end{array}$




\section{Lista de Figuras}

2.1 Representação gráfica dos elementos básicos das Redes de Petri . . . . . . . . . . . . 10

2.2 Um comparativo intuitivo entre os modelos de processos baseados em restrições e procedurais adaptado de $($ Montali, 2010) . . . . . . . . . . . . 16

2.3 Um exemplo de um modelo de processos baseado em restrições . . . . . . . . . . . 17

2.4 Um exemplo de um mecanismo de execução de uma instância em um modelo baseado em restrições . . . . . . . . . . . . . . . . . . . . . . . . . 18

3.1 Comportamento dinâmico das Esferas de Controle . . . . . . . . . . . . . . . . . 22

3.2 Exemplo da Transação Aninhada . . . . . . . . . . . . . . . . . . . . . . . . . 24

3.3 Motivação para o Bloqueio Altruísta . . . . . . . . . . . . . . . . . . 26

3.4 (a) Banco de Dados dos voos; (b) Satisfação mútua das restrições . . . . . . . . . . . 28

3.5 (a) Representação intermediária das consultas emaranhadas; (b) Avaliação das tuplas encontradas . . . . . . . . . . . . . . . . . . . . . . 29

3.6 Execução concorrente de transações multiníveis . . . . . . . . . . . . . . . . 33

3.7 Representação gráfica do processo para reserva de viagens . . . . . . . . . . . . . . . . . . . . . . . . .

3.8 Fragmento do código do passo Reserva de voo . . . . . . . . . . . . . . . . 37

3.9 Script do processo de Reserva de Viagem . . . . . . . . . . . . . . . . . . 38

3.10 Especificação das compensações no script . . . . . . . . . . . . . . . . . . 40

3.11 Especificação das invariantes no script . . . . . . . . . . . . . . . . . . . 41

3.12 As três fases da execução de uma operação . . . . . . . . . . . . . . . . . . . . . 42

3.13 Axiomas das operações ENQ e DEQ . . . . . . . . . . . . . . . . . . . . 43

3.14 (a) História linearmente consistente; (b) Execução não linearmente consistente . . . . 43

4.1 Representação clássica de um caminho primário para o processo Solicitação de Reserva de Veículo . . . . . . . . . . . . . . . . . . . . . . . . . . . . 48

4.2 Entidades participantes do processo solicitação de reserva do veículo. As linhas pontilhadas representam a ordenação temporal dos eventos . . . . . . . . . . . . . 49

4.3 Representação WED-flow adaptado de (Ferreira et al., 2010b) . . . . . . . . . . . . . 50

4.4 Processo de solicitação de reserva de veículo: (a) Representação dos elementos WEDflow e (b) WED-states para o caminho primário . . . . . . . . . . . . . 51

4.5 Representação textual do processo Solicitação de Reserva de Veículo de acordo com as definições WED-flow . . . . . . . . . . . . . . . . . . . 52

4.6 Padrões de junção e disjunção estudados em (Liberato et al., 2015) . . . . . . . . . . 53

4.7 Estruturas polimórficas WED-flow para representação dos comportamentos de (a) disjunção e de $($ b) junção . . . . . . . . . . . . . . . . . . . . . . . . . . . 53 
4.8 Uma instância WED-flow pode alcançar três classes de WED-states: AWIC-consistente, transação-consistente e inconsistente . . . . . . . . . . . . . . . 56

4.9 Execução da WED-compensation para o cancelamento da reserva do veículo . . . . . 57

4.10 Uma nova ordenação temporal dos eventos no qual um evento de exceção é considerado 58

4.11 Passo de recuperação forward inserido para tratar um evento de exceção previsto . 58

4.12 Recuperação backward para tratar um evento de cancelamento . . . . . . . . . . . . 59

4.13 Passo de recuperação backward WED- $S^{-1}$ para uma exceção imprevista . . . . . . . 61

4.14 Passo de recuperação forward para uma exceção imprevista . . . . . . . . . . . . . . 62

4.15 Passo de reversão para uma exceção imprevista . . . . . . . . . . . . . . . . . . 63

5.1 Solicitação de reserva de veículo incluindo os valores dos custos e benefícios . . . . . 69

5.2 Exemplo concreto de composição automática para recuperação no WED-flow . . . 69

5.3 Caminho secundário: um outro veículo que satisfaz as preferências do cliente é obtido 72

5.4 Caminho secundário: um veículo de uma categoria mais alta é selecionado . . . . . . 72

5.5 Caminho secundário: nenhum veículo pode ser selecionado e a reserva do cliente é

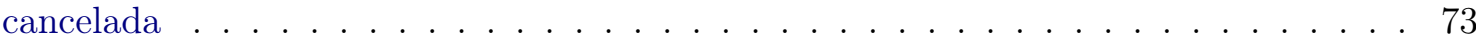

5.6 Caminho secundário: um veículo compacto é transferido de uma filial . . . . . . . . . 73

5.7 Caminho secundário: nenhum veículo é selecionado e o cliente recebe um bônus . . 74

5.8 Algoritmo de otimização para encontrar o caminho secundário de maior lucro . . . . 75

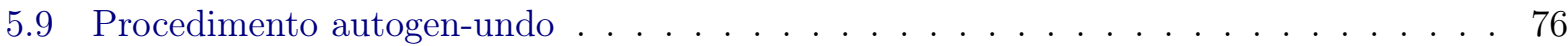

5.10 Procedimento autogen-redo . . . . . . . . . . . . . . . . . . 76

5.11 Procedimento para escolher o caminho secundário mais lucrativo . . . . . . . . . 77

6.1 Visão geral do funcionamento da WED-tool ～. . . . . . . . . . . . . . . . . . . 79

6.2 Resultados experimentais: número de instâncias versus tempo de execução (segundos) 80

6.3 Resultados experimentais: número de instâncias versus tempo médio por instância

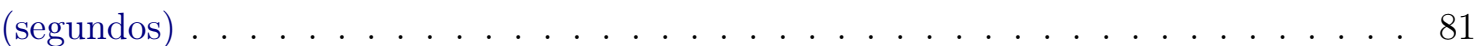




\section{Lista de Tabelas}

2.1 Regras de Transição do BPA . . . . . . . . . . . . . . . . . . . 13

2.2 Exemplo de aplicação das regras de transição do BPA . . . . . . . . . . . . . . . 13

2.3 Axiomas para BPA . . . . . . . . . . . . . . . . . . . 14

2.4 Regras de Transição para o operador entrelaçamento . . . . . . . . . . . . . . . . . 14

2.5 Categorias de Restrições adaptado de $($ Pesic, 2008) . . . . . . . . . . . . . . 17

3.1 Relação entre as operações e bloqueios abstratos . . . . . . . . . . . . . . . . . 34

3.2 Predicados de conflito . . . . . . . . . . . . . . . . . . . 35

3.3 Operações e suas compensações . . . . . . . . . . . . . . . . . . 35 
LISTA DE TABELAS 


\section{Capítulo 1}

\section{Introdução}

Atualmente, empresas e organizações estão cada vez mais empreendendo esforços para transformar rapidamente suas potenciais ideias em produtos e serviços com um menor custo possível. Por causa dessas emergentes necessidades, os sistemas de informação são obrigados a rapidamente evoluírem em resposta às alterações no ambiente das empresas e organizações provocadas por novas oportunidades ou novos parceiros de negócio. Consequentemente, há uma tendência na direção de abordagens que contemplem a separação de aplicações monolíticas em componentes ou serviços menores com o objetivo de facilitar o reuso, a adaptação e a manutenibilidade. Essa tendência tem estimulado a evolução dos sistemas de informação, que deixaram de ser desenvolvidos puramente baseados em linguagem de programação para ser apoiados por modelos de mais alto nível de abstração que descrevem a lógica dos processos. Essa mudança exigiu dos sistemas de informação um novo requisito: ser cientes ou conhecedores de processos (process-aware). Esses sistemas devem prover um meio eficiente e flexível para organizações e empresas gerenciarem seus processos (Dumas et al., 2005; Reichert e Weber, 2012).

Nesse contexto, os Sistemas de Informação cientes de Processos (PAIS, do inglês Process-Aware Information Systems) têm emergido para proporcionar apoio flexível e dinâmico para o gerenciamento de processos de negócio e na automação de aplicações científicas (e-Science) (Dumas et al. , 2005; Reichert e Weber, 2012). Dumas et al. (2005) foram os pioneiros a definirem PAIS como sistemas de software que gerenciam e executam os processos operacionais que envolvem pessoas, aplicações e/ou bases de dados baseados em modelos de processos. Esses modelos descrevem um processo em um nível mais abstrato que pode ser usado para análise, simulação e visualização (Weske, 2007). Normalmente, um modelo de processos é descrito por atividades, e pelo fluxo de controle e de dados entre elas (Reichert e Weber, 2012).

A representação desses modelos de processos é diversificada. Eles podem ser representados por uma grande variedade de linguagens de modelagem de alto nível como Business Process Model Notation (BPMN) (BPMN, 2011) e linguagens de composição de serviços Web (OASIS, 2007); e por representações matemáticas como Redes de Petri (Murata, 1989), $\pi$-calculus (Milner et al. , 1992) e Álgebra de Processos (Bergstra et al., 2001). Nessas representações, os processos são usualmente descritos como uma sequência de atividades e um conjunto de restrições que determinam explicitamente o controle do fluxo de execução. Essas abordagens apresentam significativas contribuições para a representação computacional de processos cujo comportamento pode ser totalmente pré-especificado.

Os modelos de processos normalmente descrevem explicitamente possíveis caminhos de execu- 
ção baseados no comportamento esperado dos processos. Entretanto, há ainda um desafio para ser superado quando uma execução desvia do caminho pré-estabelecido. PAIS são particularmente vulneráveis às exceções quando comparado aos tradicionais sistemas de informação (Reichert e Weber , 2012). Devido aos diferentes tipos de situações excepcionais que ocorrem no mundo real e que podem desviar a execução a partir dos comportamentos esperados, prover execuções robustas e confiáveis é uma tarefa complexa para os atuais PAIS, uma vez que todas as situações especiais não podem ser eficientemente modeladas dentro da estrutura de fluxo tradicional.

\subsection{Caracterização do problema}

A maioria dos processos tem um objetivo desejado bem definido e um caminho de execução bem-comportado para alcançar esse objetivo por meio de uma sequência pré-estabelecida de passos. Por exemplo, em um cenário de uma empresa de aluguel de veículos, um caminho bem-sucedido inclui, pelo menos, as seguintes atividades: reserva do veículo, pagamento, entrega e devolução do veículo. Esse caminho pré-estabelecido, chamado de caminho primário, é o conjunto mínimo de passos necessários para atingir o objetivo do processo. Em outras palavras, um caminho primário bem-sucedido é uma sequência de estados resultantes de uma execução esperada em que atividades que maximizam os lucros do negócio são executadas. Entretanto, caminhos primários podem ter muitas possibilidades de desvios, terminações malsucedidas e situações anômalas.

Como em todo sistema de informação, exceções e falhas também são inevitáveis em PAIS (Eder e Liebhart, 1996). Por falhas, entende-se quando o sistema não funciona como o esperado como falhas na rede de comunicação, falhas no sistema operacional, falhas de hardware ou colapso do sistema (Eder e Liebhart, 1995). Em banco de dados, por exemplo, falhas comuns são problemas de conexão e disco. Exceções surgem ao longo da execução do processo quando suas atividades não são executadas como planejado ou produzem resultados indesejados (Eder e Liebhart, 1998). Existem diversas razões para situações de exceção. Por exemplo, o processo de aluguel de veículos pode incluir situações como: atraso na devolução; condições inesperadas no veículo como problemas mecânicos ou elétricos; características especiais indisponíveis, como GPS, assentos de segurança para crianças, sistema de cobrança eletrônica de pedágios; entre outras.

Exceções são alvo de interesse deste trabalho e podem ser classificadas em dois tipos: exceções previstas e exceções imprevistas (Eder e Liebhart, 1995). Exceções previstas são comportamentos conhecidos em tempo de projeto, apesar de indesejadas e pouco prováveis em tempo de execução. Mesmo embora os projetistas estejam cientes das exceções previstas e seus efeitos colaterais para o processo, a engenharia dos processos para manipular exceções é custosa por envolver muitos passos de recuperação que necessitam ser cuidadosamente projetados. Um tratamento de exceção genérico é difícil de ser desenvolvido uma vez que ele deveria levar em consideração um estado exponencial de possíveis caminhos alternativos. Por causa disso, muitos PAIS são integrados com linguagens procedurais para codificar rotinas específicas para o tratamento de exceções. Consequentemente, o código do tratamento de exceções, para muitas possibilidades de erros, tende a ser exponencialmente maior do que o do caminho primário. Esse significativo crescimento de código conduz a sérios problemas tal como manutenção, teste e reuso. Além disso, a ocorrência e o tratamento de exceções em tempo de execução não deveria conduzir a perda de desempenho, inconsistências, ou até mesmo, erros mais graves como deadlocks. 
Exceções imprevistas são anomalias causadas por eventos imprevisíveis ao longo da execução dos processos. Quando detectadas, essas exceções normalmente causam um travamento no processo e requerem uma intervenção humana para retornar ao funcionamento. Operadores humanos em centros de atendimento ( call centers) necessitam atualmente tratar a maioria das exceções inesperadas. Eles fornecem um atendimento ao cliente em diferentes alterações ad-hoc tal como compras duplicadas ou incompletas; ou cancelamentos. Eles também são responsáveis por correções de inconsistências no banco de dados verificando taxas e pedidos errôneos e pela deteç̧ão de erros de software ou hardware. Centros de atendimento estão crescendo em taxas sem precedentes causando um considerável prejuízo financeiro para tratar exceções. Por exemplo, o gasto em centros de atendimentos somente nos Estados Unidos é estimado em mais do que 300 bilhões de dólares anuais (Hoffman e Bateson, 2016). Isso é certamente uma forma custosa e ineficiente para tratar essas situações inesperadas.

Um requisito substancial de um PAIS robusto e confiável é a sua flexibilidade e capacidade de tratar exceções que desviam a execução do processo do seu caminho primário. O tratamento de exceção é ainda mais complexo e oneroso quando os efeitos indesejáveis das situações anômalas transcendem os limites da instância do processo no qual a exceção tenha sido detectada. Por exemplo, quando um problema mecânico de um veículo é detectado, a empresa tem que enviá-lo para uma oficina mecânica onde ele será reparado. Devido ao tempo gasto no reparo, o veículo não estará disponível para algumas reservas subsequentes. Isto implica que pelo menos uma reserva não poderá ser concluída e deverá ser remarcada. Devido às diferentes necessidades dos clientes e características do ambiente de execução, cada instância do processo pode ter um caminho de recuperação específico que satisfaz as suas necessidades. Idealmente, a estratégia de recuperação deve ser capaz de encontrar um caminho de recuperação que cause o menor prejuízo para a empresa. No entanto, nenhuma das abordagens estudadas e disponíveis na literatura têm ainda investigado um mecanismo de recuperação automática que seja capaz de encontrar caminhos alternativos que reduzam os prejuízos financeiros do tratamento de exceções.

\subsection{Questão de Pesquisa}

Dado a caracterização do problema acima, é possível definir a seguinte questão de pesquisa que sintetiza os desafios abordados neste trabalho.

QP Como prover automaticamente caminhos de recuperação em PAIS que reduzam o custo financeiro do tratamento de exceções?

\subsection{Trabalhos Relacionados}

Há décadas observa-se a necessidade de PAIS robustos e confiáveis (Eder e Liebhart, 1996; Georgakopoulos et al., 1995). Confiabilidade é uma importante característica inerente aos PAIS que proveem um apoio eficiente e preciso para modelagem e implementação de rotinas de recuperação para manipulação de exceções (por exemplo, exceções previstas). Robustez é a capacidade do PAIS em permanecer em funcionamento mesmo quando exceções imprevistas tenham sido disparadas. PAIS robustos são capazes de conduzir o sistema de um estado inconsistente para um estado de consistência quando uma anormalidade causa um desvio de sua execução. 
As primeiras contribuições são inciativas que buscam incluir conceitos transacionais avançados para apoiar a execução robusta e confiável dos processos (Elmagarmid, 1992). Entre elas, García-Molina e Salem (1987) no Modelo SAGAS foram os primeiros a introduzirem ações de compensação associadas com cada atividade do processo para recuperar a consistência. A semiatomicidade proposta em (Zhang et al., 1994) estende o modelo SAGAS a fim de proporcionar caminhos de execução alternativos que conduzem o processo para um estado final aceitável após uma falha. Opera (Hagen e Alonso, 2000) integra conceitos de linguagem de programação e atomicidade transacional no qual a semântica definida por meio de construtores de linguagem é garantida por um modelo de execução baseado nos modelos transacionais estendidos (ETM, do inglês Extended Transaction Models). Embora grandes esforços tenham sido realizados em vários anos para flexibilizar as propriedades transacionais para apoiar a execução de sistemas confiáveis, contribuições derivadas dos ETM são apenas uma fração de muitos componentes necessários para prover novas abstrações na direção de processos confiáveis e robustos, como argumentado em (Alonso et al., 1996; Bhiri et al., 2006). Bhiri et al. (2006) também argumentam que as estruturas de controles básicas e os conjuntos de restrições não intuitivos impostos nas estruturas do processo são os principais motivos para a adoção limitada dos ETM no apoio das aplicações.

As primeiras contribuições que incorporam sistemas de gerenciamento de workflow com características transacionais para apoiar processos com rotinas de recuperação à falhas bem definidas foram propostas em (Eder e Liebhart, 1996; Georgakopoulos et al., 1996; Sheth e Rusinkiewicz, 1993). O modelo ConTract (Reuter et al., 1997; Wächter e Reuter, 1992) garante a consistência semântica do banco de dados ao permitir que regras de consistência semânticas conhecidas como invariantes sejam definidas e garantidas ao longo da execução. Karnath e Ramamritham (1998) propõem uma abordagem chamada de compensação e re-execução oportunista para reduzir a carga de trabalho da recuperação para tratar exceções ao permitir que o sistema desfaça parcialmente e possa então reexecutar. Task Net (Choi et al., 2002) é um modelo de workflow transacional baseado em Redes de Petri colorida usado para expressar estados de dependências intra e inter-tarefas. Essa contribuição promissora é uma clara evidência que modelos que descrevem o controle do fluxo explicitamente ainda têm desafios relacionados a confiabilidade e flexibilidade para serem superados. A necessidade do mapeamento de dependências a priori implica em uma grande sobrecarga para os analistas e projetistas e leva a concepção de modelos complexos de processos.

Com a tecnologia de workflow consolidada, significativas contribuições para garantir execuções confiáveis também têm sido propostas. Uma classificação baseada em padrões para o tratamento de exceções é proposta em (Russell et al., 2006b). Padrões para o tratamento de exceções também são abordados em (Lerner et al., 2010). Adams et al. (2007) propõem um repertório extensível e autossuficiente de tarefas para manipulação de exceção (chamados de exlets) com base em padrões de exceção em workflow e um conjunto associado de regras de seleção, para apoiar dinamicamente a manipulação de exceção em instâncias de processos. Uma visão mais abrangente que avalia diversas abordagens com relação as suas habilidades de tratar de exceção usando uma abordagem baseada padrões pode ser encontrado em (Russell et al., 2006b). A linguagem Chimera-Exc (Casati et al., 1999) foi especialmente projetada para expressar, capturar e tratar exceções em sistemas de gerenciamento de workflow. Chimera-Exc é uma linguagem baseada em regras ativas isoladas usadas para capturar eventos excepcionais e reagir a eles. Apesar de sua natureza flexível, essas abordagens têm exigido a modelagem completa e a priori dos caminhos alternativos para o tratamento de exceção, 
sem sustentação de propriedades transacionais para prover rotinas automatizadas de recuperação. Consequentemente, quando integramos linguagens específicas para o tratamento de exceção com o sistema de gerenciamento de workflow, o crescimento do código para o tratamento de exceção tende a ser exponencialmente maior do que o caminho primário devido às muitas possibilidade de erros. Esse crescimento conduz a sérios problemas tal como manutenção, teste e reuso. Além disso, essas são perspectivas híbridas no qual o tratamento de exceção é codificado fora do modelo do processo por uma outra linguagem de programação. Perspectivas híbridas no tratamento de exceção são desfavoráveis para aspectos evolucionários dos PAIS.

Atualmente, a Arquitetura Orientada a Serviço (SOA, do inglês Service Oriented Architecture) tem sido largamente adotada em sistemas distribuídos de maneira que diversas técnicas têm sido propostas para composição de serviços Web robustos e confiáveis (Angarita et al., 2015; Bushehrian et al., 2012; Sun et al., 2011). Embora composições de serviços Web estão além do escopo deste trabalho, um dos trabalhos mais importantes combina aspectos de coordenação e de organização dos PAIS e a confiabilidade do processamento de transações para composição de serviços Web (Bhiri et al., 2006). Uma visão mais detalhada pode ser encontrada em (Cardinale et al., 2011).

Todas estas abordagens têm contribuído significativamente para a melhoria do tratamento de exceção em PAIS. No entanto, até agora, com o melhor de nosso conhecimento, nenhuma das novas estratégias inclui um método de recuperação automática e otimizado que é capaz de encontrar e seguir caminhos alternativos que reduzam os custos financeiros do tratamento de exceção.

\subsection{Hipótese e sua Justificativa}

Considerando a questão de pesquisa relacionada acima e as limitações dos PAIS em tratar os diferentes desvios do caminho primário, a hipótese que direcionou o desenvolvimento deste trabalho de pesquisa pode ser sintetizada como:

Hipótese: Funções de custo-benefício podem ser utilizadas para orientar um método automático de composição de passos de recuperação transacional para reduzir os prejuízos financeiros causados por exceções em Sistemas de Informação cientes de Processos.

A detecção e o tratamento automático de exceções discutidos neste trabalho são ainda limitados em vários PAIS. Como discutido na Seção 1.3, um dos motivos dessa limitação é que prover um tratamento de exceção genérico envolve a modelagem de um número exponencial de caminhos de recuperação alternativos. Por causa disso, muitos PAIS propõem abordagens híbridas em que o tratamento de exceção é codificado por meio de alguma linguagem programação. Apesar de melhorarem a flexibilidade, essas abordagens não permitem rotinas automáticas de recuperação para tratamento de exceções, uma vez que não são sustentadas por propriedades transacionais. Abordagens que incorporam características transacionais concentram-se em execuções consistentes que são garantidas por rotinas transacionais de recuperação à falhas. Entretanto, como discutido na Seção 1.3, nenhuma delas propõem alternativas para encontrar caminhos de recuperação que reduzam o prejuízo financeiro do tratamento de exceção. Por causa disso, considera-se, neste trabalho, que o tratamento de exceção pode ser realizado por um método automático de composição para recuperação. Esse método tem como base funções de custo e benefício que podem ser usadas para 
orientar a execução automática de passos de recuperação com o objetivo de minimizar os prejuízos financeiros causados pelas exceções.

\subsection{Objetivos}

O objetivo deste trabalho é introduzir um método de composição para recuperação ciente de custos e benefícios que é capaz de encontrar e seguir caminhos alternativos que reduzam os prejuízos financeiros do tratamento de exceções. Mais especificamente, o método de recuperação proposto estende a abordagem WED-flow (Workflow, Event processing and Data-flow) (Ferreira et al., 2010b, 2012) para permitir a composição ciente de custos e benefícios de passos de recuperação transacionais backward e forward. A abordagem WED-flow provê a especificação de procedimentos de tratamento de exceção, a tradução da especificação em programas executáveis e um ambiente para execução robusto de instâncias WED-flow que podem ser recuperadas automaticamente a partir de falhas e desvios do caminho primário. A abordagem WED-flow fornece um ambiente composição dinâmico no qual diversos métodos de tratamento de exceção podem ser integrados que resultam em resultados consistentes. A principal contribuição deste trabalho é uma extensão da abordagem WED-flow para fornecer o tratamento de exceção automatizado e otimizado ao calcular os custos e benefícios de cada caminho de recuperação e escolher o caminho com a melhor relação custo-benefício disponível.

\subsection{Publicações}

As publicações listadas abaixo são alguns trabalhos produzidos no decorrer do curso de doutoramento e estão relacionados ao desenvolvimento desta tese.

- Rafael Liberato, André Luis Schwerz, Osvaldo Kotaro Takai e João Eduardo Ferreira. Gerenciador de dados compartilhados entre processos de negócio: Data-control process para wed-tool. Em VIII Workshop Brasileiro em Gestão de Processos de Negócios, volume 02 do WBPM 2014, páginas 26-33, Londrina, PR, Brasil (Liberato et al., 2014).

- Rafael Liberato, André Luis Schwerz, Calton Pu e João Eduardo Ferreira. Abordagem transacional para padrões de controle de fluxo de processos científicos e de negócios. Em XXX Simpósio Brasileiro de Banco de Dados, SBBD 2015, páginas 15-20, Petrópolis, RJ, Brasil (Liberato et al., 2015).

- Bruno Padilha, André Luis Schwerz e Rafael Liberato Roberto. WED-SQL: A Relational Framework for Design and Implementation of Process-Aware Information Systems. Proceedings of the IEEE 37th International Conference on Distributed Computing Systems Workshops, ICDCSW 2017, páginas 364-369, Atlanta, GA, USA (Padilha et al., 2017).

- André Luis Schwerz, Rafael Liberato, Calton Pu e João Eduardo Ferreira. Robust and reliable process-aware information system. IEEE Transactions on Services Computing. Aceito para publicação, 2018 (Schwerz et al., 2018). 


\subsection{Organização da Tese}

O restante deste trabalho está organizado da seguinte forma. No Capítulo 2 são discutidos os fundamentos dos Sistemas de Informação cientes de Processos. Mais especificamente, serão discutidos os modelos de processos que são enfatizados na literatura para os PAIS. No Capítulo 3 serão apresentados um resumo das principais soluções transacionais propostas pela comunidade acadêmica de banco de dados e como elas podem ser usadas para apoiar a execução dos processos. Os conceitos de modelagem e as definições da abordagem WED-flow serão apresentados no Capítulo 4. No Capítulo 5, será detalhada a solução proposta para o método de composição de passos para recuperação ciente dos custos e benefícios para o tratamento de exceções. O Capítulo 6 apresentará alguns resultados experimentais e uma discussão sobre as vantagens do método proposto neste trabalho. O Capítulo 7 apresentará as considerações finais sobre o trabalho que inclui uma breve discussão sobre os trabalhos futuros. 


\section{Capítulo 2}

\section{Sistemas de Informação cientes de Processos}

As organizações e empresas têm cada vez mais buscado transformar seus sistemas de informação em conhecedores de processos com o objetivo de melhorar a qualidade e a eficiência de seus produtos e serviços. Neste cenário, os Sistemas de Informação cientes de Processos (PAIS, do inglês ProcessAware Information Systems) têm emergido como uma alternativa flexível e dinâmica para apoiar processos (Dumas et al., 2005). Um processo é um conjunto de atividades que são coordenadas em um ambiente organizacional. Essas atividades realizam conjuntamente o objetivo de negócio. Cada processo é executado por uma única organização, mas pode interagir com processos executados por outras organizações (Weske, 2007).

Para que os processos atualmente automatizados possam aproveitar-se dos benefícios dos PAIS e agregar valor aos produtos e serviços, um procedimento de transição contínuo que envolve significativos esforços de reengenharia e otimização deve ser realizado (Dumas et al., 2005). O objetivo da reengenharia dos processos é reduzir os custos operacionais dos serviços e de manufatura dos produtos, aumentar a satisfação dos clientes e reduzir as taxas de erros.

Nessa reengenharia é necessário que todas as partes interessadas estejam evolvidas e sejam capazes de avaliar o processo de acordo com os seus objetivos. Para atingir esse propósito, o conhecimento do processo deve primeiramente ser descrito na forma de modelos de processos. Weske (2007) define um modelo de processos como um conjunto de atividades e restrições de execução entre elas. Normalmente, esses modelos são representações abstratas e podem ser usados para análise, simulação e visualização dos processos (Reichert e Weber, 2012). Esses modelos são o principal artefato para implementação dos processos (Weske, 2007).

Atividades de um processo podem ser realizadas manualmente ou automatizadas com apoio de sistemas de software. Desta forma, há uma distinção entre modelo de processos e modelo de processos executáveis também chamados de modelo de workflows (Reichert e Weber, 2012). Os sofisticados PAIS descrevem a lógica do processo em termos de modelos de processos executáveis que provê um esquema do processo para a sua execução. Um esquema do processo é descrito por atividades a serem executadas, suas dependências de fluxo, entidades organizacionais que realizam essas atividades e os objetos do negócio que fornecem os dados para as atividades (Weber et al. , 2006). Uma instância do processo representa um caso concreto no negócio da organização que é executado de acordo com o subjacente esquema do processo. 
Há uma grande variabilidade de processos que apresentam diferentes características e necessidades. Reichert e Weber (2012) classificam os processos de acordo com suas especificidades de controle de fluxo. Há processos que são bem estruturados e altamente repetitivos cujo seu comportamento de controle de fluxo pode ser previamente especificado. Por outro lado, há processos que são altamente dinâmicos e de intenso conhecimento cujo controle de fluxo é determinado apenas em tempo de execução. Essas especificidades de controle de fluxo refletem na escolha do modelo mais adequado para modelagem e execução do processo. Para processos cujo a lógica é conhecida a priori e o seu controle de fluxo pode ser previamente determinado, destaca-se os modelos de processos baseados em formalismos matemáticos como Redes de Petri (Murata, 1989), Álgebra de Processos (Fokkink, 2000) e Grafos (Weske, 2007). Por outro lado, quando a lógica do processo não pode ser totalmente especificada previamente, destacam-se abordagens declarativas baseadas em regras (Bry et al., 2006) e restrições (Aalst et al., 2009).

Este capítulo apresenta características das principais estratégias utilizadas nos PAIS para apoiar a modelagem e a execução de processos. Na Seção 2.1, serão apresentados os modelos de processos tradicionais que possuem fundamentos matemáticos sólidos para a modelagem e execução de processos. Nessa seção incluem os modelos de processos baseados em Redes de Petri, Álgebra de Processos e Grafos. Posteriormente, os modelos declarativos serão discutidos na Seção 2.2 que inclui as abordagens baseadas em regras e restrições. As considerações finais são apresentadas na Seção 2.3 .

\subsection{Modelos de Processos Tradicionais}

Nesta seção, serão descritos alguns dos modelos de processos tradicionais cujo formalismo matemático é uma das principais vantagens na modelagem e análise de processos. Na Seção 2.1.1, as Redes de Petri são discutidas como um dos mais tradicionais modelos usados para a modelagem, análise e simulação de processos. Em seguida, os modelos baseados em Grafos e Álgebra de Processos são discutidos nas seções 2.1 .2 e 2.1.3, respectivamente.

\subsubsection{Redes de Petri}

Redes de Petri são usadas para especificação formal de processos. Baseadas em uma linguagem formal, as Redes de Petri são capazes de representar modelos de processos sem ambiguidade. O conceito foi inicialmente proposto por Carl Adam Petri em 1962 e, mais tarde, ficou conhecido como Teoria de Rede de Petri. Redes de Petri são úteis para modelagem de sistemas cujo comportamento é proeminentemente descrito pelo fluxo de controle, informação e objetos. Entre as vantagens das Redes de Petri para modelagem de processos, destacam-se (i) a definição clara e precisa do processo; (ii) a linguagem gráfica intuitiva; (iii) seu alto nível de expressividade; e (iv) os fundamentos matemáticos sólidos usados para prover propriedades e avaliar desempenho dos processos (Aalst, 1998).

Redes de Petri são descritas por lugares (places), transições e arestas direcionadas conectando lugares e transições. Essa representação faz com que ela possa ser descrita como um grafo bipartido, tal que nenhuma aresta conecta dois lugares ou duas transições. Um lugar é um componente passivo da rede que armazena as variáveis de estados. Por outro lado, as transições representam os componentes ativos que correspondem a ações, tarefas ou eventos do processo que resultam na 
movimentação das fichas (tokens). A Figura 2.1 ilustra os componentes básicos das Redes de Petri, na qual um lugar é representado por um círculo e uma transição por um retângulo. As fichas são representadas por círculos sólidos localizados nos lugares. Por ser um grafo bipartido, as arestas podem apenas conectar lugares e transições.

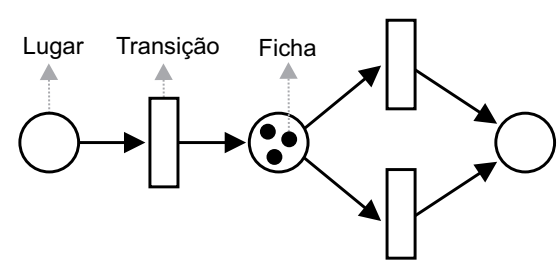

Figura 2.1: Representação gráfica dos elementos básicos das Redes de Petri

O formalismo das Redes de Petri permite a representação precisa e ilustrativa dos processos, além de permitir simulação e análise do controle de fluxo de componentes concorrentes e de fenômeno de sincronização. De acordo com (Weske, 2007), uma Rede de Petri $P N$ é formalmente descrita como:

$$
P N=\langle P, T, F\rangle
$$

em que:

- $P=\left\{p_{1}, p_{2}, \ldots, p_{m}\right\}$ é um conjunto finito de lugares;

- $T=\left\{t_{1}, t_{2}, \ldots, t_{n}\right\}$ é um conjunto finito de transições, tal que $P \cap T=\emptyset$;

- $F \subseteq(P \times T) \cup(T \times P)$ é um conjunto de arestas direcionados também chamado de relações de fluxo;

- Um lugar $p \in P$ é um lugar de entrada de uma transição $t \in T$ se, e somente se, existir uma aresta direcionada a partir de $p$ para $t$, isto é, se, e somente se, $(p, t) \in F$. O conjunto de lugares de entrada para uma transição $t$ é denotado por $\bullet$;

- Um lugar $p \in P$ é um lugar de saída de uma transição $t \in T$ se, e somente se, existir uma aresta direcionada a partir de $t$ para $p$, isto é, se, e somente se, $(t, p) \in F$. O conjunto de lugares de saída para uma transição $t$ é denotado por t•;

Toda transição tem pelo menos um lugar de entrada e outro de saída. O comportamento dinâmico do processo é representado por fichas (tokens) armazenadas nos lugares. As fichas podem alterar suas posições de acordo com regras de disparo. A distribuição atual das fichas entre os lugares determina o estado da Rede de Petri. A forma que as fichas são consumidas e produzidas pelas transições pode variar de acordo com a classe da Rede de Petri. Em geral, sempre que uma transição é disparada, as fichas de seus lugares de entrada são consumidas e novas fichas em seus lugares de saída são produzidas.

A marcação (ou estado) $M$ é definido pela função $M: P \rightarrow \mathbb{N}$ que mapeia o conjunto de lugares com números naturais. Seja uma Rede de Petri $P N$ e uma marcação $M$, de acordo com (Weske , 2007), o disparo de uma transição é representado por uma mudança de estado da Rede de Petri tal que :

- $M \stackrel{t}{\rightarrow} M^{\prime}$ indica que a Rede de Petri mudou do estado $M$ para o $M^{\prime}$ a partir do disparo de $t$. 
- $M \rightarrow M^{\prime}$ indica que existe uma transição $t$ tal que $M \stackrel{t}{\rightarrow} M^{\prime}$.

- $M_{1} \stackrel{*}{\rightarrow} M_{n}$ indica que existe uma sequência de transições $t_{1}, t_{2}, \cdots, t_{n-1}$ tal que $M_{i} \stackrel{t_{i}}{\rightarrow} M_{i+1}$ para $1 \leq i<n$.

- Um estado $M^{\prime}$ é alcançável a partir de um estado $M$ se e somente se $M \stackrel{*}{\rightarrow} M^{\prime}$.

Uma Rede de Petri pode ser estendida para especificar o comportamento dinâmico necessário para a representação dos processos. Seja $\langle P, T, F, \omega\rangle$ uma Rede de Petri estendida tal que $\omega: F \rightarrow \mathbb{N}$ é uma função que atribui pesos para as arestas. O comportamento dinâmico da transição é definido como (Weske, 2007):

- Uma transição $t$ é habilitada se cada lugar de entrada $p$ de $t$ contém pelo menos o número mínimo de fichas definido como o peso da aresta que conecta $p$ e $t$, isto e, se $M(p) \geq \omega(p, t)$

- Quando uma transição $t$ dispara, o número de fichas removido dos seus lugares de entrada e inserido no lugares de saída é determinado pelos pesos das arestas correspondentes.

- O disparo de uma transição $t$ em um estado $M$ resulta em um estado $M^{\prime}$, onde $(\forall p \in$ $\bullet t) M^{\prime}(p)=M(p)-\omega(p, t) \wedge(\forall p \in t \bullet) M^{\prime}(p)=M(p)+\omega(t, p)$

Mais detalhes sobre as Redes de Petri e suas variações podem ser encontrados em (Murata , 1989). A seguir, são apresentadas as características do modelo de processos baseado em grafos.

\subsubsection{Modelos de Processos baseados em Grafos}

Os modelos de processos baseados em grafos direcionados são normalmente usados no contexto de sistemas de gerenciamento de workflow comerciais. Taverna (Taverna, 2016), Pegasus (Pegasus, 2016) e DAGMan (DAGMan, 2016) são alguns exemplos de sistemas de gerenciamento de workflow que usam modelos de processos baseados em grafos direcionados. Sua principal característica é a representação explícita das dependências de dados e de controle entre as atividades, e da semântica da execução dos processos de negócio.

Nesses modelos, as atividades são descritas como os vértices do grafo, enquanto as arestas representam o fluxo de controle. Cada atividade pode ser associada a um conjunto de parâmetros de entrada e a um conjunto de parâmetros de saída. Há uma relação de dependência de A para B (isto é, B dependente de A) se A produz algum parâmetro que é consumido por B.

O mecanismo de execução dos grafos de processos é baseado em marcações nas arestas. Cada aresta tem associada uma condição que resulta nas marcações verdadeiro ou falso. Essa condição é avaliada ao término da execução de sua atividade de origem. Se a condição for satisfeita, a aresta é marcada com verdadeiro. Caso contrário, a aresta é marcada como falso.

Uma condição de inicialização também é associada a cada atividade. Essa condição é descrita sobre as marcações das arestas que incidem na atividade e sobre os parâmetros de entrada necessários para a sua execução. Se a condição for verdadeira, a atividade é inicializada. Caso contrário, a atividade é ignorada e suas arestas de saída são assinaladas com falso.

Uma das vantagens das marcações das arestas e as condições de inicialização das atividades, é a capacidade de expressar diversos comportamentos padrões de controle de fluxo (Aalst et al., 2003). Em especial, comportamentos de divisão (split) e junção (join) tal como escolha exclusiva (XOR), 
múltipla escolha (OR) e paralelas (AND). Abordagens que não permitem a dupla marcação têm problemas ao tratar a junção quando a divisão OR é considerada. Com a dupla marcação, todos os caminhos são sinalizados, inclusive aqueles caminhos que não foram tomados durante a execução.

Embora muitos sistemas de gerenciamento de workflow comerciais usem modelos baseados em grafos, o armazenamento e a representação desses grafos é realizado por meio de uma linguagem própria, normalmente, baseada em XML (do inglês, Extensible Markup Language). Por exemplo, o Pegasus usa um formato baseado em XML chamado DAX (do inglês, Directed Acyclic Graph in $X M L)$ (Pegasus, 2016).

Mais detalhes sobre modelos baseados em grafos podem ser encontrados em (Weske, 2007). Na próxima seção, é discutido como os processos podem ser modelados usando a Álgebra de Processos.

\subsection{3 Álgebra de Processos}

A Álgebra de Processos é outra alternativa para representação formal dos processos, com ênfase em processos que são executados concorrentemente. Com essa representação, propriedades indesejáveis podem ser detectadas e propriedades desejáveis de uma especificação do sistema podem ser formalmente derivadas. Nesta seção, são introduzidos resumidamente os conceitos básicos sobre Álgebra de Processos descrito em (Fokkink, 2000).

A noção de álgebra de processo sustenta-se no pressuposto de que processos concorrentes podem ter uma estrutura algébrica. Por exemplo, dado dois processos $p_{1}$ e $p_{2}$, um novo processo pode ser formado, combinando $p_{1}$ e $p_{2}$ sequencialmente ou em paralelo. O resultado dessa combinação será um novo processo cujo comportamento depende de $p_{1}$ e $p_{2}$ e da operação usada para combiná-los. Desta forma, a Álgebra de Processos apresenta enfoque na especificação e manipulação dos termos do processo por meio de uma coleção de operadores. A maioria das álgebras contêm um conjunto básico de operadores para construir processos finitos, operadores de comunicação para expressar a concorrência, e alguma operadores de recursão para capturar o comportamento infinito.

Uma estrutura básica para a Álgebra de Processos pode ser descrita pelos seguintes operadores:

- Um conjunto finito e não vazio $A$ de ações atômicas que representam um comportamento indivisível. O predicado $\stackrel{a}{\longrightarrow} \sqrt{ }$ representa a terminação com sucesso após a execução de uma ação atômica $a$;

- Um operador binário + , referenciado como composição alternativa. Se os termos $t_{1}$ e $t_{2}$ representam os processos $p_{1}$ e $p_{2}$, respectivamente, então o termo $t_{1}+t_{2}$ representa a execução de $p_{1}$ ou $p_{2}$.

- Um operador binário ·, chamado de composição sequencial. Se os termos $t_{1}$ e $t_{2}$ representam os processos $p_{1}$ e $p_{2}$, respectivamente, então o termo $t_{1} \cdot t_{2}$ representa a execução de $p_{1}$ seguida por $p_{2}$.

Cada processo finito pode ser representado por um termo que é construído por ações atômicas do conjunto $A$ e pelos operadores binários $+\mathrm{e} \cdot$. Esse termo é chamado de termo básico do processo e a coleção de todos os termos é chamado de Álgebra de Processos Básica (BPA, do inglês Basic Process Algebra).

A semântica estrutural das operações é definida por uma coleção de regras de transição. Uma transição $t \stackrel{a}{\longrightarrow} t^{\prime}$ expressa que o termo $t$ pode evoluir para o termo $t^{\prime}$ pela execução da ação $a$ e 
o predicado $t \stackrel{a}{\longrightarrow} \sqrt{ }$ expressa que o termo $t$ pode terminar com sucesso ao executar a ação $a$. A Tabela 2.1 apresenta a especificação do sistema de transição que constitui da semântica operacional estrutural da BPA. As variáveis $x, x^{\prime}, y$ e $y^{\prime}$ nas regras de transição referem-se a coleção de termos básicos do processo, e $v$ refere-se ao conjunto $A$ de ações atômicas.

Tabela 2.1: Regras de Transição do BPA

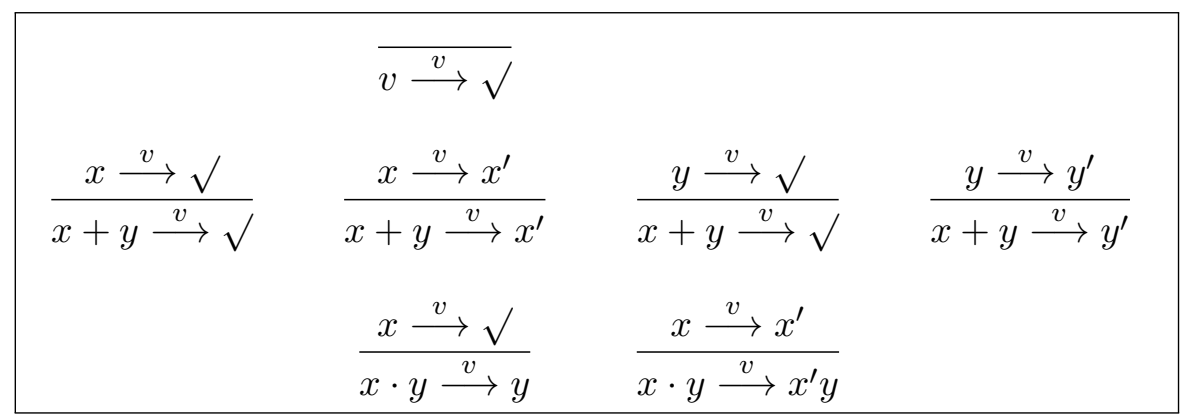

A especificação do sistema de transição do BPA fornece:

- A primeira regra determina que cada ação atômica $v$ pode terminar com sucesso pela execução dela própria;

- As quatro regras seguintes expressam que o termo $t+t^{\prime}$ executa $t$ ou $t^{\prime}$; e

- A duas últimas regras expressam que $t \cdot t^{\prime}$ executa $t$ até sua execução completa e, então, executa $t^{\prime}$.

As regras de transição, por exemplo, dão apoio para que a transição $((a+b) \cdot c) \cdot d \stackrel{b}{\longrightarrow} c \cdot d$ seja realizada. Esse exemplo pode ser visto na Tabela 2.2. Do lado direito, as regras de transição são aplicadas em passos consecutivos. As substituições são mostradas do lado esquerdo.

Tabela 2.2: Exemplo de aplicação das regras de transição do BPA

\begin{tabular}{|lll|}
\hline 1$)$ & $\left(\frac{b}{v \stackrel{v}{\longrightarrow} \sqrt{ }}\right.$, & $v:=b)$ \\
$2)$ & $a+b \stackrel{b}{\longrightarrow} \sqrt{ }$ & $\left(\frac{y \stackrel{v}{\longrightarrow} \sqrt{ }}{x+y \stackrel{v}{\longrightarrow} \sqrt{ }}, \quad v:=b, x:=a, y:=b\right)$ \\
$3)$ & $(a+b) \cdot c \stackrel{b}{\longrightarrow} c$ & $\left(\frac{x \stackrel{v}{\longrightarrow} \sqrt{ }}{x \cdot y \stackrel{v}{\longrightarrow} y}, \quad v:=b, x:=a+b, y:=c\right)$ \\
$4)$ & $((a+b) \cdot c) \cdot d \stackrel{b}{\longrightarrow} c \cdot d$ & $\left(\frac{x \stackrel{v}{\longrightarrow} x^{\prime}}{x \cdot y \stackrel{v}{\longrightarrow} x^{\prime} y}, \quad v:=b, x:=(a+b) \cdot c, x^{\prime}:=c, y:=d\right)$ \\
\hline
\end{tabular}

A avaliação da igualdade de dois processos por meio de grafos é um árduo trabalho. A Álgebra de Processos propõe axiomas que podem ser usados para avaliar a igualdade entre dois termos de processo. Na Tabela 2.3 são exibidos os axiomas referentes à BPA. As variáveis $x, y$ e $z$ são termos básicos de processo. 
Tabela 2.3: Axiomas para BPA

$$
\begin{array}{ll}
\text { A1 } & x+y=y+x \\
\text { A2 } & (x+y)+z=x+(y+z) \\
\text { A3 } & x+x=x \\
\text { A4 } & (x+y) \cdot z=x \cdot z+y \cdot z \\
\text { A5 } & (x \cdot y) \cdot z=x \cdot(y \cdot z)
\end{array}
$$

Suponha os termos $t_{1}:(a+a) \cdot b$ e $t_{2}: a \cdot b+a \cdot(b+b)$. Ao aplicar o axioma A3 em ambos termos, é possível obter $t_{1}: a \cdot b$ e $t_{2}: a \cdot b+a \cdot b$. Se a substituição for novamente aplicada para o termo $t_{2}$, obtém-se que $t_{2}: a \cdot b$. Dessa forma, é possível demonstrar que os termos $t_{1}$ e $t_{2}$ são equivalentes.

Até agora, apenas os operadores de uma estrutura básica da Álgebra de Processos foram discutidos. A maioria das álgebras de processos contém outros operadores. Por exemplo, o operador binário \| chamado de entrelaçamento, introduzido por Milner et al. (1992), pode também ser definido. O termo $s \| t$ indica que os termos $s$ e $t$ serão executados em paralelo. As regras de transição da Tabela 2.4 formalizam o comportamento do operador entrelaçamento.

Tabela 2.4: Regras de Transição para o operador entrelaçamento

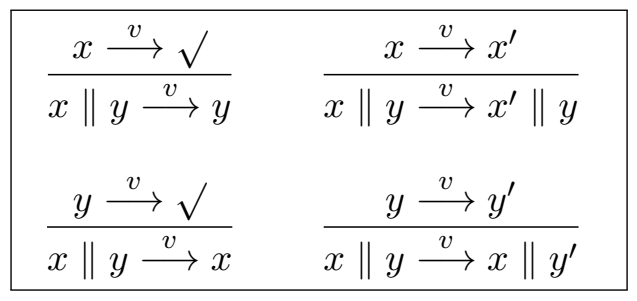

Nesta seção, observou-se resumidamente os conceitos de Álgebra de Processos. As expressões algébricas possuem vantagens para modelagem de processos porque podem ser facilmente manipuladas computacionalmente e permitem mecanismos de análise e simulação. Por outro lado, as versões de novas expressões algébricas para atender a evolução do processo não são facilmente formalizadas e não há uma representação explícita de estados de dados.

\subsection{Modelos Declarativos}

O modelos declarativos proveem mais flexibilidade na modelagem de processos ao evitar as estruturas rígidas de controle de fluxo das abordagem procedurais. Nesta seção, serão apresentadas duas diferentes e promissoras abordagens declarativas utilizadas para modelar processos com características dinâmicas. Na Seção 2.2.1, serão discutidas as características das abordagens declarativas baseadas em regras. Na Seção 2.2.2, serão apresentados os principais fundamentos dos modelos declarativos baseados em restrições. 


\subsubsection{Abordagem baseada em regras}

Há vários anos sistemas de banco de dados ativos têm usado abordagens baseadas em regras para reagir às alterações em seus dados (Dayal, 1994). Enquanto os gatilhos (triggers) em banco de dados reagem à eventos de inserção, remoção e atualização, regras podem também ser usadas na especificação de processos para reagir a vários tipos de eventos. Mais especificamente, regras ECA (Evento-Condição-Ação) oferecem uma abordagem modular, adaptativa e flexível para concretização de processos (Bry et al., 2006). Cada regra está associada com uma ou mais atividades e com suas propriedades tais como pré e pós condições de execução. O mecanismo de execução do processo é um motor de regras de inferência. Em tempo de execução, o motor examina as condições de dados e de controle e determina a melhor ordem para a execução das atividades (Lu e Sadiq, 2007).

Uma regra ECA $T$ pode ser formalmente definida como:

$$
T=\langle E, C, A\rangle
$$

em que o conjunto de evento $E$ resulta na ativação da regra, a condição $C$ determina a ativação da regra e o conjunto de ações $A$ é executado se a condição da regra for satisfeita.

Um evento especifica quando uma regra deve ser avaliada por meio da transformação de um estado de execução para outro. Um evento pode ser uma mudança de estado de execução do processo (término de execução de uma atividade) ou um evento complexo do processo (dois dias após a entrega do produto). A condição é uma pré-condição para ser avaliada antes que qualquer ação subsequente seja disparada. Por exemplo, uma venda somente pode ser executada se há produtos disponíveis em estoque. Uma ação pode ser a execução de uma certa atividade ou a avaliação de outra regra ECA. O resultado da execução de uma ação pode também desencadear um outro evento. Uma regra ECA pode ser estendida para tratar algum evento que não satisfaz a condição por meio da inclusão da cláusula ELSE.

Uma abordagem baseada em regras ECA para a especificação de processos de negócios tem as seguintes vantagens (Bry et al., 2006):

- Os requisitos dos processos são frequentemente descritos na forma de regras expressas em alguma linguagem natural. Por exemplo, a requisição de um veículo (evento) será efetivada (ação) se o cliente confirmar o depósito antes da entrega do veículo (condição).

- Regras ECA são reativas e facilmente integradas com outros tipos de regras (por exemplo, regras dedutivas e normativas) normalmente usadas em aplicações de negócio.

- Regras ECA são flexíveis e facilmente adaptáveis as alterações de requisitos.

- Exceções são eventos especiais que podem ser tratados da mesma forma que os eventos normais.

- As regras podem ser mantidas em uma única base de regras, bem como distribuídas em várias bases.

- Em abordagens procedurais, as atividades são inicializadas como uma reação ao término de outras atividades. Reações a partir de estados intermediários das atividades não são considerados. Ao invés disso, regras ECA com ênfase em eventos são mais flexíveis para especificar o controle do fluxo. 
Regras ECA também possuem algumas limitações apontadas em (Bry et al., 2006). Entre elas, destaca-se a dificuldade de muitos projetistas de processos familiarizados com o pensamento procedural em usarem regras ECA. Isso tem um impacto negativo na escolha da abordagem utilizada na modelagem do processo feita pelos projetistas. Os autores também afirmam que as regras ECA não tem um estado bem definido que caracterize a instância do processo.

Uma descrição mais detalhada sobre as regras ECA pode ser encontrada em (Bry et al., 2006). Na próxima seção, serão discutidos conceitos básicos das abordagens baseadas em restrições.

\subsubsection{Abordagens baseadas em restrições}

Atualmente, abordagens baseadas em restrições têm se popularizado como uma alternativa promissora e flexível de apoiar processos dinâmicos (Aalst et al., 2009; Montali, 2010; Montali et al., 2010; Pesic et al., 2007). Entende-se por processos dinâmicos aqueles cujo controle de fluxo não pode ser previamente definido em tempo de projeto (Reichert e Weber, 2012). Nesse contexto, modelos que determinam estritamente o que deve ser executado não são adequados. Por outro lado, os modelos baseados em restrições enfatizam que todas as alternativas são permitidas, exceto aqueles explicitamente proibidas.

A Figura 2.2 ilustra um comparativo entre abordagens procedurais e as abordagens baseadas em restrições adaptado de (Montali, 2010). Como ilustrado na Figura 2.2(a), processos têm comportamentos desejados, não especificados, e proibidos. As abordagens procedurais apoiam explicitamente todos caminhos de execução desejados e proíbem todos os demais caminhos, como ilustrado na Figura 2.2(b). Por causa disso, elas também excluem caminhos que não são desejados nem proibidos. Consequentemente, elas sacrificam a flexibilidade, são muito restritivas e são propensas à especificações excessivas ${ }^{1}$. Por outro lado, abordagens baseadas restrições concentram-se em elicitar apenas comportamentos proibidos, permitindo a execução de todos os demais caminhos e preservando a flexibilidade ao evitar restringir caminhos adicionais como ilustrado na Figura 2.2(c). Enquanto modelos procedurais definem em qual ordem e sob quais circunstâncias as atividades são executadas, modelos baseados em restrições apenas proíbem os comportamentos indesejados de execução.

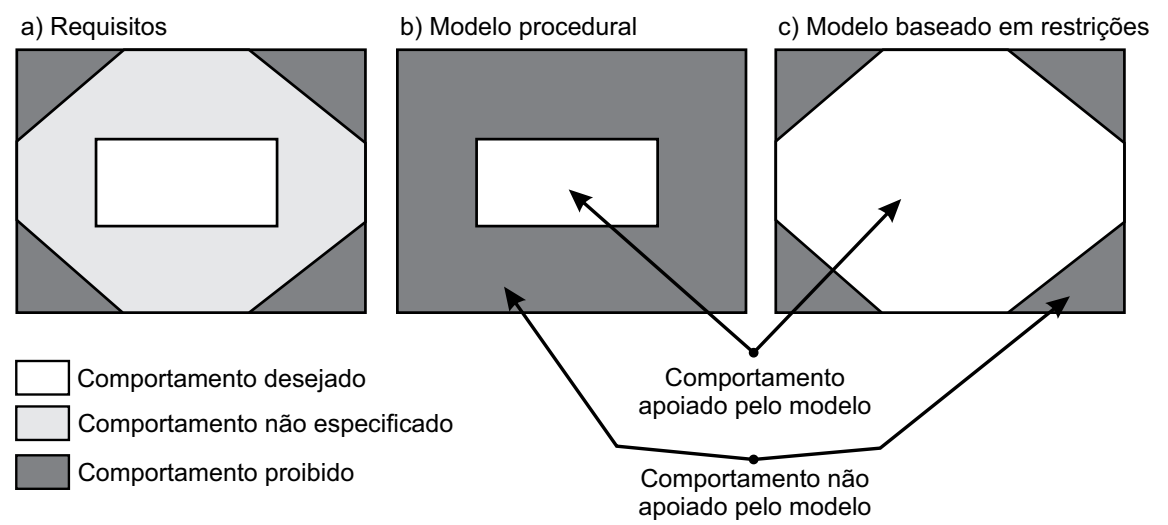

Figura 2.2: Um comparativo intuitivo entre os modelos de processos baseados em restrições e procedurais adaptado de (Montali, 2010)

De acordo com (Reichert e Weber, 2012), um modelo de processos baseado em restrições é descrito como:

$$
S=\langle A, C\rangle
$$

\footnotetext{
${ }^{1}$ do inglês over-specification
} 
tal que $A$ é um conjunto finito de atividades e $C$ é um conjunto finito de restrições que proíbem o comportamento indesejado de execução. Além disso, o conjunto de restrições $C=C_{M} \cup C_{O}$ pode ser dividido em dois subconjuntos disjuntos. $C_{M}$ é o conjunto de restrições obrigatórias (proibições) e $C_{O}$ representa o conjunto de restrições optativas (preferências). A Tabela 2.5 descreve algumas possíveis categorias de restrições que podem ser usadas nesses modelos.

Tabela 2.5: Categorias de Restrições adaptado de (Pesic, 2008)

\begin{tabular}{|l|l|}
\hline Categoria & Descrição \\
\hline Restrições de Existência & $\begin{array}{l}\text { Especificam a frequência que as atividades podem ou devem ser } \\
\text { executadas. }\end{array}$ \\
\hline Restrições de Escolha & Permitem escolhas de execuções em um conjunto de atividades. \\
\hline Restrições de Relação & Impõem proibições na relação entre duas atividades. \\
\hline Restrições de Negação & Definem relações de negação entre duas atividades. \\
\hline Restrições de Ramificação & $\begin{array}{l}\text { Permitem especificar relações e negações envolvendo mais do que } \\
\text { duas atividades. }\end{array}$ \\
\hline
\end{tabular}

A Figura 2.3 ilustra um modelo baseado em restrições $S=\langle A, C\rangle$ tal que $A=\{a, b, c, d\}$ e $C=\left\{c_{1}, c_{2}\right\}$. A restrição $c_{1}=$ init(a) indica que o processo deve iniciar sua execução obrigatoriamente pela atividade $a$. A restrição $c_{2}=\operatorname{response}(\mathrm{a}, \mathrm{b})$ determina que se a atividade $a$ tiver sido executada, a atividade $b$ deve ser executada posteriormente (mas não necessariamente de forma consecutiva). Ainda, a Figura 2.3 ilustra as histórias de execução de quatro instâncias. As instâncias $\sigma_{1}$ e $\sigma_{2}$ são consistentes com o modelo enquanto as instâncias $\sigma_{3}$ e $\sigma_{4}$ são inconsistentes. $\sigma_{3}$ viola $c_{2}$ uma vez que a atividade $b$ não foi executada e $\sigma_{4}$ não respeita $c_{1}$ porque inicia com a atividade $c$.

\section{Esquema $S=(A, C)$}

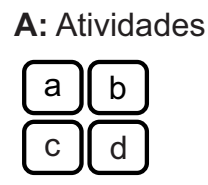

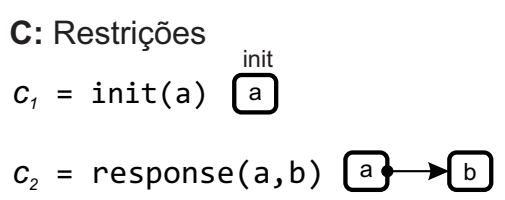

\section{Histórias de Execução}

$\begin{array}{ll}\sigma_{1}=(a, a, b, c, d) & \text { Consistente } \\ \sigma_{2}=(a, b, b, c) & \text { Consistente } \\ \sigma_{3}=(a, c) & \text { Viola } c_{2} \\ \sigma_{4}=(c) & \text { Viola } c_{1}\end{array}$

Figura 2.3: Um exemplo de um modelo de processos baseado em restrições

O mecanismo de execução permite que uma instância esteja em um dos três estados possíveis: satisfeita, temporariamente violada e violada. Uma instância cuja história de execução respeita todas as restrições encontra-se no estado de satisfeita. Uma instância está no estado de temporariamente violada se existe um sufixo para ser executado capaz de conduzi-la para o estado de satisfeita. Quando esse sufixo não é possível de ser executado, a instância está no estado de violada (Reichert e Weber, 2012). Note que, na Figura 2.3, a instância $\sigma_{3}$ é temporariamente violada, pois ainda pode executar a atividade $b$ para tornar-se satisfeita e a instância $\sigma_{4}$ está no estado de violada, pois não poderá mais satisfazer a restrição $c_{1}$.

Na prática, o mecanismo de execução não permite que uma instância seja conduzida para o estado de violada. A ideia é que mecanismo mantenha um subconjunto de atividades habilitadas para execução que não viole nenhuma restrição. A Figura 2.4 descreve a lista de atividades habilitadas assumindo o modelo proposto na Figura 2.3. Nesse exemplo, cada instância é inicializada no estado de temporariamente violada uma vez que a restrição $c_{1}$ é violada. Observe que o subcon- 
junto de atividades habilitadas inicialmente contém apenas a atividade $a$ porque a execução das demais atividades levaria a instância para o estado de violada. Após a execução da atividade $a$, todas as demais atividades são habilitadas para execução. Apesar disso, a instância é mantida no estado de temporariamente violada porque sua história ainda não respeita a restrição $c_{2}$. $\mathrm{O}$ estado da instância é alterado para satisfeita apenas quando a restrição $c_{2}$ tiver também sido satisfeita.

\begin{tabular}{|c|c|c|c|c|c|c|}
\hline $\begin{array}{c}\text { História de } \\
\text { Execução Parcial }\end{array}$ & $\begin{array}{l}\text { Estado da } \\
\text { Instância }\end{array}$ & \multicolumn{5}{|c|}{ Conjunto de Atividades Habilitadas } \\
\hline() & temporariamente violada & $a$ & \multicolumn{4}{|c|}{$\begin{array}{l}\text { Apenas a atividade a pode ser executada. } \\
\text { A restrição } c_{1} \text { é violada. }\end{array}$} \\
\hline (a) & temporariamente violada & $a$ & $b$ & c & d & $\begin{array}{l}\text { Todas as atividades são habilitadas. } \\
c_{1} \text { é satisfeita e } c_{2} \text { é violada. }\end{array}$ \\
\hline$(a, c)$ & temporariamente violada & $a$ & $b$ & $c$ & d & $\begin{array}{l}\text { Todas as atividades são habilitadas. } \\
c_{1} \text { é satisfeita e } c_{2} \text { é violada. }\end{array}$ \\
\hline$(a, c, b)$ & satisfeita & $a$ & $b$ & $c$ & $d$ & $\begin{array}{l}\text { O estado da instância é alterado. } \\
c_{1} \text { e } c_{2} \text { são satisfeitas. }\end{array}$ \\
\hline
\end{tabular}

Figura 2.4: Um exemplo de um mecanismo de execução de uma instância em um modelo baseado em restrições

Um desafio em abordagens baseadas em restrições é manter o subconjunto de atividades habilitadas para execução. Aalst et al. (2009) propõem o mapeamento do conjunto de restrições em uma Lógica Temporal Linear (LTL) (Pnueli, 1977). Baseado em uma fórmula LTL que representa todas as restrições descritas no modelo, é possível criar um autômato finito que pode ser usado para determinar as atividades habilitadas para execução e determinar o estado de execução de cada instância. Entretanto, essa estratégia é custosa e pode ter problemas de desempenho quando um grande número de restrições é considerado. Além disso, qualquer alteração do esquema que inclua ou remova restrições acarretará na produção de um novo autômato.

\subsection{Considerações Finais}

Neste capítulo foi discutido brevemente a necessidade de sistemas de informação conhecedores de processos para modelagem, análise, execução e monitoramento dos processos. Nesse sentido, discutiu-se a dicotomia existente atualmente na literatura. Por um lado, abordagens procedurais que há vários anos têm sido usadas com sucesso para modelagem e execução de processos. Mais especificamente, modelos de processos tradicionais como Redes de Petri, Álgebra de Processos e Grafos que propiciam um formalismo matemático que é requisito para métodos de análise, simulação e visualização de processos. Por outro lado, abordagens declarativas que incorporam características flexíveis para modelagem e execução de processos. Essa dicotomia também tem sido discutida em (Aalst et al., 2009; Lu e Sadiq, 2007).

Embora as estratégias procedurais sejam contribuições significativas para processos bem estruturadas cujo comportamento pode ser pré-especificado, esses modelos ainda apresentam algumas importantes limitações relacionadas à necessidade de tratar exceções, isto é, situações anômalas e assíncronas que desviam do controle de fluxo normal. Essas abordagens requerem que diferentes caminhos de recuperação ou de contingência tenham sido previamente modelado para cada exceção conhecida. Isso é um árduo trabalho e tem sérias implicações na modelagem uma vez que o 
tratamento de exceção pode se tornar exponencialmente difícil, quando todos os resultados e valores possíveis são considerados, e seu tratamento traduzido em programas procedurais. Os modelos de processos baseados em regras ou restrições incorporam os requisitos de flexibilidade necessários para alguns casos específicos de aplicações. Ainda, uma vez que diferem do pensamento intuitivo e bem consolidado de modelagem, eles são complexos para serem modelados. A manutenibilidade das regras e restrições também é uma importante questão de pesquisa em aberto.

Os modelos dos processos discutidos neste capítulo são requisitos para os PAIS gerenciarem e executarem processos. Entretanto, como a execução dos processos pode divergir dos comportamentos esperados, os PAIS exigem uma abordagem mais ágil que permita o entrelaçamento mais próximo da modelagem e execução (Reichert e Weber, 2012). Para o contexto deste trabalho, acredita-se que esse entrelaçamento pode ser alcançado por meio de abordagens que incorporem propriedades transacionais capazes de garantir execuções confiáveis e robustas, e prover rotinas de recuperação automáticas que reduzam a complexidade do tratamento de exceções. Com isso em mente, no próximo capítulo, serão apresentados os modelos transacionais que garantem consistência e confiabilidade na execução dos processos. 


\section{Capítulo 3}

\section{Modelos Transacionais}

Os sistemas de bancos de dados são um dos mais importantes avanços da ciência e engenharia da computação para o desenvolvimento de aplicações. Eles fornecem métodos organizados, versáteis e uniformes para armazenamento e manipulação de grandes volumes de dados. Os sistemas de banco de dados apoiam uma grande variedade de aplicações como sistemas bancários, sistemas de reserva e emissão de passagens aéreas, sistemas de informação organizacional, entre outros. Um dos principais objetivos de um sistema de banco de dados é prover o controle de concorrência transparente e a recuperação de falhas (Agrawal e Abbadi, 1992).

As propriedades básicas que consagraram o modelo clássico de transações são amplamente conhecidas como propriedades ACID (Gray, 1981). A seguir, estão elas:

- Atomicidade - Uma transação é uma unidade de processamento única. As operações de uma transação devem ser tratadas em sua totalidade ou não serem realizadas de forma alguma;

- Consistência - Se uma transação for executada do início ao fim sem interferência de outras transações, ela conduz o banco de dados de um estado consistente para um outro estado consistente. Um estado consistente do banco de dados é aquele que satisfaz as restrições especificadas no esquema;

- Isolamento - Uma transação deve executar sem considerar os efeitos de outras transações mesmo que muitas delas estejam sendo executadas de maneira simultânea. Em outras palavras, a execução de uma transação não observa resultados intermediários e não sofre interferência de outras transações; e

- Durabilidade - Todas as alterações produzidas pelas transações finalizadas com sucesso devem ser permanentemente armazenadas no banco de dados.

Há várias décadas, a comunidade acadêmica tem investigado aspectos teóricos e pragmáticos do modelo clássico de transação. As propriedades fundamentais, tais como atomicidade da execução das transações, isolamento dos resultados intermediários e critério de correção (seriação) têm sido intensamente estudadas. Entretanto, grande parte dessa discussão é relevante para aplicações em banco de dados cujas transações são simples, de curta duração e de estrutura linear. Ao considerar transações mais complexas e com um vasto tempo de execução, a maioria dos métodos de controle de concorrência baseados em protocolos de bloqueio são inadequados, uma vez que proíbem acessos aos dados compartilhados por um longo período de tempo (Elmagarmid, 1992). 
Uma das premissas que tornaram o modelo clássico de transações extremamente popular e útil para o desenvolvimento de aplicações em banco de dados é sua capacidade de recuperação de falhas. Se uma transação falhar, por qualquer motivo, antes de seu ponto de confirmação, todos os seus efeitos podem ser facilmente revertidos. Um sistema de banco de dados que garante essa propriedade é dito ser recuperável (Bernstein et al., 1987). O modelo clássico de transação mantém a capacidade de recuperação ao proibir acessos aos dados intermediários das transações.

Por outro lado, manter a propriedade de recuperação e ao mesmo tempo permitir a exposição dos resultados intermediários para outras transações pode ser muito custoso, uma vez que os efeitos colaterais de uma falha podem comprometer a execução de diversas transações e, consequentemente, o desempenho da aplicação. Se uma transação $T_{i}$ abortar e, consequentemente, for revertida, qualquer transação $T_{j}$ que tenha lido o valor de algum item de dado atualizado por $T_{i}$ também deve ser revertida. Similarmente, quando $T_{j}$ for revertida, qualquer transação $T_{k}$, que tenha lido o valor de algum item de dado atualizado por $T_{j}$, também deve ser revertida, e assim por diante. Esse fenômeno indesejável é bem difundido na comunidade de banco de dados, sendo conhecido como rollback em cascata (Elmasri e Navathe, 1999). Uma vez que o rollback em cascata é complexo e demorado, o modelo clássico de transações proíbe escalonamentos que causem esse tipo de propagação em uma situação de recuperação de falhas.

Nas últimas duas décadas, diversos autores têm argumentado que o modelo clássico de transação apresenta aplicabilidade limitada quando usado em aplicações modernas em banco de dados (Elmagarmid, 1992). Normalmente, tais aplicações apresentam transações que executam por um longo período de tempo, conhecidas como Transações Longas ou Transações de Longa Duração (LLT, do inglês Long-lived Transactions). Por esse motivo, para garantir a propriedade do isolamento, o protocolo de bloqueio bifásico praticamente inviabiliza a execução de transações longas que concorrem sobre os mesmos itens de dados. Mais recentemente, Kot et al. (2010) também reconhecem essa necessidade, ao chamar a atenção da comunidade acadêmica para transcender o isolamento a fim de elaborar novas abstrações que permitam suprir as características emergentes das aplicações modernas. Embora o isolamento tenha sido fundamental para o modelo clássico de transações, ele tornou-se inadequado para cenários nos quais transações requerem a exposição dos resultados intermediários.

Diante dos novos requisitos apresentados pelas aplicações modernas, diversos modelos transacionais avançados têm apresentado estratégias para minimizar a rigidez das propriedades ACID do modelo transacional clássico. Este capítulo apresenta uma visão geral das principais contribuições que flexibilizam as premissas garantidas pelo modelo transacional clássico para contemplar transações cujas características satisfazem alguns requisitos das aplicações modernas. Para auxiliar nessa discussão, é necessário recuperar o conceito amplo e genérico que deu origem ao modelo transacional clássico, o conceito das Esferas de Controle proposto por Davies e Björk (Björk, 1973; Davies Jr, 1973, 1978). A Esfera de Controle é um conceito genérico para controlar execuções concorrentes em ambientes multiusuários distribuídos, bem como controlar os efeitos colaterais de possíveis falhas. O conceito é baseado em duas premissas básicas (Gray e Reuter, 1992):

- conhecer os efeitos das operações arbitrárias enquanto existir algum cenário em que elas possam ser revogadas;

- monitorar as dependências estabelecidas durante a execução de forma que seja capaz de 
recuperar o histórico de execução em caso de falha.

Uma Esfera de Controle poder ter um comportamento estático, similar a um Tipo Abstrato de Dados (TAD), que encapsula os dados e não externaliza como eles são controlados ou processados. No entanto, alguns cenários demandam um comportamento dinâmico do controle sobre os dados. A Esfera de Controle pode dinamicamente expandir ou reduzir o controle sobre os dados baseada em restrições de consistência ou dependências de acesso a dados compartilhados. No contexto das transações, esse comportamento dinâmico significa que o controle sobre os dados produzidos por um processo atômico transcende o limite imposto pelo seu término. Para ilustrar esse comportamento, a Figura 3.1 ilustra um cenário com a execução de cinco esferas de controle que acessam dados compartilhados.

(a)

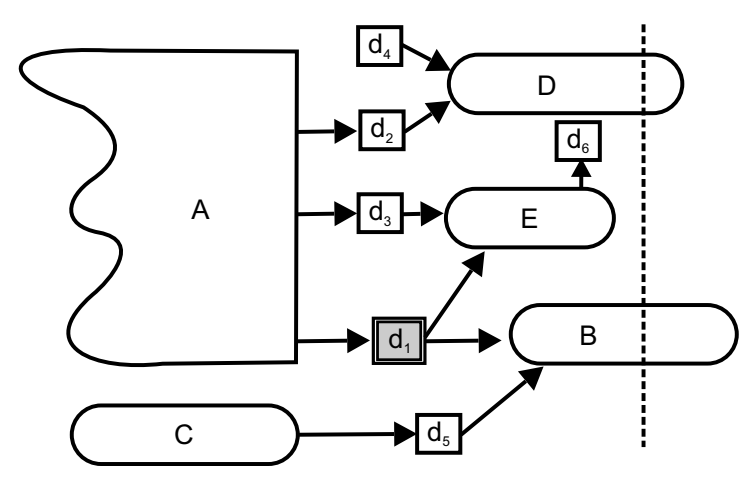

(b)

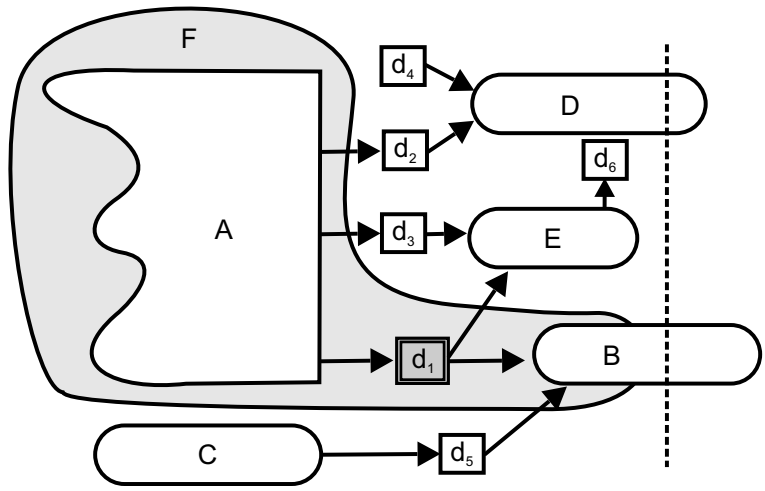

(c)

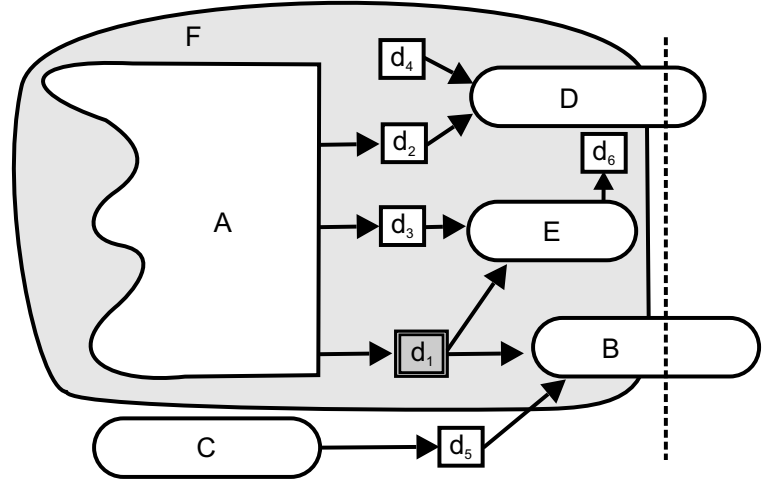

Figura 3.1: Comportamento dinâmico das Esferas de Controle

Nesse cenário, o tempo é representado pela linha tracejada em que as esferas $A, C$ e $E$ foram completamente executadas e as esferas $D$ e $B$ estão em execução. Os itens de dados são representados pelos quadrados denotados por $d_{i}$. Na Figura 3.1(a), durante a execução da esfera $B$ foi identificado um problema com o item de dado $d_{1}$. No entanto, para evitar inconsistência, não basta que somente as ações realizadas por $B$ sejam desfeitas, pois outras esferas podem também ser dependentes de $d_{1}$. No exemplo, a esfera $E$ é dependente de $d_{1}$ e já finalizou sua execução. Dessa forma, a primeira providência a ser tomada é rastrear e encontrar qual esfera gerou o dado defeituoso. O passo seguinte é criação de uma nova esfera de controle englobando as esferas já concluídas para atuar como um ambiente de recuperação. O resultado desse passo é ilustrado na Figura 3.1(b), na qual a esfera de controle $F$ é dinamicamente criada englobando as esferas $A$ e $B$ e tornando-se um ambiente para a recuperação da inconsistência identificada. O próximo passo contempla as ações necessárias para reverter e refazer a produção do item $d_{1}$. Como consequência, é necessário recuperar todas as 
esferas que tornaram-se dependente de qualquer item de dado produzido pela esfera $A$ que criou $d_{1}$. Isso faz com que a esfera $F$ seja expandida adicionando as esferas $D$ e $E$, como mostra a Figura 3.1(c). Dessa forma, a esfera de controle $F$ deve conduzir as ações necessárias para verificar se as esferas $D$ e $E$ foram afetadas pela medida tomada no passo anterior. Gray (1981) chama atenção para a importância do controle sobre os dados produzidos pelas esferas. Ele afirma que não há uma maneira realística de evitar a dependência quando resultados intermediários são expostos. Prevenir as esferas de controle de tornarem-se dependentes de resultados intermediários, significa que nenhum dado pode ser externalizado até que ele torne-se globalmente consistente. No entanto, para alguns cenários isso é inviável. Os dados deveriam ser externalizados para outras esferas mesmo antes de serem considerados globalmente consistentes. Para isso, o sistema deve manter um histórico de quem criou, atualizou ou removeu o dado, quem tornou-se dependente ao escrever ou ler o dado e assim por diante. Esse histórico de execução deve ser mantido enquanto houver a possibilidade do surgimento de falhas.

Apesar do conceito das Esferas de Controle ter sido fundamental ao evidenciar diretrizes no gerenciamento de execuções concorrentes, ele não teve o mesmo êxito sob a perspectiva prática. Nesse sentido, o modelo transacional clássico pode ser considerado uma esfera de controle extremamente restrita que limita o controle originalmente proposto pelo conceito por meio das propriedades ACID. Posteriormente, os modelos transacionais avançados apresentaram diferentes Esferas de Controle a fim de minimizar as restrições impostas pelas propriedades ACID no contexto das transações de longa duração. De maneira geral, essas soluções ampliam a aplicabilidade do modelo clássico ao flexibilizar algumas das propriedades ACID para apoiar a execução de transações de longa duração. Dessa forma, a seguir, as estratégias propostas pelos modelos transacionais avançados serão apresentadas sob a perspectiva de três categorias restritas das Esferas de Controle. A primeira categoria representa as abordagens que estendem a seriação realizando pequenos ajustes na proposta original. A segunda categoria apresenta estratégias que flexibilizam a seriação ao permitir confirmações parciais durante a execução das transações. Finalmente, a terceira categoria destaca abordagens que substituem a seriação por um critério de correção alternativo.

\subsection{Abordagens que estendem a seriação}

As abordagens dessa categoria propõem estratégias baseadas em variações do protocolo de bloqueio. Essas variações são especialmente projetadas para flexibilizar a propriedade de isolamento enquanto mantém agendas seriáveis. A seguir, serão descritas as características de três abordagens que se destacam nessa categoria: o Modelo Transacional Hierárquico (Nested Transaction Model), o Bloqueio Altruísta (Altruistic Locking) e as Transações Emaranhadas (Entangled Transactions).

\subsubsection{Modelo Transacional Hierárquico}

O Modelo Transacional Hierárquico, proposto por Moss (1985), apresenta o conceito de transações aninhadas (Nested Transactions). Uma transação aninhada é um conjunto de sub-transações que podem, recursivamente, conter outras sub-transações formando uma hierarquia na forma de uma árvore (Moss, 1985). De modo geral, uma transação aninhada pode ser considerada como uma generalização das transações clássicas com pontos seguros (savepoints) (Gray, 1981).

Uma transação aninhada é formada por uma árvore de sub-transações, em que os vértices 
são transações clássicas ou outras transações aninhadas. As transações nas folhas da árvore são obrigatoriamente clássicas. A transação na raiz da árvore é chamada de transação de alto nível (top-level transaction) e as demais são chamadas de sub-transações. Uma transação predecessora na árvore é chamada de pai e a transação no nível seguinte é chamada de filha. A Figura 3.2 ilustra a estrutura de uma transação do modelo transacional hierárquico.

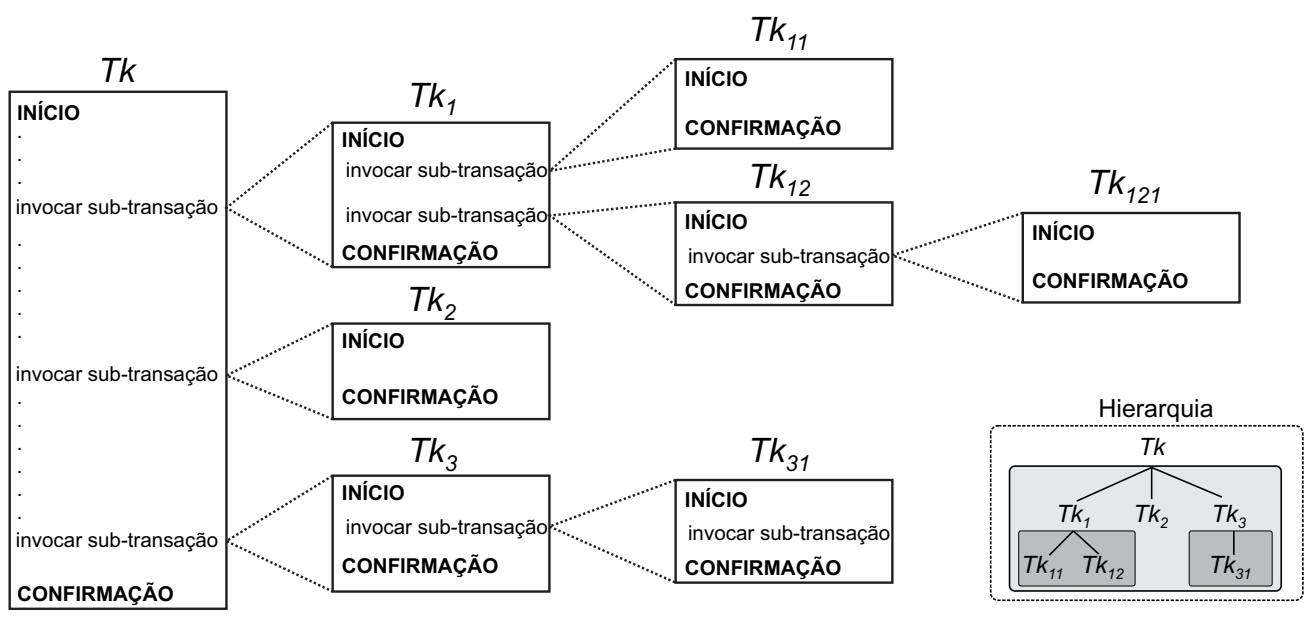

Figura 3.2: Exemplo da Transação Aninhada

Tanto a (sub)transação pai quanto a sub-transação filha podem efetuar operações de confirmação ou de aborto. No entanto, esses dois tipos de transações têm comportamentos distintos. O comportamento das transações aninhadas são sumariadas nas três regras seguintes:

- Regra de confirmação: A confirmação de uma sub-transação filha tem um escopo local, ou seja, os efeitos da confirmação somente são visíveis para a (sub)transação pai e para as sub-transações irmãs. Uma sub-transação será efetivamente confirmada (expor seus resultados globalmente) somente quando todos os seus ancestrais forem confirmados. Por exemplo, na Figura 3.2, o resultado da sub-transação $T k_{121}$ somente será conhecida no mundo externo quando as transações $T k_{12}, T k_{1}$ e $T k$ forem confirmadas. Consequentemente, uma sub-transação somente produzirá efeito permanente no banco de dados quando a transação da raiz for confirmada. A confirmação de uma (sub)transação pai depende da confirmação de todas as sub-transações filhas. Ou seja, a (sub)transação pai somente é confirmada após a confirmação de todas as suas filhas. No exemplo da Figura 3.2, a sub-transação $T k_{1}$ somente pode ser confirmada após a finalização das sub-transações $T k_{11}$ e $T k_{12}$. Diante dessa regra, pode-se afirmar que uma sub-transação desse modelo se diferencia da transação clássica ao não respeitar estritamente a propriedade de durabilidade;

- Regra de desfazimento: Se uma (sub)transação em qualquer nível da hierarquia é abortada, todas as suas sub-transações filhas também são abortadas, independente do seu status de confirmação. Esse comportamento é replicado recursivamente para os níveis inferiores da hierarquia. Sob a perspectiva da (sub)transação pai, a falha de uma sub-transação filha não implica na falha do pai. Nesse caso, o pai pode escolher sua própria forma de recuperação. Por exemplo, o pai pode ressubmeter a execução da sub-transação ou executar outra sub-transação que realiza uma ação alternativa (uma sub-transação de contingência);

- Regra de visibilidade: O Modelo Transacional Hierárquico propõe um controle de con- 
corrência baseado na extensão do Protocolo de Bloqueio Bifásico. O gerenciador de bloqueio utiliza a estrutura hierárquica para controlar os bloqueios. Como uma sub-transação filha apresenta uma execução Atômica, Isolada e Consistente, o gerenciador de bloqueio aplica bloqueios tradicionais nos itens de dados usados pela sub-transação. Quando a sub-transação filha é confirmada, os bloqueios solicitados na sua execução são transferidos para seu pai. Dessa forma, uma (sub)transação pai assume os bloqueios das sub-transações filhas após elas serem confirmadas. Ao assumir os bloqueios, a (sub)transação pai garante a prerrogativa de um desfazimento seguro de suas filhas. Por isso, as alterações realizadas por uma sub-transação somente tornam-se visíveis para a (sub)transação pai após sua confirmação.

Resumindo, a confirmação de uma transação filha não é final, mas relativa ao seu pai. Já o aborto da (sub)transação pai é final, acarretando no aborto de todos os seus descendentes, mesmo aqueles que haviam sido provisoriamente confirmados.

Uma das principais motivações do Modelo Transacional Hierárquico é ampliar a concorrência na execução de transações de longa duração sem perder a segurança e o suporte propiciado pelas propriedades ACID. Mais especificamente, o modelo explora a estrutura hierárquica para propiciar a concorrência dentro da transação (intra-transação). Para tipos de cenários específicos, essa estratégia pode reduzir o tempo de espera das transações. Além disso, o modelo também minimiza a taxa de aborto ao prover autonomia à (sub)transação pai no caso de falha de uma de suas filhas.

Sob uma perspectiva inter-transação, a abordagem provê o isolamento total entre as transações, assim como no modelo transacional clássico. No entanto, sob uma perspectiva intra-transação, a abordagem introduz uma sutil flexibilização na propriedade de isolamento que proporciona a modularização da transação, um tratamento de falhas mais sofisticado e, principalmente, um alto grau de concorrência dentro da transação. O Modelo Transacional Hierárquico foi uma significativa contribuição para ascensão dos modelos transacionais avançados. Os conceitos propostos por esse modelo têm sido incorporados em diferentes modelos transacionais avançados ao adotar a estrutura hierárquica para as transações.

\subsubsection{Bloqueio Altruísta}

O Bloqueio Altruísta (Altruistic Locking) (Salem et al., 1994) é uma estratégia de bloqueio que melhora o desempenho do Protocolo Bloqueio Bifásico quando transações de longa duração estão presentes. A ideia básica é permitir que transações longas disponibilizem seus bloqueios antecipadamente, desde que os dados protegidos pelo bloqueio não sejam mais usados por elas. Essa estratégia garante escalonamentos serializáveis e não impõem restrições na forma de acesso ao dado.

Suponha o exemplo da Figura 3.3, adaptado de (Salem et al., 1994), no qual os itens de dados a, b, c, d, e, f e g são acessados e atualizados pela transação $T_{1}$. Após a transação $T_{1}$ terminar sua execução sobre o item de dado d, outras três transações $T_{2}, T_{3}$ e $T_{4}$ tentam suas execuções. Se o Protocolo de Bloqueio Bifásico é usado, $T_{2}$ e $T_{3}$ não poderiam executar até que $T_{1}$ finalizasse sua execução e liberasse seus bloqueios. A motivação do Bloqueio Altruísta parte da observação desse exemplo. Como $T_{1}$ não usará mais os itens de dados pretendidos por $T_{2}$, o escalonador poderia autorizar a execução de $T_{2}$ sem esperas ou violação da seriação. Embora a e b estejam bloqueados pela transação $T_{1}$, nesse momento, $T_{1}$ já finalizou o acesso a esses itens de dados. Uma vez que $T_{2}$ acessa somente os itens que $T_{1}$ finalizou, ele pode aparecer após $T_{1}$ na seriação do escalonamento. Baseado nessa observação, o Bloqueio Altruísta propõem um mecanismo no qual transações, como 
$T_{1}$, podem informar ao escalonador que elas finalizaram a execução sobre um item de dado. Dessa forma, o escalonador pode usar dessa informação para permitir que outras transações acessem esses itens. A ideia fundamental para o uso do termo altruísta é que transações que fornecem essa informação não recebem qualquer benefício por essa ação. Ao invés disso, essa informação pode beneficiar outras transações concorrentes.

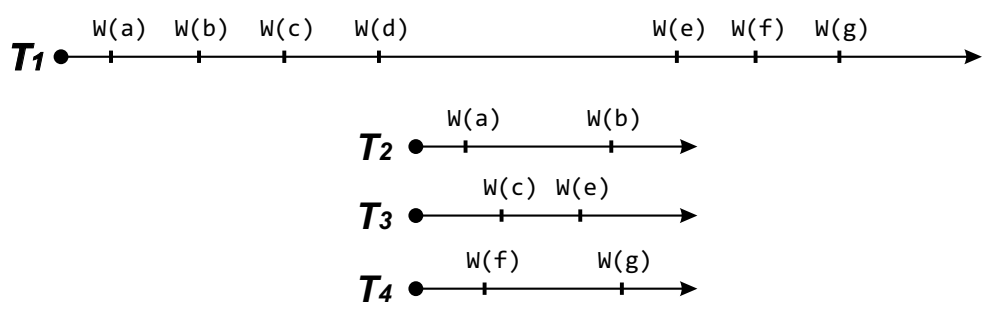

Figura 3.3: Motivação para o Bloqueio Altruísta

O Bloqueio Altruísta é uma modificação do Protocolo de Bloqueio Bifásico no qual, sob certas condições, diversas transações podem manter simultaneamente bloqueios em um item de dados. Para o exemplo da Figura 3.3, o escalonador permitirá que a transação $T_{2}$ acesse os itens a e b, embora $T_{1}$ ainda mantenha os bloqueios desses itens.

Além das operações de LOCK e UNLOCK, o Bloqueio Altruísta fornece uma terceira operação chamada DONATE. Como o UNLOCK, a operação DONATE é usada pela transação para informar o escalonador que o acesso ao item de dado não é mais necessário. Entretanto, quando a operação DONATE é usada, a transação está livre para continuar adquirindo novos bloqueios, isto é, as operações DONATE e LOCK não necessitam ser projetadas em duas fases.

Diferentes regras definem o uso correto da operação DONATE: (i) transações podem somente doar itens que ainda estejam bloqueados para si; (ii) transações não podem mais acessar os itens doados; (iii) uma doação não substitui a operação de desbloqueio UNLOCK; e (iv) é opcional para as transações doarem seus itens de dados.

Um escalonador altruísta não deve permitir acessos arbitrários a um item dado que tenha sido doado, mas que ainda não foi desbloqueado. No exemplo da Figura 3.3, existiria uma violação do escalonamento serializável se $T_{3}$ pudesse acessar o item c doado por $T_{1}$ e bloquear o item e antes que $T_{1}$ tenha oportunidade de acessá-lo. Para evitar esse problema, o escalonador altruísta deve impor restrições sobre o acesso aos itens doados. Essas restrições são descritas em duas regras que são observadas pelo escalonador altruísta.

Regra 1. Duas transações não podem manter simultaneamente bloqueios sobre o mesmo item de dado, a menos que uma delas doe primeiro o bloqueio.

É dito que um item de dado $\mathrm{x}$ é a onda ${ }^{1}$ de $T_{a}$, se $\mathrm{x}$ é disponibilizado por meio da operação DONATE de $T_{a}$. Se uma transação $T_{b}$ bloqueia um item de dado que foi doado (e não ainda foi desbloqueado) por outra transação $T_{a}$, é dito que $T_{b}$ está na onda da transação $T_{a}$. Uma transação está completamente na onda de outra transação, se todos os itens que ela bloqueia estão na onda da outra transação.

Regra 2. Se uma transação $T_{a}$ está na onda de uma outra transação $T_{b}$, então $T_{a}$ deve estar completamente na onda de $T_{b}$ até $T_{b}$ executar sua primeira operação UNLOCK.

\footnotetext{
${ }^{1}$ a expressão "é a onda" é uma tradução livre da expressão "is the wake"
} 
Considerando novamente o exemplo da Figura 3.3, para acessar seus itens de dados, a transação $T_{1}$ bloqueia cada um dos itens um pouco antes de atualizá-los. Quando $T_{1}$ não necessita mais acessar ao dado, a transação pode doar cada item ao executar uma operação DONATE. Dessa forma, enquanto $T_{1}$ acessa o item d, sua onda consiste dos itens a,b e c. Nesse momento, as outras três transações tentam executar. Como consequência:

- $T_{2}$ será bem-sucedida, pois ela poderá executar completamente na onda de $T_{1}$;

- $T_{4}$ também será bem-sucedida, pois ela acessa apenas itens ainda não bloqueados por $T_{1}$; e

- $T_{3}$ não poderá executar, pois, embora esteja na onda de $T_{1}$, ela não está completamente na onda.

Em resumo, essa abordagem apresenta melhores resultados em comparação com o Protocolo de Bloqueio Bifásico que não permitiria a execução de $T_{2}$ e $T_{4}$. Em contrapartida, um efeito colateral da abordagem é que o aborto de $T_{1}$ causaria o rollback em cascata de todas as transações que estão na onda de $T_{1}$.

\subsubsection{Transações Emaranhadas}

Essa abordagem apresenta uma forma de coordenação de transações por meio do conceito de Transações Emaranhadas (Entangled Transactions) (Gupta et al., 2011b). As transações emaranhadas estendem as transações clássicas flexibilizando de forma pontual o isolamento. Essa flexibilização é efetuada por meio de pontos de sincronização chamados de Consultas Emaranhadas (Entangled Queries) (Gupta et al., 2011a). As consultas emaranhadas apresentam um mecanismo que permite uma interação limitada entre consultas no banco de dados para que a execução possa prosseguir de forma coordenada. Para auxiliar no entendimento dessa abordagem, suponha o seguinte exemplo adaptado de (Gupta et al., 2011b):

Os amigos Mickey e Minnie desejam viajar para Los Angeles no mesmo voo e ficar hospedados no mesmo hotel. A data de chegada é flexível, mas a data da partida já está definida. Eles iniciam escolhendo conjuntamente um voo que satisfaça ambas as restrições. Uma vez que o voo está definido, eles devem agendar uma reserva para o mesmo hotel durante o período da viagem.

As consultas emaranhadas podem ser utilizadas para coordenar a escolha do voo e a escolha do hotel. Porém, essas consultas devem ser incorporadas dentro de unidades maiores denominadas Transações Emaranhadas. A seguir, são apresentados detalhes das consultas e transações emaranhadas.

As consultas emaranhadas são expressas em uma extensão da linguagem SQL. Seguindo o exemplo anterior, a consulta emaranhada do Mickey para coordenar a escolha do voo com a Minnie é ilustrada pelo seguinte código.

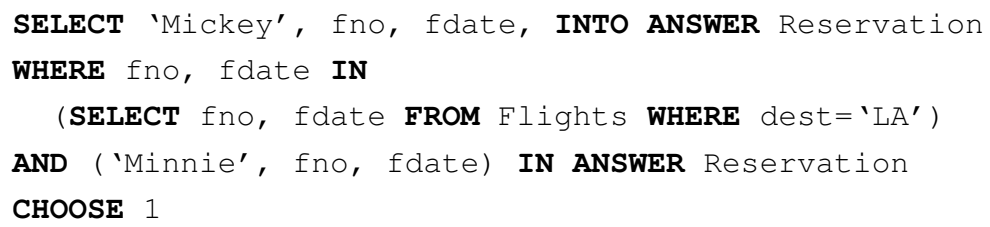


A cláusula INTO ANSWER referencia relações conceituais que coletam as respostas de todas as consultas. Nesse exemplo, a relação Reservation armazena as respostas de todas as consultas relacionadas ao agendamento de voos. A cláusula SELECT especifica a própria resposta esperada pelo Mickey. Essa é uma tupla contendo a constante Mickey, o número e a data do voo. A existência da resposta do Mickey, entretanto, é condicionada a dois requisitos, que são definidas pela cláusula WHERE. Primeiro, o destino do voo deve ser Los Angeles. Segundo, a relação Reservation deve conter uma tupla com o mesmo número e data do voo, mas com Minnie como nome do passageiro. A cláusula CHOOSE1 no fim da consulta indica que o sistema deve escolher somente um voo entre aqueles disponíveis.

Agora suponha que a Minnie quer viajar com o Mickey, mas somente se for em um dos voos da empresa aérea United. Sua consulta é ilustrada a seguir:

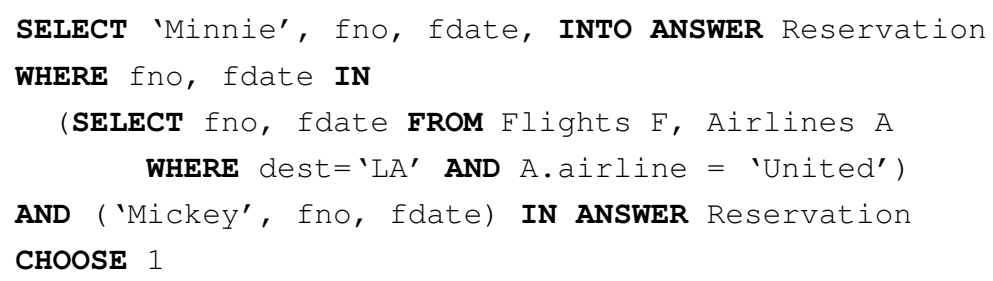

Quando o sistema recebe as duas consultas, ele responde a ambas simultaneamente, garantindo uma escolha coordenada do voo. Considerando o banco de dados ilustrado na Figura 3.4(a), o sistema escolherá entre os voos 122 ou 123 e retornará as tuplas apropriadas como resposta às consultas. A Figura 3.4(b) mostra a satisfação mútua das restrições das consultas que ocorre ao selecionar o voo 122. A relação Reservation é abreviada por R. O Mickey e a Minnie não veem as respostas um do outro, mas eles têm a garantia de que suas restrições foram completamente atendidas. Esse é um exemplo simplificado da execução das consultas; na prática, outras verificações são necessárias, tais como a verificação da disponibilidade dos assentos.

\begin{tabular}{|c|c|c|c|c|}
\hline \multicolumn{3}{|c|}{ Voos } & \multicolumn{2}{|c|}{$\begin{array}{c}\text { Companhias } \\
\text { aéreas }\end{array}$} \\
\hline fno & fdate & dest & fno & airline \\
\hline 122 & 3 de março & LA & 122 & United \\
\hline 123 & 4 de março & LA & 123 & United \\
\hline 124 & 3 de março & USAir & 124 & USAir \\
\hline 235 & 5 de maio & Paris & 235 & Delta \\
\hline
\end{tabular}

(a)

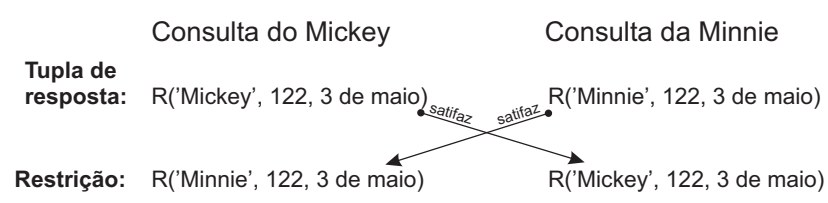

(b)

Figura 3.4: (a) Banco de Dados dos voos; (b) Satisfação mútua das restrições

Embora as consultas sejam especificadas em uma extensão da SQL, elas são transformadas em uma representação intermediária para facilitar a sua avaliação. A representação intermediária usa uma sintaxe similar a de uma Linguagem de Regras Relacional. Nessa representação, uma consulta emaranhada tem a seguinte forma: 
em que $C$ e $H$ são conjunções de átomos relacionais sobre as relações de resposta e $B$ é uma consulta sobre as relações do banco de dados. $B, H$ e $C$ representam o corpo, a cabeça e a pós-condição da consulta, respectivamente. Cada átomo na representação pode conter constantes ou variáveis. Todas as variáveis que aparecem em $H$ ou $C$ devem também aparecer em $B$. Para uma consulta expressa em SQL estendida, $H$ corresponde a cláusula SELECT INTO, enquanto $B$ e $C$ correspondem a informações contidas na cláusula WHERE. $C$ especifica todas as condições sobre as relações de respostas da cláusula WHERE. $B$ especifica as condições sobre as relações do banco de dados da cláusula WHERE, além de servir para vincular as variáveis utilizadas em $H$ e $C$. A Figura 3.5(a) ilustra a representação intermediária das consultas de Mickey e Minnie. As relações Reservation, Flights e Airlines são abreviadas como R, F e A, respectivamente.

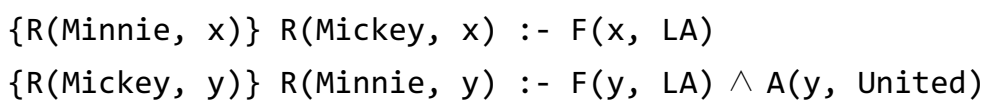

(a)

$\begin{array}{lll}\text { 1: } & \{\mathrm{R}(\text { Minnie }, 122)\} & \mathrm{R}(\text { Mickey, } 122) \\ \text { 2: } & \{\mathrm{R}(\text { Minnie }, 123)\} & \mathrm{R}(\text { Mickey }, 123) \\ 3: & \{\mathrm{R}(\text { Minnie }, 124)\} & \mathrm{R}(\text { Mickey }, 124) \\ & & \\ \text { 4: } & \{\mathrm{R}(\text { Mickey }, 122)\} & \mathrm{R}(\text { Minnie }, 122) \\ 5: & \{\mathrm{R}(\text { Mickey }, 123)\} & \mathrm{R}(\text { Minnie }, 123)\end{array}$

(b)

Figura 3.5: (a) Representação intermediária das consultas emaranhadas; (b) Avaliação das tuplas encontradas

Do ponto de vista de uma única consulta, a avaliação é um processo que devolve uma resposta, ou seja, uma tupla da relação de resposta. Do ponto de vista do sistema, a avaliação sempre envolve um conjunto de consultas e o objetivo é popular as relações de resposta de modo que respeite todas as restrições de coordenação das consultas. Na Figura 3.5(b), as linhas 1, 2 e 3 representam o conjunto das tuplas que satisfazem a consulta do Mickey, enquanto que as linhas 4 e 5 apresentam as tuplas que satisfazem a consulta da Minnie. As tuplas apresentadas nas linhas 1 e 4, bem como nas linhas 2 e 5 indicam que as consultas do Mickey e da Minnie podem ser coordenadas por meio do voo 122 ou 123. Mais detalhes da semântica dessa avaliação podem ser encontrados em (Gupta et al., 2011a).

Uma transação emaranhada é especificada pelo código entre os construtores BEGIN TRANSACTION e COMMIT e deve conter uma ou mais consultas emaranhadas. O exemplo a seguir ilustra a transação do Mickey que coordena sua execução com a transação da Minnie, conforme o exemplo apresentado inicialmente. A relação Hotels contém informações sobre os hotéis, incluindo os atributos de identificação (hid) e de localização. FlightRes e HotelRes são relações de resposta para coordenar os agendamentos de voos e hotéis, respectivamente.

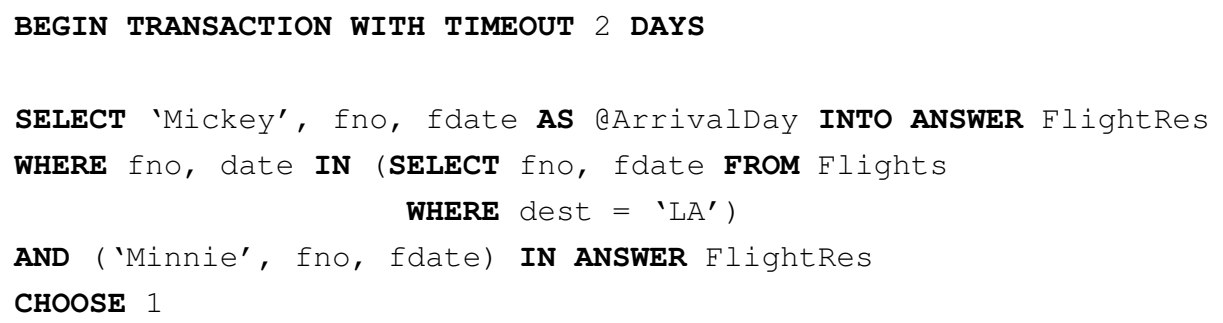




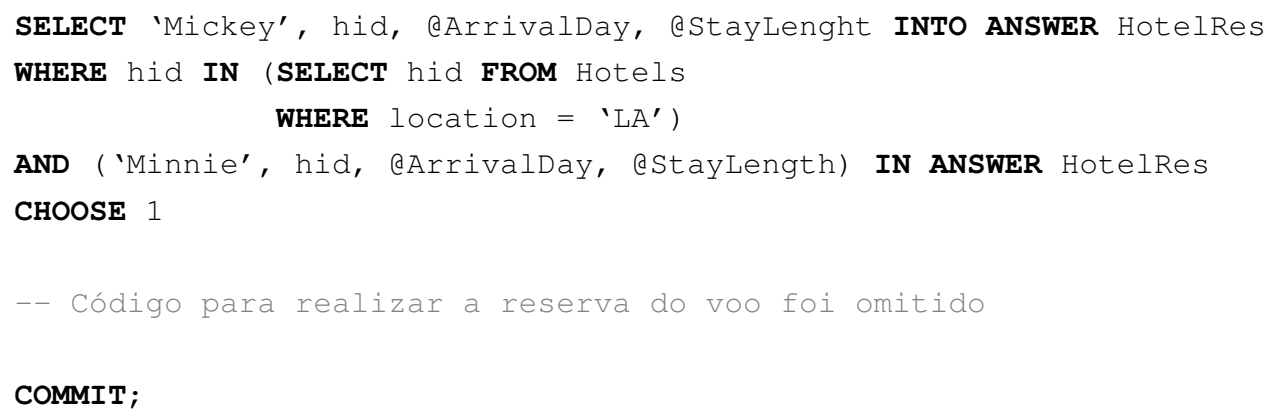

Além da possibilidade de troca de informações, as consultas emaranhadas também fornecem um ponto explícito de sincronização entre as transações. Uma vez que uma consulta emaranhada é respondida, a transação tem a garantia de que todos os parceiros de coordenação executaram o código precedente as suas consultas. Por exemplo, se o Mickey está coordenando o agendamento do hotel com a Minnie então ele tem a garantia de que o voo já foi agendado entre eles. As chamadas para avaliação de uma consulta emaranhada são bloqueantes, ou seja, a transação não prossegue até que a consulta receba uma resposta. Para evitar uma longa espera, é estabelecido um parâmetro de tempo limite para execução da transação. Esse parâmetro limita o tempo máximo que a transação pode esperar por seu parceiro.

Diante desses pontos de sincronismo, a abordagem apresenta um novo significado para as propriedades ACID, estendendo a proposta original. A propriedade de isolamento é a mais afetada. Nesse novo cenário novas anomalias surgiram: as transações viúvas e a leitura aparentemente não repetível $^{2}$. A anomalia das transações viúvas surge quando uma transação $T_{i}$ está apta para efetuar o commit, mas sua parceira $T_{j}$ por algum motivo aborta. Assim, a abordagem não deve permitir que $T_{i}$ efetive suas ações. Para evitar essa anomalia, a abordagem propõe o ponto de confirmação em grupo para as transações que estão coordenando. A anomalia da leitura aparentemente não repetível é solucionada com um protocolo de bloqueio tradicional. Por exemplo, após as transações da Minnie e Mickey coordenarem o agendamento dos voos, não é permitido a inserção de nenhum novo voo, ou seja, esse recurso é bloqueado enquanto as transações estiverem em execução. Mais detalhes podem ser encontrados em (Gupta et al., 2011b).

Essa abordagem enfraquece a propriedade de isolamento ao prover pontos de sincronização por meio das consultas emaranhadas durante a execução das transações. Ao receber uma resposta da consulta emaranhada, a transação torna-se ciente da existência de outras transações no sistema. Essa estratégia representa uma contribuição significativa. No entanto, o comportamento de isolar o recurso após a coordenação entre as transações é similar ao comportamento das transações do modelo transacional clássico. Além disso, essa abordagem é inviável para tratar de transações de longa duração nas quais resultados intermediários precisam ser expostos.

\subsection{Abordagens que flexibilizam a seriação}

As abordagens dessa categoria flexibilizam a seriação ao considerar aspectos semânticos das aplicações com objetivo de tornar os protocolos de bloqueio mais flexíveis. A seguir, serão apresentadas duas abordagens que flexibilizam a seriação enquanto garantem a consistência do banco de

\footnotetext{
${ }^{2}$ tradução livre do termo unrepeatable quasi-read
} 
dados: o modelo SAGAS e o Modelo Hierárquico Aberto (Open Nested Model).

\subsubsection{Modelo SAGAS}

García-Molina e Salem (1987) propõem o Modelo SAGAS com intuito de minimizar o problema das longas esperas no contexto das transações longas. Os autores discutem os problemas relacionados as Transações de Longas Duração e as definem como aquelas que executam por um longo período de tempo, acessam diversas bases de dados, têm computações demoradas, possuem pausas para interação com usuário, ou uma combinação desses fatores (García-Molina e Salem, 1987).

O tratamento das transações de longas duração como transações comuns exige que elas sejam executadas de forma atômica para preservar a consistência do banco de dados. Assim, para garantir essa execução atômica, bem como as outras propriedades ACID, o arcabouço transacional bloqueia os itens de dados acessados pela transação até que ela seja finalizada e confirmada. Como consequência, os itens de dados acessados pela transação ficam retidos por longos períodos de tempo e, consequentemente, atrasam o término de outras transações.

Os autores ainda argumentam que, para algumas aplicações, é possível contornar o problema descrito relaxando a propriedade de atomicidade das transações convencionais e adaptando-a ao contexto das transações longas. A propriedade de atomicidade é generalizada de modo a garantir a terminação de uma transação em que a execução não ocorre de forma atômica. Dessa forma, a transação de longa duração pode liberar os itens de dados antes do término de sua execução, sem comprometer a consistência do banco de dados. No entanto, isso somente é possível quando uma transação de longa duração é composta por uma sequência de passos independentes.

O termo $S A G A$ é utilizado para referenciar uma transação de longa duração a qual consiste de uma coleção de sub-transações (passos SAGA) que podem ser intercaladas de qualquer maneira com outras transações (García-Molina e Salem, 1987). Cada sub-transação é uma transação real de modo que sua execução preserva a consistência do banco de dados. No entanto, essas sub-transações devem ser executadas como uma unidade (não atômica) e qualquer execução parcial deve ser desfeita ou compensada. Para evitar as execuções parciais, a abordagem define que, para cada passo SAGA $t_{i}$, deve ser provida uma sub-transação de compensação $c_{i}$. A compensação desfaz, do ponto de vista semântico, qualquer ação realizada por $t_{i}$, mas não necessariamente restaura o banco de dados para o estado anterior à execução de $t_{i}$. Uma vez que as compensações $c_{1}, c_{2}, \ldots, c_{n}$ são definidas para a SAGA formada por $t_{1}, t_{2}, \ldots, t_{n}$, o arcabouço garante que uma das sequências a seguir será executada:

- Execução completa: $t_{1}, t_{2}, \ldots, t_{n}$;

- Compensação: $t_{1}, t_{2}, \ldots, t_{j}, c_{j}, \ldots, c_{2}, c_{1}$, para algum $1 \leq j<n$.

Quando uma SAGA é interrompida por uma falha, há duas formas de recuperá-la: recuperação backward ou recuperação forward. Genericamente, na recuperação forward, os passos restantes são executados enquanto que, na recuperação backward, os passos já executados são compensados. Na recuperação backward as compensações são executadas na ordem inversa aos passos executados para garantir que, após a execução de cada compensação, o estado da SAGA seja semanticamente equivalente ao estado produzido caso a SAGA tivesse sido executada até aquele ponto.

Os autores ressaltam que, ao considerar que os passos SAGA são independentes, outras subtransações podem ver os efeitos da execução parcial de uma SAGA e que nenhum esforço é realizado 
para notificar ou abortar as sub-transações que acessaram os resultados de $t_{i}$ antes da sua compensação $c_{i}$. Conceitualmente, a principal contribuição do modelo SAGAS é o conceito de compensação associada a cada passo da transação longa (Alonso, 2005).

\subsubsection{Modelo Transacional Hierárquico Aberto}

O Modelo Transacional Hierárquico Aberto (Open Nested Model) estende o Modelo Transacional Hierárquico original (Moss, 1985) ao levar em consideração a semântica da aplicação para flexibilizar a seriação. Esse modelo também é conhecido como Modelo Multinível como discutido em (Moss , 2011; Weikum e Schek, 1992). O principal conceito dessa abordagem é explorar a semântica das operações em níveis de abstração específicos em que as relações de conflito reflitam a comutatividade das operações (Weikum e Schek, 1992). A especificação de uma operação em um nível abstrato mais alto implica na execução de operações de mais baixo nível. Por exemplo, suponha a execução concorrente de duas transações de longa duração $T_{i}$ e $T_{j}$ em que um dos objetivos é a transferência de uma determinada quantia entre contas bancárias. A transação $T_{i}$ realiza uma transferência da conta $a$ para conta $c$ e continua sua execução. Da mesma forma, a transação $T_{j}$ realiza uma transferência da conta $b$ para conta $c$ e continua sua execução. Uma transferência é composta de uma operação de leitura (R) seguida de uma operação de escrita (W) na conta origem e uma operação de leitura seguida de uma operação de escrita na conta destino. Com intuito de simplificar o exemplo, os valores a serem transferidos são ocultados. Dessa forma, as transações $T_{i}$ e $T_{j}$ executam as seguintes operações:

$$
\begin{array}{llll}
\mathrm{T}_{\mathrm{i}}: \mathrm{R}_{\mathrm{i}}(\mathrm{a}) & \mathrm{W}_{\mathrm{i}}(\mathrm{a}) & \mathrm{R}_{\mathrm{i}}(\mathrm{c}) & \mathrm{W}_{\mathrm{i}}(\mathrm{c}) \cdots \\
\mathrm{T}_{\mathrm{j}}: \mathrm{R}_{\mathrm{j}}(\mathrm{b}) & \mathrm{W}_{\mathrm{j}}(\mathrm{b}) & \mathrm{R}_{\mathrm{j}}(\mathrm{c}) & \mathrm{W}_{\mathrm{j}}(\mathrm{c}) \cdots
\end{array}
$$

Agora considere o seguinte escalonamento da execução das transações $T_{i}$ e $T_{j}$ :

$$
\begin{array}{lllllll}
R_{i}(a) & R_{j}(b) & W_{i}(a) & W_{j}(b) & R_{j}(c) & W_{j}(c) & R_{i}(c)
\end{array} W_{i}(c) \cdots
$$

Pela Teoria da Seriação esse escalonamento não é válido devido o acesso concorrente a conta $c$. O protocolo de bloqueio tradicional impede que a transação $T_{j}$ acesse a conta bancária $c$, pois ela estará bloqueada para a transação $T_{i}$. No entanto, ao considerar um nível semântico mais abstrato, as operações de leitura e escrita podem ser agrupadas para representar as operações de saque e depósito. Assim, uma transferência pode ser representada por uma operação de saque na conta origem, seguida de uma operação de depósito na conta destino. Tanto a operação de saque quanto a operação de depósito agrupam uma leitura e uma escrita na conta bancária. Com essa abstração, as transações $T_{i}$ e $T_{j}$ podem ser representadas da seguinte forma:

$$
\begin{array}{ll}
T_{i}: \operatorname{saque}(a) & \operatorname{deposito}(c) \cdots \\
T_{j}: \operatorname{saque}(b) & \operatorname{deposito}(c) \cdots
\end{array}
$$

A Figura 3.6 ilustra um possível escalonamento da execução concorrente das transações longas $T_{i}$ e $T_{j}$, considerando diferentes níveis de abstração. Observando o escalonamento no nível mais abstrato, ainda existe um conflito ao efetuar o depósito na conta $c$. No entanto, ao analisar a semântica da relação entre as operações de depósito, observa-se que elas são comutáveis e, portanto, não possuem conflitos. Assim, a execução das operações deposito ${ }_{i}(c)$ e deposito ${ }_{j}(c)$ podem ser 
executadas concorrentemente sem causar inconsistências. Weikum e Schek (1992) definem que duas operações $f$ e $g$ são consideradas comutativas (e portanto livre de conflito) se, e somente se, para cada possível estado do sistema $\sigma$, duas condições forem mantidas: (i) os estados que resultam da execução das sequências $(f ; g)$ e $(g ; f)$ aplicadas a $\sigma$ são indistinguíveis; e (ii) as operações $f$ e $g$ possuem os mesmos valores de retorno em ambas as sequências de execução.

O exemplo ilustrado pela Figura 3.6 mostra que, quando as operações são definidas em um nível mais abstrato, é possível explorar a comutatividade entre elas para aumentar a concorrência na execução de transações longas. A comutatividade faz com que os conflitos identificados no nível zero tornem-se um pseudo-conflito ou um falso conflito. Além disso, a comutatividade permite que resultados intermediários sejam expostos sem criar dependências entre as transações. Assim, o acesso aos resultados intermediários expostos por uma operação somente serão liberados às operações comutativas. No Modelo Transacional Hierárquico Aberto, as operações são implementadas por sub-transações na hierarquia da transação e a relação de conflito entre as operações devem ser especificadas a priori pelo projetista. O gerenciador de bloqueio utiliza as informações das operações e suas relações de conflito para garantir a execução concorrente entre as transações de forma segura.

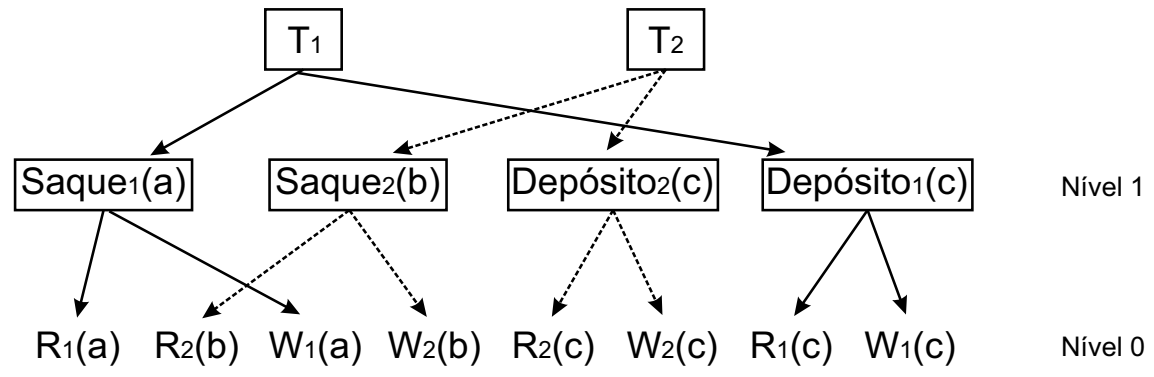

Figura 3.6: Execução concorrente de transações multiníveis

Para exemplificar formas concretas para representar esses conflitos abstratos, Moss (2011) utiliza o exemplo descrito a seguir. Considere uma estrutura de dados implementada em uma lista ligada que represente um conjunto. Esse conjunto contém elementos de dados que são compartilhados entre as transações. As operações permitidas sobre o conjunto são: $\operatorname{add}(\mathrm{x})$ e remove(x) para inserir e remover o item $\mathrm{x}$ do conjunto, size() para devolver a quantidade de elementos do conjunto e contains (x) para verificar se $\mathrm{x}$ está contido no conjunto. Suponha também que os elementos a, b e c foram inseridos no conjunto por meio da operação add. A operação add sempre acrescenta o item no final da lista ligada e não permite elementos duplicados. Em seguida, a transação $t_{i}$ adiciona o item d e continua sua execução. A operação add(d) percorre os elementos a, b e c, cria um novo nó na lista e altera a ligação do nó em que c está armazenado. Antes da transação $t_{i}$ finalizar sua execução, outra transação $t_{j}$ executa concorrentemente a operação contains(e) para verificar se o item e está presente no conjunto. Nesse cenário, a operação contains(e) conflita com a operação $\operatorname{add}(d)$, pois a operação contains não pode acessar dados ainda não confirmados pelas transações. Nesse caso, o item d somente será efetivamente inserido caso a transação $t_{i}$ finalize sua execução e seja confirmada. Caso contrário, a transação aborta e cancela a inserção de d. O mesmo conflito ocorre caso outra transação tente remover, por exemplo, o item d do conjunto. Como mencionado anteriormente, nesse exemplo, como os protocolos de bloqueios tradicionais não são factíveis, é necessário um gerenciador de bloqueio para tratar conflitos abstratos. Dessa forma, Moss (2011) apresenta duas formas para implementar os conflitos abstratos: (i) definição de blo- 
queios abstratos; ou (ii) definição de predicados de conflito. Na primeira forma, o projetista deve definir os bloqueios abstratos, a relação de conflito entre eles e a associação entre os bloqueios e as operações. Considerando o exemplo anterior, os bloqueios definidos são:

- S: Bloqueio compartilhado para leitura;

- X: Bloqueio exclusivo para escrita;

- R: Bloqueio para leitura da cardinalidade do conjunto;

- M: Bloqueio para modificação da cardinalidade do conjunto.

Os bloqueios $(\mathrm{S})$ e $(\mathrm{X})$ são exercidos em um único item de dado e são idênticos aos de um protocolo de bloqueio tradicional. De forma complementar, os bloqueios (R) e (M) atuam sobre uma cardinalidade do conjunto. A relação de conflito entre esses dois modos são: dois bloqueios (R) não conflitam, dois bloqueios (M) não conflitam, mas os bloqueios (R) e (M) são conflitantes. A Tabela 3.1 ilustra a relação entre as operações e os modos de bloqueio.

Tabela 3.1: Relação entre as operações e bloqueios abstratos

\begin{tabular}{l|l}
\hline Operação & Bloqueio abstrato \\
\hline add (a) & Bloqueio modo X em a; Bloqueio modo M na cardinalidade \\
remove (a) & Bloqueio modo X em a; Bloqueio modo M na cardinalidade \\
contains (a) & Bloqueio modo S em a \\
size () & Bloqueio modo R na cardinalidade \\
\hline
\end{tabular}

Como cada operação sobre o conjunto é executada como uma sub-transação então, antes de executar, é necessário a aquisição dos bloqueios abstratos especificados. Caso não seja possível, a sub-transação está em conflito com alguma outra sub-transação em execução e deve ser bloqueada. Uma sub-transação bloqueada pode aguardar a liberação do bloqueio ou, simplesmente, optar pelo aborto de sua execução.

Similar ao Modelo Transacional Hierárquico original, quando uma sub-transação aborta, a sua transação pai é responsável por optar por um caminho alternativo ou tentar novamente a execução da sub-transação. Os autores alegam que muitos conflitos são temporários e a possibilidade de ressubmeter a execução de uma sub-transação minimiza a taxa de aborto das transações.

A segunda forma de representar os conflitos abstratos é por meio de uma tabela de predicados de conflito. Os predicados indicam quais operações conflitam entre si. A Tabela 3.2 indica os predicados de conflito das operações apresentadas no exemplo anterior. Em geral, essa tabela é verificada em tempo de execução pelo mecanismo de controle de concorrência. Nessa tabela, as operações da primeira coluna representam operações executadas por uma transação e as operações da primeira linha representam operações submetidas a execução por outra transação. Cada entrada na tabela indica a condição sob as quais a nova requisição conflita com a que está em execução. Essa condição resulta nos literais true ou false. O literal true significa que as operações são conflitantes e a operação representada pela coluna não pode ser executada. O literal false indica que não há conflito ou as operações são comutativas, assim, a operação representada pela coluna pode ser executada sem criar dependências. 
Tabela 3.2: Predicados de conflito

\begin{tabular}{|l|c|c|c|c|}
\hline & add $(\mathrm{y})$ & remove $(\mathrm{y})$ & contains $(\mathrm{y})$ & size () \\
\hline add $(\mathrm{x})$ & $\mathrm{x}=\mathrm{y}$ & $\mathrm{x}=\mathrm{y}$ & $\mathrm{x}=\mathrm{y}$ & true \\
\hline remove $(\mathrm{x})$ & $\mathrm{x}=\mathrm{y}$ & $\mathrm{x}=\mathrm{y}$ & $\mathrm{x}=\mathrm{y}$ & true \\
\hline contains $(\mathrm{x})$ & $\mathrm{x}=\mathrm{y}$ & $\mathrm{x}=\mathrm{y}$ & false & false \\
\hline size () & true & true & false & false \\
\hline
\end{tabular}

Nessa abordagem, diferente do Modelo Transacional Hierárquico original, as operações representadas por sub-transações podem ser confirmadas, o que torna o efeito de suas ações permanente. A confirmação das sub-transações não implica na exposição total desses dados, como mencionado anteriormente, os dados somente são expostos para as sub-transações que sejam comutativas. No entanto, essa confirmação antecipada traz desafios quando uma transação aborta. Para desfazer as sub-transações que já foram confirmadas, a abordagem aplica compensações ou ações inversas. Para isso, o projetista também deve prover as compensações das operações definidas. A Tabela 3.3 ilustra as compensações das operações definidas no exemplo. A entrada - significa que nenhuma compensação é necessária para a operação.

Tabela 3.3: Operações e suas compensações

\begin{tabular}{|l|c|c|c|c|}
\hline Operação & $\operatorname{add}(\mathbf{x})$ & remove $(\mathbf{x})$ & $\operatorname{contains}(\mathbf{x})$ & size () \\
\hline Compensação & $\operatorname{remove}(\mathrm{x})$ & $\operatorname{add}(\mathrm{x})$ & - & - \\
\hline
\end{tabular}

Enquanto o Modelo Transacional Hierárquico original visa apoiar a concorrência segura dentro de uma transação, o Modelo Transacional Hierárquico Aberto tem como objetivo prover concorrência entre transações de longa duração, evitando falsos conflitos ao considerar a semântica das operações sobre os dados compartilhados.

\subsection{Abordagens que substituem a seriação}

As abordagens dessa categoria substituem a seriação por um critério de correção alternativo. A seguir, serão apresentadas as características do Modelo ConTract e da Consistência Linear que propõem um critério de correção alternativo à seriação.

\subsubsection{Modelo ConTract}

Wächter e Reuter (1992) propuseram o Modelo ConTract com objetivo de prover uma base formal para definir e controlar transações longas de forma similar as transações tradicionais. Os autores apontam que a principal desvantagem do modelo transacional clássico no contexto de transações longas é o fato de não ser capaz de representar relações entre transações, por exemplo, as dependências do fluxo de controle. Essa característica fica sob a responsabilidade da aplicação. Esse modelo transacional introduz uma unidade de trabalho e controle que engloba toda a aplicação em detrimento de execuções individuais que transacionam estados do banco de dados. O mecanismo de controle é construído sob as transações ACID convencionais. No entanto, a abordagem 
não é uma extensão do modelo transacional clássico, mas um modelo programável que, em contraste com as linguagens de programação tradicionais, proporciona persistência, consistência, recuperação, sincronização e cooperação.

O termo ConTract é utilizado para definir uma transação longa que consiste de passos prédefinidos (steps) executados de acordo com a descrição explícita de um fluxo de controle (script). Para exemplificar o mecanismo do modelo ConTract, será utilizado o exemplo clássico do planejamento de uma viagem, como ilustrado em (Wächter e Reuter, 1992). A Figura 3.7 ilustra uma representação gráfica simplificada do processo. De modo geral, o planejamento da viagem é composto pelas atividades de reserva do voo $\left(S_{3}\right)$, reserva do hotel $\left(S_{4}\right)$ e reserva do automóvel $\left(S_{5}\right)$. O processo inicia com a entrada dos dados da viagem $\left(S_{1}\right)$, seguida de uma pesquisa dos voos disponíveis $\left(S_{2}\right)$. Nesse exemplo, os voos são pesquisados paralelamente em três companhias distintas, como ilustra a atividade $S_{2}$. Após a pesquisa, o voo é reservado na atividade $S_{3}$. Em seguida, a reserva do hotel e do automóvel são realizados atomicamente, representados por $T_{1}$ ao englobar as atividades $S_{4}$ e $S_{5}$. São realizadas apenas duas tentativas de reservar o hotel e o automóvel ( $T_{1}$ e $T_{2}$ ). A seguir, serão detalhados como o fluxo de controle é modelado por meio dos passos e scripts.

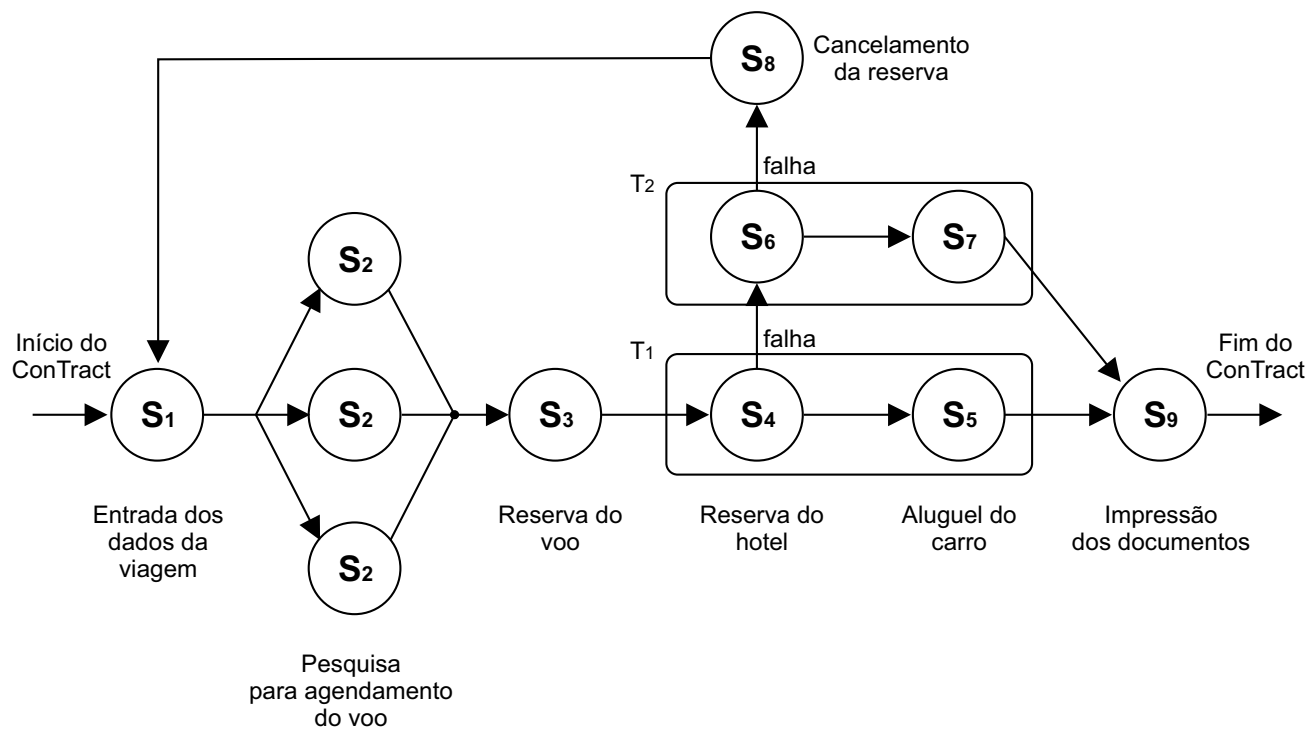

Figura 3.7: Representação gráfica do processo para reserva de viagens

\section{Fluxo de controle: scripts e passos}

Os passos são unidades essenciais no Modelo ConTract. Cada passo representa a execução de uma atividade ou uma computação básica de uma tarefa, por exemplo, reservar um voo, cancelar uma reserva e assim por diante. Os autores assumem que não pode haver paralelismo dentro da execução de um passo e, portanto, pode ser implementado por uma linguagem de programação estruturada arbitrária. O tamanho de um passo é determinado pela quantia de trabalho que a aplicação tolera perder em caso de falha. A Figura 3.8 exemplifica um fragmento do possível código do passo que reserva o voo.

Um script descreve o fluxo de controle e outras estratégias de execução para uma atividade de longa duração, como ilustrado na Figura 3.7. O fluxo de controle entre os passos pode ser modelado por construtores tradicionais, tais como: o encadeamento de tarefas, execução repetitiva, execução paralela, execução exclusiva, entre outras. É possível também especificar uma estrutura de repetição 


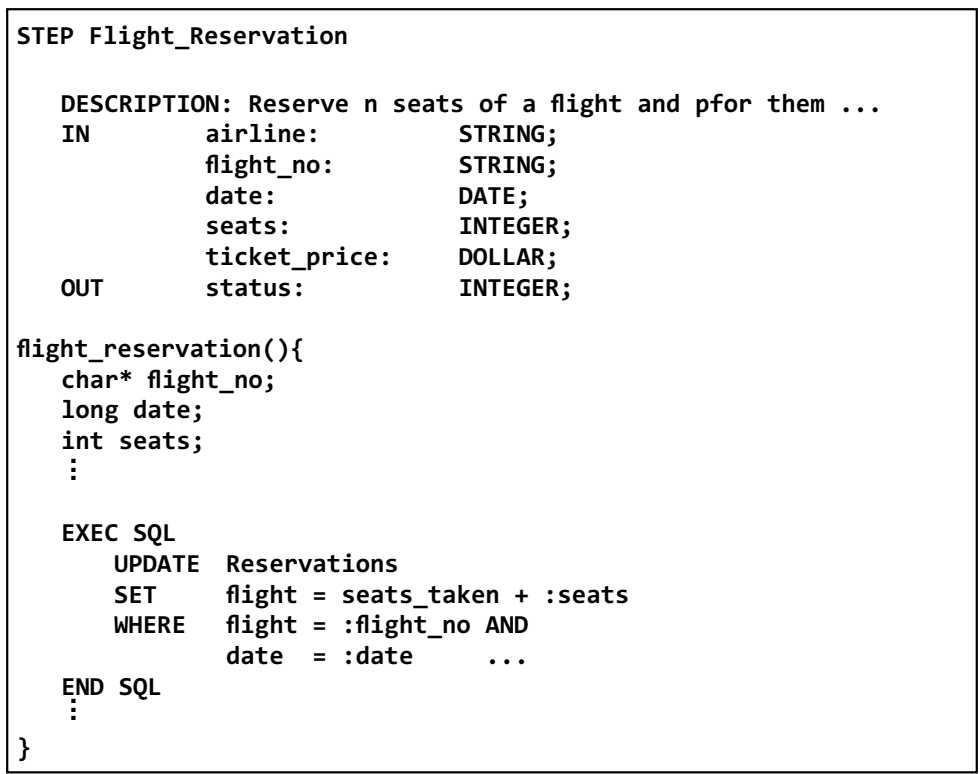

Figura 3.8: Fragmento do código do passo Reserva de voo

sobre um conjunto de tuplas selecionadas no banco de dados. No processo do planejamento de viagem, a declaração PAR_FOREACH(airline...) consulta dinamicamente os horários das $n$ companhias aéreas consultadas em paralelo.

Os passos são codificados sem levar em consideração que eles serão posteriormente combinados ou concatenados em uma unidade maior. Eles são executados individualmente de acordo com o fluxo definido no script. O projetista também pode agrupar a execução de diferentes passos em uma unidade atômica. Na Figura 3.7, os passos $S_{4}$ e $S_{5}$, bem como os passos $S_{6}$ e $S_{7}$, são agrupados pelas unidades atômicas $T_{1}$ e $T_{2}$, respectivamente. Em uma notação textual, essa execução atômica é representada da seguinte forma:

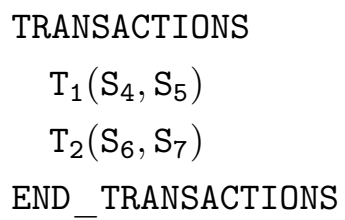

Os autores ressaltam que o modelo visa o controle da execução das atividades e não a especificação das atividades. Ou seja, uma forma explícita de especificar o fluxo de controle para operações em itens de dados compartilhados. A especificação dos passos é utilizada para estender o controle para além dos limites das propriedades transacionais. A ideia básica é que o script descreva a estrutura (fluxo de controle) de uma atividade complexa, enquanto os passos implementam a parte algorítmica. O gerenciador de execução do ConTract implementa internamente um controle de fluxo orientado a evento ao utilizar um tipo de rede de transição de predicado para especificar as condições de ativação e término dos passos. A execução de um passo é iniciada se o predicado do evento para sua ativação torna-se verdadeiro e se os recursos para sua execução estão disponíveis. Por exemplo, o passo $S_{3}$ da Figura 3.7 é disparado quando todas as execuções paralelas da atividade $S_{2}$ são finalizadas. 


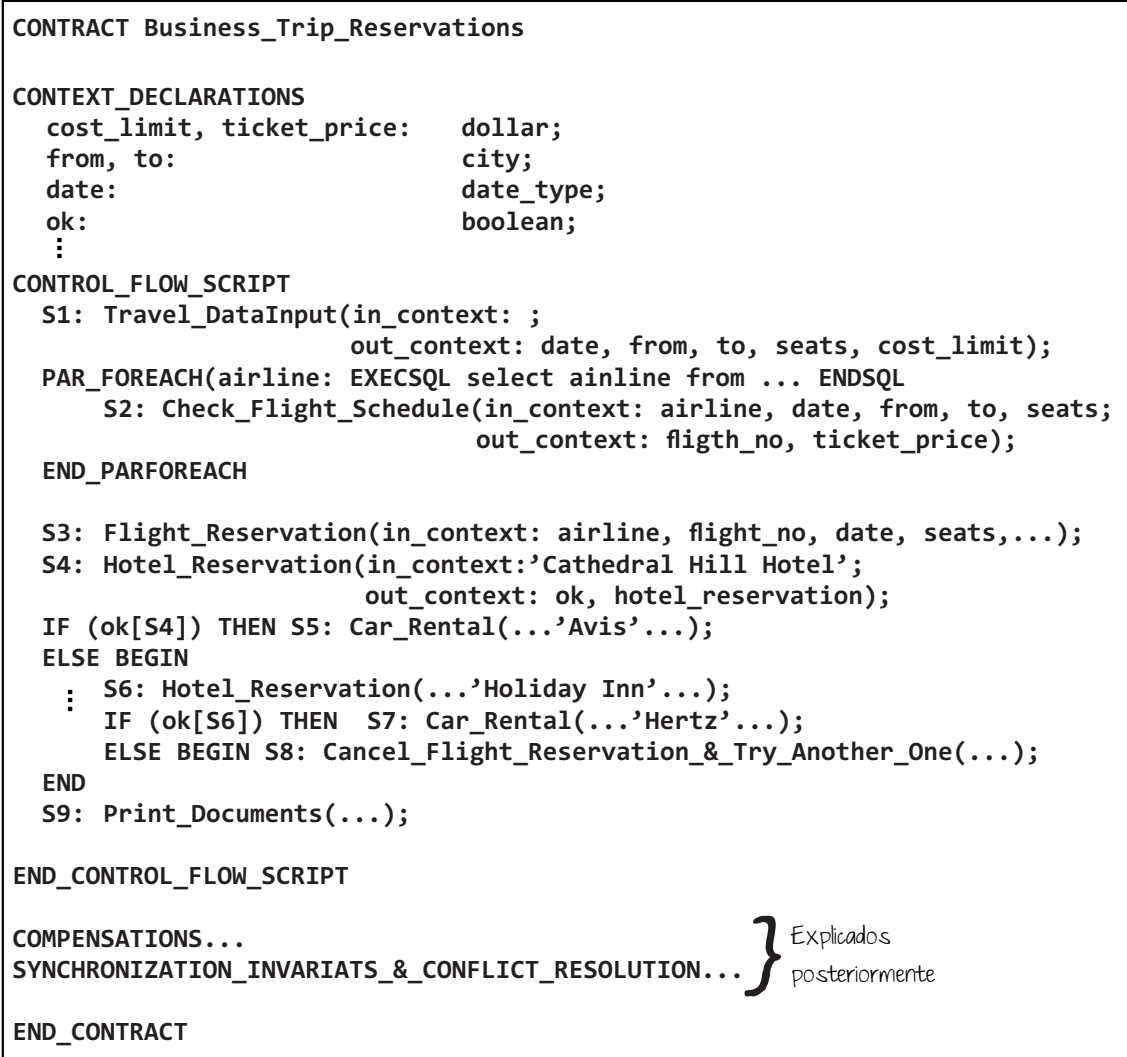

Figura 3.9: Script do processo de Reserva de Viagem

\section{Propriedades Transacionais}

O modelo ConTract provê propriedades transacionais para a execução das transações de longa duração. Essas propriedades são garantidas sob a perspectiva de execução dos passos e sob a perspectiva de execução de toda a transação longa. Sob a perspectiva de execução do passo, a transação ACID convencional é utilizada para implementar e executar um passo, caso nada tenha sido especificado no construtor TRANSACTIONS do script. Dessa forma, a execução de um passo possui todas as propriedades ACID. No entanto, somente a consistência local dos itens de dados manipulados é assegurada. Com relação a execução da transação longa (script), não é possível assegurar toda a transação como uma unidade de trabalho tal como a transação ACID. Seguem as principais diferenças:

- Atomicidade: O modelo ConTract renuncia a propriedade de atomicidade com alegação de que essa propriedade é incompatível com as necessidades das transações de longa duração. Quando um ConTract é interrompido pelo usuário ou por uma falha, ele pode ser continuado usando uma recuperação forward tomando um caminho alternativo na execução ou optar por uma recuperação backward para compensação;

- Consistência: O modelo mantém a consistência por meio de um critério de correção alternativo. A abordagem substitui os protocolos de bloqueio tradicionais por um mecanismo que garante a consistência do banco de dados sob o ponto de vista semântico;

- Isolamento: A abordagem flexibiliza a propriedade de isolamento permitindo a exposição de resultados intermediários das transações longas. A abordagem propõe um isolamento semân- 
tico que é baseado em invariantes específicos da aplicação (predicados sobre itens de dados compartilhados) que devem ser mantidos pelo sistema durante a execução da transação longa; e

- Durabilidade: Os efeitos produzidos ao final de cada passo tornam-se permanentes e duráveis no banco de dados. Portanto, os efeitos produzidos pela transação longa (concatenação dos efeitos da execução de todos os passos) também são permanentes e duráveis.

\section{Controle da Consistência e Resolução de Conflito}

Como mencionado anteriormente, a execução de um ConTract $C T_{i}$ não é atômica e leva um longo período de tempo. Além disso, durante sua execução alguns dos resultados intermediários são expostos e confirmados no banco de dados. Como consequência, outro ConTract $C T_{j}$ pode acessar e utilizar os dados externalizados por $C T_{i}$, tornando $C T_{j}$ dependente de $C T_{i}$. Como $C T_{i}$ ainda não foi confirmada, existe a chance de revogar a execução de alguns de seus passos. Esse comportamento cria dois tipos de problemas de consistência:

- Compensação: Quando um ConTract é abortado os efeitos globais de suas ações não podem ser desfeitas simplesmente restaurando o estado do banco de dados. Ao invés disso, os efeitos devem ser compensados por meio de um desfazimento semântico. Dependendo das circunstâncias, outros ConTracts podem ser afetados a fim de desfazer seu efeitos por meio de compensações; e

- Sincronização Semântica: Ao dispensar os mecanismos de bloqueio tradicionais, tal como no modelo SAGAS, pode conduzir a execução das transações a severas inconsistências. Por isso, o modelo ConTract propõe um mecanismo alternativo para garantir uma execução correta das transações. Esse mecanismo alternativo é baseado na sincronização por meio de invariantes sobre os estados compartilhados.

As técnicas utilizadas pelo modelo ConTract para lidar com a compensação e a sincronização semântica serão detalhadas a seguir.

\section{Compensação}

Uma vez que as atualizações efetivadas pelas transações são externalizadas ao fim de cada passo, não é possível simplesmente desfazer uma execução de um passo recuperando o estado do banco de dados. Ao invés disso, uma ação compensatória deve ser aplicada para desfazer semanticamente as atualizações realizadas pelo passo correspondente. Assim como no modelo SAGAS, deve-se prover uma compensação para cada passo executado no script. As compensações são especificadas em uma parte distinta do script, como ilustra a Figura 3.10.

No exemplo ilustrado pela Figura 3.7, o cliente envolvido no processo pode a qualquer momento desistir da viagem. No pior caso, para cancelar o processo, todas as compensações de $C_{1}$ até $C_{9}$ devem ser executadas para desfazer os efeitos dos passos executados. Algumas compensações podem ser realizadas em paralelo, por exemplo, o cancelamento da reserva do carro $S_{5}$, do hotel $S_{4}$ e do voo $S_{3}$. Os passos $S_{1}$ e $S_{2}$ que representam as atividades da entrada dos dados da viagem e da pesquisa do voo não necessitam de compensação. Portanto, uma compensação vazia (Do_Nothing_Step()) 


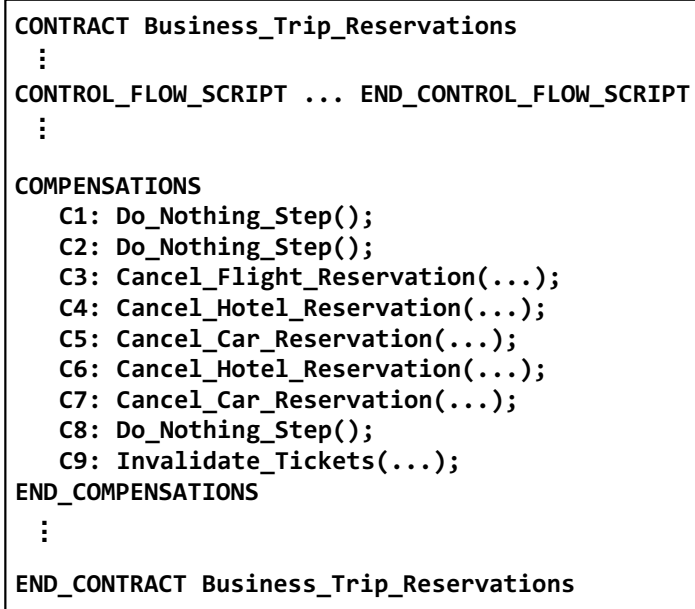

Figura 3.10: Especificação das compensações no script

é associada a esses passos. Após a compensação de todos os passos, a transação longa é considerada desfeita.

Além de desfazer todos os passos da transação longa, os efeitos colaterais da exposição antecipada também devem ser desfeitos. Suponha que uma transação longa $C T_{1}$ tenha sido executada e o passo $S_{i}$ realizou uma operação de crédito na conta $X$. Em paralelo, a transação $C T_{2}$ está em execução e o passo $S_{k}$ realizou um débito na conta $X$. Agora considere que a transação $C T_{1}$ foi cancelada e a compensação $C_{i}$ desfez o crédito efetuado por $S_{i}$. Ao atualizar o item de dado compartilhado $X$, a compensação $C_{i}$ afeta a transação $C T_{2}$, pois desfaz o crédito anteriormente feito e pode deixar a conta $X$ com saldo insuficiente para o débito de $S_{k}$ da transação $C T_{2}$. Para evitar esse problema, o sistema invalida a execução da transação $C T_{2}$ a partir do passo $S_{k}$ compensando os passos $S_{k}, S_{k+1}, \ldots, S_{k+n}$ e submete a execução de $S_{k}$ novamente.

Para determinar se outros passos foram afetados pela compensação $C_{i}$, o sistema mantém um histórico de todos os passos que acessaram um item de dado $X$ entre a execução de $S_{i}$ e sua compensação $C_{i}$. Um passo $S_{k}$ da transação $C T_{2}$ é afetado se seu invariante de entrada for invalidado após a execução da compensação $C_{i}$ da transação $C T_{1}$. Se a transação $C T_{2}$ for afetada de tal forma que $S_{k}$ torne-se inválido, o sistema recupera o estado da transação até $S_{k}$ compensando todos os seus sucessores. Assim, $C T_{2}$ pode voltar a execução a partir de $S_{k}$.

\section{Sincronização com Invariantes}

O modelo ConTract utiliza a sincronização por invariantes para substituir os mecanismos de bloqueio tradicionais. Ao invés de bloquear os itens de dados compartilhados, a sincronização por invariantes garante que predicados sobre os itens de dados compartilhados sejam mantidos no banco de dados. Esse mecanismo deixa o banco de dados livre de solicitações pendentes. Os autores argumentam que, ao invés de prevenir alterações em um item de dado por meio de bloqueio, em muitas situações é suficiente, por exemplo, ter a certeza de que uma certa tupla não seja excluída, de que certo valor de atributo não extrapole uma faixa de valores, de que não haja mais do que $x$ tipos de tuplas, etc. A abordagem considera que, ao garantir a validade dos predicados sobre os itens de dados compartilhados impostos pela transação, a propriedade de isolamento é alcançada sob um ponto de vista semântico. 
Para implementar o mecanismo de sincronização por invariantes o script necessita de duas características:

1. O sistema deve ser capaz de averiguar o estado do invariante do predicado após a execução de um determinado passo. Essa pós-condição define um requisito de isolamento do modelo ConTract chamado de invariante de saída (exit invariant);

2. O sistema deve ser capaz de especificar quais desses invariantes de saída devem ser assegurados para que os passos subsequentes sejam executados. Esse predicado é chamado de invariante de entrada (entry invariant).

A Figura 3.11 apresenta a parte do script que define os invariantes do exemplo da Figura 3.7. Nesse exemplo, o projetista estabelece que no passo $S_{1}$ deve ser verificado se o orçamento do departamento (budget) comporta os gastos da viagem proposta. Para isso, o projetista utiliza como parâmetro o custo limite para viagens (cost_limit) estabelecido pelo departamento. Para utilizar esse predicado em sincronizações futuras no processo, o projetista do script define um invariante de saída no passo $S_{1}$ contendo o predicado: (cost_limit < budget). Antes de agendar o voo, o passo $S_{3}$ revalida esse invariante para garantir que o orçamento do departamento ainda comporta o custo da viagem. Dessa forma, $S_{3}$ é sincronizado corretamente. Essa sincronização é importante para garantir que ainda há dinheiro suficiente para a viagem, pois outras transações podem estar, ao mesmo tempo, utilizando o orçamento do departamento (budget). Após o agendamento do voo pelo passo $S_{3}$, o valor pago na passagem deve ser descontado do orçamento do departamento. Assim, a pós-condição de $S_{3}$ é especificada pelo invariante: (cost_limit-ticket_price < budget). Os outros invariantes definidos na Figura 3.11 seguem a mesma lógica. Mais detalhes podem ser encontrados em (Wächter e Reuter, 1992).

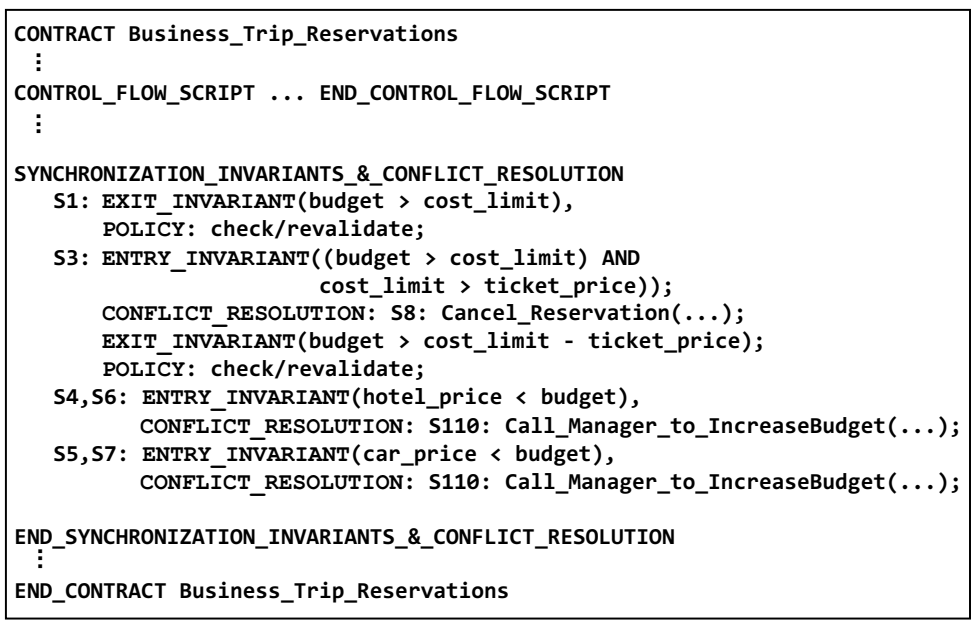

Figura 3.11: Especificação das invariantes no script

\subsubsection{Consistência Linear}

Outra alternativa para flexibilização do isolamento é a substituição da seriação pela condição de correção conhecida como consistência linear ${ }^{3}$. A consistência linear é usada para controlar a concorrência em itens de dados compartilhados explorando os tipos de dados abstratos (Herlihy e Wing,

\footnotetext{
${ }^{3}$ tradução livre do termo linearizability
} 
1990). Os itens de dados compartilhados possuem um tipo que define os valores que os itens podem assumir e um conjunto de operações primitivas. O conjunto de operações provê o único meio de acessar e manipular os itens de dados. A execução de uma operação é composta por três fases: (i) a invocação da operação, na qual o solicitante requisita a execução da operação; (ii) o ponto de linearização que é o momento em que a operação produz efeito; e (iii) a resposta da invocação, em que o solicitante é notificado sobre resultado da execução da operação. A Figura 3.12 apresenta uma representação gráfica das três fases que compõem a execução de uma operação.

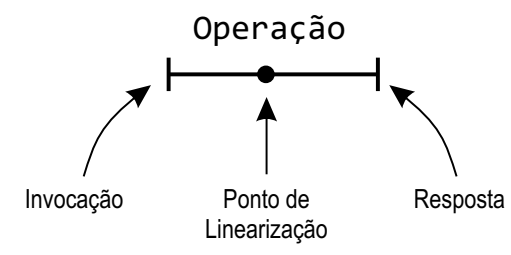

Figura 3.12: As três fases da execução de uma operação

Em um ambiente concorrente, as operações são intercaladas para atender satisfatoriamente os processos. A consistência linear apresenta uma forma segura para intercalar as execuções mantendo a consistência do item de dado compartilhado. A consistência linear é fundamentada pelo seguinte princípio:

A execução de uma operação deve parecer fazer efeito em algum momento entre sua invocação e sua resposta.

Para exemplificar o comportamento dessa condição de correção, será utilizado um exemplo no qual o item de dado compartilhado é uma fila Q (FIFO, do inglês Firt In, First Out). As operações $\operatorname{ENQ}(\mathrm{Q}, \mathrm{x})$ e $\operatorname{DEQ}(\mathrm{Q})$ enfileira e desenfileira um elemento da fila $\mathrm{Q}$. A Figura 3.14 apresenta duas histórias de execução em que a invocação e resposta das operações ENQ e DEQ são intercaladas pelos processos $T_{1}$ e $T_{2}$. A história de um item de dado é considerado linearmente consistente quando apresentar as seguintes características:

- a execução das operações deve parecer fazer efeito instantaneamente entre a invocação e a resposta (ponto de linearização);

- a ordem de execução das operações não concorrentes (execuções não sobrepostas) deve ser preservada;

- semântica das operações deve ser respeitada na execução. Por exemplo, se o elemento $x$ estiver no início da fila $Q$, então nenhum processo pode desenfileirar um elemento que seja diferente de $x$. Para respeitar a semântica das operações são definidas especificações axiomáticas sobre o estado do item de dado compartilhado.

As especificações axiomáticas têm como objetivo garantir que a semântica das operações seja respeitada. Para explicitar esse comportamento, são definidos axiomas que provêm pré e pós-condições para a execução da operação. A Figura 3.13 ilustra os axiomas das operações ENQ e DEQ. No axioma da operação $\operatorname{ENQ}(\mathrm{Q}, e)$, a pós-condição define que, após a execução da operação, a nova fila Q' é composta pela fila $Q$ mais o elemento e inserido. No axioma da operação $\mathrm{DEQ}(\mathrm{Q})$, a pré-condição indica que a fila $Q$ não pode estar vazia e a pós-condição especifica que, após a execução, o primeiro 
elemento da fila Q é removido e atribuído para a variável e. A especificação dos axiomas é importante para refletir o comportamento desejado das operações executadas sobre o item de dado. Por exemplo, o comportamento das operações especificadas para uma fila não são adequadas para um pilha.
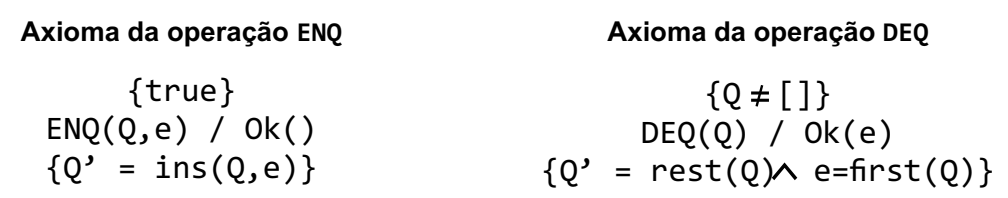

Figura 3.13: Axiomas das operações $E N Q$ e $D E Q$

A Figura 3.14(a) apresenta uma história linearmente consistente em que inicialmente o processo $T_{1}$ enfileira $\mathrm{x}$ na fila $\mathrm{Q}$, seguido do enfileiramento do elemento y pelo processo $T_{2}$. Logo em seguida, o processo $T_{2}$ desenfileira o elemento x que está na cabeça da fila e, por fim, o processo $T_{2}$ desenfileira o elemento y. Essa história é linearmente consistente, pois preserva as três característica citadas anteriormente. Em contrapartida, a Figura 3.14(b) apresenta uma história que não é linearmente consistente. Nessa história, a semântica das operações não é respeitada no momento em que o processo $T_{1}$ desenfileira o elemento y enquanto o elemento x é quem está no início da fila.

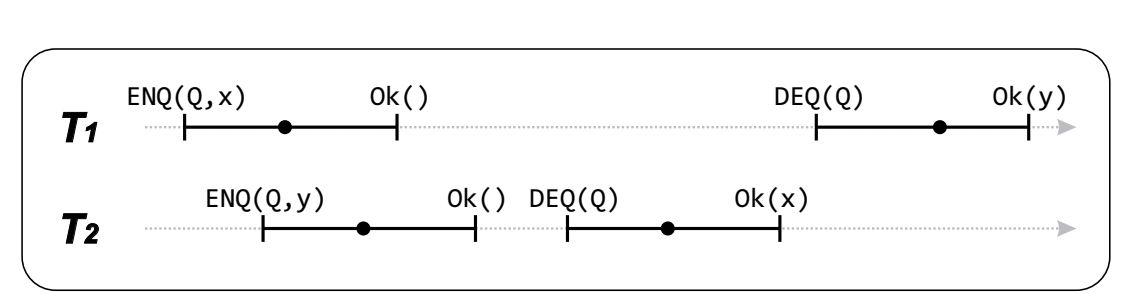

(a)

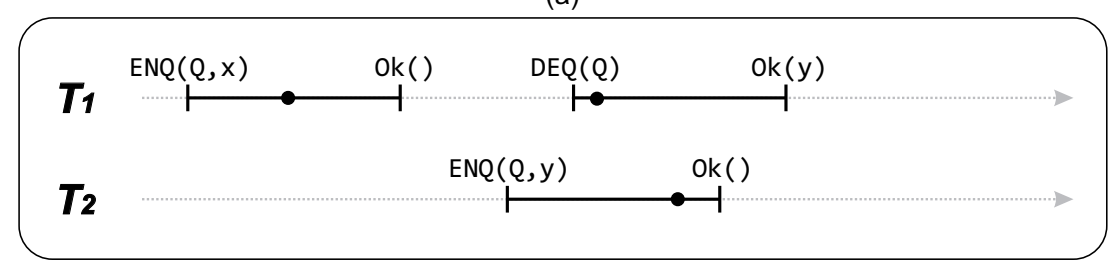

(b)

\section{História}

T1: $\operatorname{ENQ}(Q, x)$

T2: $\operatorname{ENQ}(Q, y)$

T1: Ok()

T2: Ok()

T2: $\operatorname{DEQ}(\mathrm{Q})$

T2: $\operatorname{Ok}(\mathrm{X})$

T1: $\operatorname{DEQ}(\mathrm{Q})$

T1: Ok(y)

\section{História}

T1: $\operatorname{ENQ}(Q, x)$

T1: Ok()

T2: $\operatorname{ENQ}(\mathrm{Q}, \mathrm{y})$

T1: $\operatorname{DEQ}(Q)$

T2: Ok()

T1: Ok(y)

Figura 3.14: (a) História linearmente consistente; (b) Execução não linearmente consistente

A consistência linear pode ser vista como um caso especial da seriação na qual transações são restritas a uma única operação aplicada a um único objeto. No entanto, mesmo com essa restrição de uma única operação, a consistência linear tem um amplo alcance em termos práticos e formais (Herlihy e Wing, 1990). Uma consequência prática e imediata é o fato dos mecanismos de controle de concorrência apropriados para a seriação serem geralmente inapropriados para a consistência linear, pois introduzem uma sobrecarga desnecessária e significativas restrições na concorrência. No exemplo da fila, previamente citado, a implementação utilizando a consistência linear como critério de correção é muito mais eficiente e muito mais concorrente do que uma implementação análoga usando a seriação.

Existem duas importantes diferenças entre a consistência linear e a seriação. Primeiro, a consistência linear é uma propriedade local em que os itens de dados são implementados e verificados independentemente e o escalonamento em tempo de execução pode ser completamente descentralizado. Um sistema é linearizável se cada item de dado é individualmente linearizável. Como uma 
consequência, a consistência linear amplia a modularidade e a concorrência dos itens de dados. Um sistema concorrente baseado em uma propriedade de correção não-local deve contar com um escalonador centralizado para todos os itens de dados ou satisfazer restrições adicionais impostas aos itens de dados para garantir que eles estejam de acordo com um protocolo de escalonamento. Esse último é o caso da seriação que impõem convenções globais para garantir o controle de concorrência.

A segunda diferença é que a seriação impõe restrições mais rigorosas na concorrência. A seriação é caracterizada como uma propriedade bloqueante. Por outro lado, a consistência linear proporciona uma propriedade não bloqueante. Em outras palavras, uma invocação pendente de uma operação definida não é obrigada a esperar pelo término de outra invocação pendente para ser concluída.

Ao analisar a consistência linear em cenários de transações de longa duração, é possível notar que ela permite que dependências sejam criadas entre as transações, isto é, uma transação observa resultados intermediários de outra transação. Entretanto, não há um monitoramento capaz de verificar situações anômalas. Por exemplo, ao considerar $T_{1}$ e $T_{2}$ como transações longas e analisar a história ilustrada pela Figura 3.14(a), verifica-se que, ao permitir que $T_{2}$ enfileire o elemento y, o sistema expõe um resultado intermediário de $T_{1}$. Em contrapartida, no caso de uma falha de $T_{1}$, as ações de $T_{2}$ estariam inconsistentes no contexto de transações longas. Embora a consistência linear seja capaz de manter a correção do item de dado em ambientes concorrentes, uma visão global das transações ainda é necessária para manter a correção no contexto de transações de longa duração.

\subsection{Considerações Finais}

Historicamente, a manutenção do isolamento dos dados compartilhados é a garantia que o sistema será mantido consistente e capaz de ser recuperado quando uma falha ocorrer. Entretanto, o seu efeito colateral é muito custoso e inviabiliza a execução das transações de longa duração em aplicações modernas. Um dos principais requisitos dessas aplicações é a exposição dos dados compartilhados e, ao mesmo tempo, a capacidade de recuperar a consistência quando uma anormalidade desviar do caminho esperado.

Neste capítulo, os modelos transacionais avançados foram apresentados sob a perspectiva das Esferas de Controle. Dessa forma, foram apresentadas abordagens que estendem, flexibilizam e substituem a seriação com o objetivo de amenizar a propriedade de isolamento e atender aos requisitos das aplicações modernas em banco de dados. Além das abordagens apresentadas, há ainda importantes contribuições que também buscam, de alguma forma, flexibilizar a propriedade de isolamento, tais como (García-Molina, 1983; Nodine e Zdonik, 1990; Ramamritham e Pu, 1995; Weihl, 1988), entre outras resumidas em (Barghouti e Kaiser, 1991).

As abordagens da primeira categoria propõem estratégias baseadas em variações do Protocolo de Bloqueio Bifásico, tais como o Modelo Transacional Hierárquico (Moss, 1985), o Bloqueio Altruísta (Salem et al., 1994) e as Transações Emaranhadas (Gupta et al., 2011b). O Modelo Transacional Hierárquico propõem um aninhamento de transações com o objetivo de explorar a concorrência intra-transações. Essa abordagem introduz uma flexibilização sutil da propriedade de isolamento, permitindo que sub-transações de níveis hierarquicamente inferiores compartilhem os mesmos itens de dados. O Modelo Transacional Hierárquico tem sido reconhecido como uma contribuição importante entre os modelos transacionais. Diferentes modelos transacionais avançados incorporaram o mesmo conceito, ao estruturar transações em uma hierarquia de sub-transações. Uma dessas abor- 
dagens é o Bloqueio Altruísta que propõem uma espécie de hierarquia entre as transações construída em tempo de execução. Nessa abordagem, quando uma transação não necessita mais do dado bloqueado, ela pode doar o bloqueio para outras transações que, ao usarem o bloqueio doado, ficam dependentes. Dessa forma, essa estratégia também cria uma certa dependência hierárquica entre as transações para reduzir a retenção e incrementar a concorrência. Com um propósito diferente das demais abordagens, as Transações Emaranhadas também flexibilizam o isolamento, mas com o objetivo de prover a coordenação e a comunicação entre transações. Conceitualmente, essa solução mostra para a comunidade acadêmica que o isolamento deve ser revisitado e que é possível prover abstrações elegantes que atendam aos novos requisitos das aplicações.

Na segunda categoria, as abordagens apresentam estratégias que evidenciam aspectos semânticos para flexibilizar a seriação ao permitir a exposição dos resultados parciais das transações. Nessa categoria destacam-se o Modelo SAGAS (García-Molina e Salem, 1987) e o Modelo Transacional Hierárquico Aberto (Moss, 2011; Weikum e Schek, 1992). Ambas abordagens apresentam significativas contribuições para os modelos transacionais. O Modelo SAGAS foi o pioneiro em tratar transações de longa duração destacando a necessidade dos modelos transacionais em rever as propriedades ACID. A principal contribuição da abordagem é o conceito de compensação associada a cada passo da transação longa. Quando um passo SAGA termina e expõem os seus resultados, qualquer outra transação pode utilizar-se desses dados. Para tratar desse problema, o Modelo SAGAS assume que os passos SAGAS são independentes. Em outras palavras, isso significa que os passos SAGAS devem ser projetados de forma que seja possível reverter seus efeitos por meio de uma compensação. Ideia similar é apresentada pelo Modelo Transacional Hierárquico Aberto, no qual os dados são expostos para sub-transações que executam operações abstratas comutativas. Intuitivamente, ambas soluções apresentam ideias bem semelhantes. Entretanto, no Modelo Transacional Hierárquico Aberto a exposição para operações comutativas é claramente definida e especificada, enquanto no Modelo SAGAS a exposição está relacionada à capacidade de reverter os efeitos semânticos por meio de compensações.

Por fim, na última categoria, são apresentadas duas estratégias que substituem a seriação por outros critérios de correção. Nesse sentido, são listados o ConTract (Wächter e Reuter, 1992) e a Consistência Linear (Herlihy e Wing, 1990). O ConTract propõe manter a consistência semântica dos itens de dados compartilhados por meio de regras semânticas chamadas invariantes. Entretanto, a especificação desses invariantes para cada passo não é uma solução genérica capaz de prover apoio transacional. Além disso, o ConTract não estabelece condições de correção para manter seguro o acesso ao dado compartilhados. Uma outra alternativa para substituir a seriação é a consistência linear. Entretanto, a consistência linear é uma propriedade local originalmente proposta para garantir a consistência dos itens de dado compartilhados de forma independente em que cada operação sobre o dado é vista como uma transação única.

Em resumo, destaca-se, neste capítulo, importantes modelos transacionais avançados que contribuíram com o estado da arte do processamento de transações. Essas abordagens apresentam soluções transacionais para amenizar o isolamento com o objetivo de expor dados intermediários ao mesmo tempo que são capazes de manter as transações recuperáveis. 


\section{Capítulo 4}

\section{A Abordagem WED-flow}

A abordagem WED-flow (Workflow, Event processing and Data-flow) (WED-flow, 2016), inicialmente proposta em (Ferreira et al., 2010a,b), é uma alternativa para modelagem, implementação e execução de processos desenvolvida pelo grupo de pesquisa DATA (do inglês, Database Modeling, Transactions, and Data Analysis) (DATA, 2016) do IME-USP. Ao contrário das abordagens tradicionais no qual o fluxo de controle é explicitamente definido, a abordagem WED-flow combina composição de workflow, workflow orientado a dados e processamento de eventos ao integrar quatro elementos dos processos: eventos, dados, condições e transições. A integração desses elementos é baseada em três importantes regras definidas em (Ferreira et al., 2010a): (i) um conjunto distinto de transições que modifica o estado de dado atual deve ser descrito para cada evento; (ii) qualquer estado de dado que for consultado, modificado ou gerado por uma transição, deve ser explicitamente representado e armazenado permanentemente; e (iii) todas as transições que alteram um estado de dado devem ser disparadas por eventos quando um conjunto específico de condições for satisfeito.

A composição das atividades das instâncias dos processos na abordagem WED-flow é determinada por gatilhos que capturam o acontecimento dos eventos materializados por estados de dados. Com essa finalidade, os gatilhos são descritos por um conjunto de pares condição-transição que determinam quais atividades devem ser executadas em uma instância do processo. Assim, toda vez que um evento ocorre e satisfaz um conjunto de condições sobre os valores dos atributos, isto é, os estados de dados, a execução de uma transição é habilitada. Dessa forma, os eventos são tratados pela execução de transições que produzem novos estados de dados, os quais também serão avaliados e podem disparar outras transições. Portanto, a composição das atividades é determinada dinamicamente durante a execução das instâncias.

Mais recentemente, a abordagem WED-flow foi expandida em (Ferreira et al., 2012), para fornecer recuperação transacional por meio da evolução incremental do tratamento de exceções. Em (Garcia et al., 2012a), uma versão preliminar do arcabouço foi devidamente implementada de acordo com os aspectos teóricos da abordagem WED-flow.

Neste capítulo, serão descritos os fundamentos teóricos apresentados em (Ferreira et al., 2012) e a implementação da ferramenta WED-tool proposta em (Garcia et al., 2012a). Além disso, alguns aspectos a respeito do mecanismo para manipulação de exceções propostos em (Ferreira et al., 2012) e devidamente implementados em (Silva, 2013) também serão discutidos. 


\subsection{Definições da abordagem WED-flow}

A abordagem WED-flow é formalmente descrita pelas definições abaixo que tiveram suas versões preliminares em (Ferreira et al., 2010a,b, 2012). As definições 1, 2, 3, 4 e 5 introduzem os componentes fundamentais da abordagem WED-flow: atributos, estados de dados, condições, transições e gatilhos, respectivamente. A Definição 6 descreve um WED-flow como um conjunto de eventos (capturados por gatilhos) e duas condições que identificam os conjuntos de estados de dados iniciais e finais. A Definição 7 garante o armazenamento adequado da história de execução das instâncias de um processo. Para evitar ambiguidades, as definições da abordagem WED-flow descritas em (Ferreira et al., 2012) e adaptadas para este trabalho são descritas abaixo.

Definição 1. WED-attributes. Um processo pode envolver diferentes bancos de dados autônomos. Entretanto, nem todos os atributos desses bancos são de interesse do processo. Cada aplicação possui um conjunto de atributos que são utilizados para definir o fluxo de atividades e que são alterados durante a execução do processo. Com isso, é denotado por WED-attributes a tupla $\mathcal{A}=\left\langle a_{1}, a_{2}, \ldots, a_{n}\right\rangle$, em que cada $a_{i}(\operatorname{com} 1 \leq i \leq n)$ é um atributo de interesse da aplicação.

Definição 2. WED-state. Um WED-state é uma tupla $\left\langle v_{1}, v_{2}, \ldots, v_{n}\right\rangle$, em que $v_{i}(\operatorname{com} 1 \leq i \leq n)$ é o $i$-ésimo atributo de $\mathcal{A}$. Ao considerar os WED-attributes como atributos de uma relação de um banco de dados, um WED-state é uma tupla específica (ou seja, uma linha) dessa relação. O conjunto $\mathcal{S}$ é o conjunto de todos os possíveis WED-states de uma aplicação sendo definido formalmente como:

$$
\mathcal{S}=\left\{\left\langle v_{1}, v_{2}, \ldots, v_{n}\right\rangle \mid \forall i \in[1 ; n], v_{i} \in \operatorname{domain}\left(a_{i}\right)\right\}
$$

no qual $a_{i}$ é o $i$-ésimo atributo de $\mathcal{A}$ e $\operatorname{domain}\left(a_{i}\right)$ é o conjunto de valores assumido por esse atributo.

Definição 3. WED-condition. Uma WED-condition é um conjunto de predicados definidos sobre os WED-attributes de uma aplicação. O conjunto $\mathcal{C}$ representa todas as WED-conditions definidas para a aplicação. Seja um WED-state $s \in \mathcal{S}$ e uma WED-condition $c \in \mathcal{C}$, é dito que $s$ satisfaz $c$ se os valores dos atributos de $s$ tornam os predicados de $c$ verdadeiros.

Definição 4. WED-transition. Uma WED-transition $t$ é uma função $t: \mathcal{S} \rightarrow \mathcal{S}$, ou seja, uma função que recebe um WED-state como entrada e produz outro WED-state como saída. A especificação de uma WED-transition $t$ inclui um conjunto de atributos $\mathcal{U}_{t}=\left\langle u_{1}, u_{2}, \ldots, u_{m}\right\rangle$, tal que $u_{i}$ (com $1 \leq i \leq m \leq n$ ) é um elemento de $\mathcal{A}$. O conjunto $\mathcal{U}_{t}$ indica quais atributos são atualizados por $t$. O conjunto de todas as WED-transitions definidas para a aplicação é denotado por $\mathcal{T}$. Uma WED-transition pode ser vista como uma transação convencional que é implementada com base no modelo SAGAS.

Definição 5. WED-trigger. Um WED-trigger é um par $g=\langle c, t\rangle$, no qual $c \in \mathcal{C}$ é uma WEDcondition e $t \in \mathcal{T}$ é uma WED-transition. Quando um WED-state $s \in \mathcal{S}$ satisfaz a condição $c, g$ é responsável por disparar a transição $t$. O conjunto $\mathcal{G}$ representa o conjunto de todos os WED-triggers definidos para a aplicação.

Definição 6. WED-flow. Um WED-flow $W f$ é uma tripla $\left\langle\mathcal{G}^{\prime}, c_{i}, c_{f}\right\rangle$, em que $\mathcal{G}^{\prime} \subseteq \mathcal{G}$ é um conjunto de WED-triggers e $c_{i}$ e $c_{f}$ são WED-conditions. A condição $c_{i}$ é a condição inicial do WED-flow, a qual define o conjunto de WED-states iniciais válidos, e a condição $c_{f}$ é a condição 
final do WED-flow, a qual define o conjunto de WED-states finais válidos. Quando um novo WEDstate é fornecido como inicial, uma nova instância do WED-flow é criada para manipular esse estado.

Definição 7. História de uma instância WED-flow. Um registro na história armazena a execução de uma WED-transition e pode ser representado pela 4 -tupla $\left\langle s_{c}, t, s_{i}, s_{o}\right\rangle$, em que:

- $s_{c} \in S$ indica o WED-state que satisfez a condição que disparou $t$;

- $t \in T$ é a WED-transition (passo SAGA) executado;

- $s_{i} \in S$ indica o WED-state fornecido como entrada para $t$; e

- $s_{o} \in S$ indica o WED-state gerado como saída de $t$.

A história de uma instância WED-flow é uma sequência $e_{1}, e_{2}, \ldots, e_{k}$ em que cada $e_{i}(\operatorname{com} 1 \leq i \leq k)$ é um registro na história.

\subsection{Modelagem de processos na abordagem WED-flow}

As diretrizes indicadas em (Ferreira et al., 2010b) para modelagem e implementação de processos na abordagem WED-flow são resumidas nesta seção. Essas diretrizes de desenvolvimento WED-flow são contempladas por três etapas de modelagem e implementação descritas a seguir.

- Separação do processo em duas partes: caminho primário e tratamento de exceções (aquelas previstas);

- Modelagem de ambas as partes em uma composição dos quatro conceitos fundamentais (eventos, dados, condições e transições);

- Escrita do modelo WED-flow utilizando uma linguagem concreta de especificação. O resultado será interpretado e convertido automaticamente em programas executáveis por meio de ferramentas de software.

Para ilustrar a modelagem e implementação de um processo usando a abordagem WED-flow, foi utilizado uma versão simplificada de um sistema de aluguel de veículos no qual clientes podem reservar veículos por meio de solicitações on-line. Normalmente, um sistema de aluguel de veículos controla solicitações, valida formas de pagamentos, entregas, devoluções, locais de recebimento, etc. Essa versão simplificada desse processo é chamada de solicitação de reserva de veículo e suas principais atividades são ilustradas na Figura 4.1. Essas atividades descrevem um comportamento esperado de uma instância cujo objetivo é realizar a solicitação de reserva de um veículo.

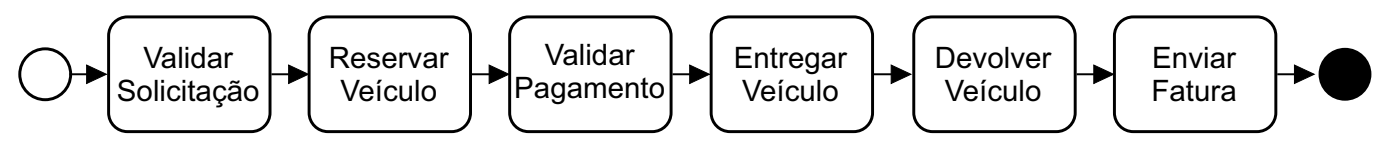

Figura 4.1: Representação clássica de um caminho primário para o processo Solicitação de Reserva de Veículo

As atividades ilustradas na Figura 4.1 são detalhadas abaixo: 
- Validar solicitação - verifica se os dados da solicitação estão corretos e o cliente informado está registrado na base de dados;

- Reservar veículo - atribui um veículo para a reserva de acordo com os requisitos do cliente;

- Validar pagamento - os dados financeiros do cliente são confirmados;

- Entregar veículo - o veículo reservado é retirado pelo cliente;

- Devolver veículo - o veículo é devolvido pelo cliente; e

- Enviar fatura - a reserva é finalizada e uma fatura é encaminhada para o cliente.

Na primeira etapa das diretrizes, os eventos que caracterizam o caminho primário e os eventos das exceções previstas são identificados e descritos. Eventos são manifestações fenomenológicas que acontecem durante a execução de um processo e afetam a sequência de atividades do processo. O conjunto de eventos do caminho primário representa aquele conjunto necessário de eventos para atingir o objetivo principal do processo. Na abordagem WED-flow, os estados de dados materializam os eventos da aplicação. O caminho primário é obtido a partir das transições entre esses estados de dados. Todos os demais eventos são considerados eventos de exceção. Nesta seção, apenas os eventos do caminho primário serão discutidos. Exceções previstas e imprevistas serão discutidas na Seção 4.5 .

Os eventos estão vinculados a diferentes entidades ou classes de dados, sendo que cada uma possui uma sequência específica de estados de dados válidos. No processo ilustrado na Figura 4.1 existem três entidades envolvidas (PEDIDO, CLIENTE e VEICULO) que apresentam distintas sequências de estados, conforme ilustrado pela Figura 4.2. Por exemplo, a classe de dados PEDIDO possui quatro estados (SOLICITADO, VALIDADO, APROVADO e FINALIZADO) representados pelos retângulos com cantos arredondados que são alcançados pelo acontecimento de eventos distintos. Na Figura 4.2, as classes de dados e a sequência dos estados atingíveis são combinados. Dessa maneira, os estados das diferentes sequências são vinculados de acordo com uma ordenação temporal dos eventos, permitindo a criação dos WED-states. Cada evento mapeado no processo é manifestado em uma mudança de estado que podem atingir uma ou mais classes de dados. A duração de cada estado é ilustrado pelas variações do tamanho de cada retângulo. As linhas verticais tracejadas representam os eventos e cada coluna formada por elas representa um WED-state do caminho primário.

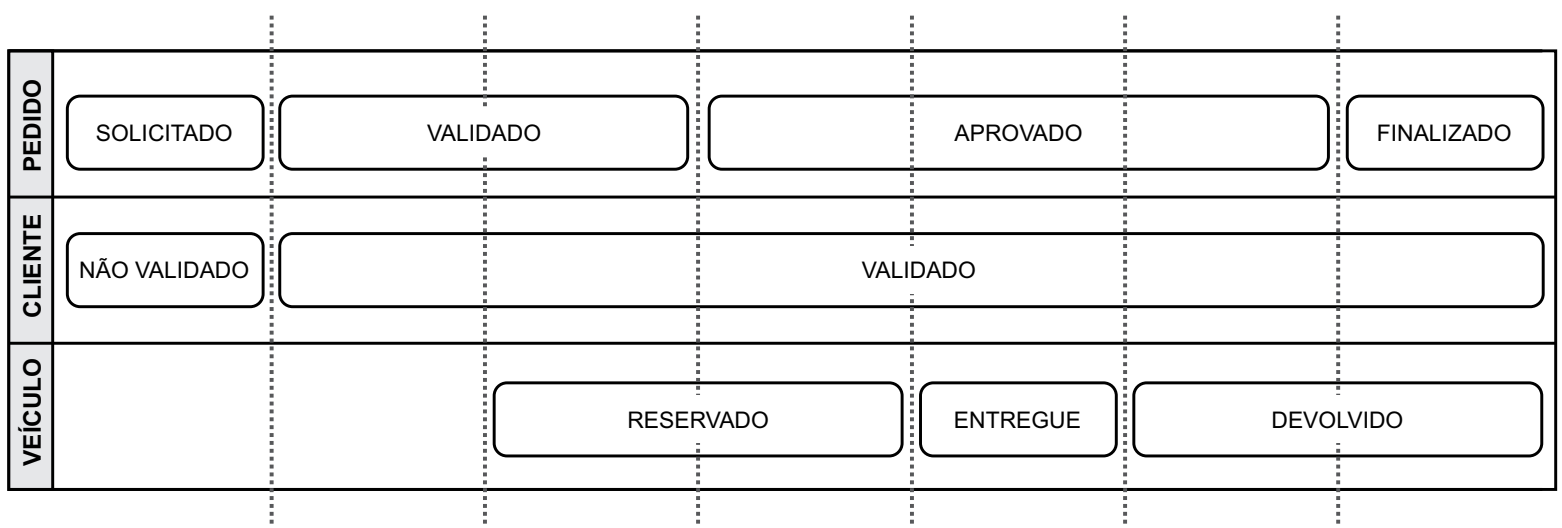

Figura 4.2: Entidades participantes do processo solicitação de reserva do veículo. As linhas pontilhadas representam a ordenação temporal dos eventos 
Na segunda etapa, WED-attributes, WED-states, WED-conditions, WED-transitions e WEDtriggers são descritos para cada evento identificado na etapa anterior. Primeiramente, um conjunto de atributos (conhecidos como WED-attributes) deve ser extraído para cada entidade ou classe de dados pertencente ao caminho primário. Os domínios desses WED-attributes determinam os possíveis WED-states alcançados no processo. Em seguida, uma sequência temporalmente ordenada de WED-states válidos para o caminho primário é projetada. Para cada evento, uma WED-condition responsável por sua identificação e captura deve ser especificada. Além disso, a WED-transition deve ser projetada e implementada para tratar do evento capturado pela WED-condition. Finalmente, para cada evento, o par WED-condition e WED-transition é descrito como um WED-trigger. Os WED-triggers são implementados semelhantemente às consultas contínuas (Liu et al., 1999). Uma WED-condition é um conjunto de predicados sobre os atributos e identifica a ocorrência de um evento específico. Uma WED-transition é uma unidade de trabalho tal como um passo SAGA e sua execução bem-sucedida resulta em um novo WED-state.

A Figura 4.3 ilustra o mecanismo de captura de eventos e armazenamento de estados de dados na abordagem WED-flow. Cada vez que um evento ocorre, um WED-state $\mathrm{S}_{\mathrm{i}}$ é armazenado e avaliado por um conjunto de WED-conditions. Para cada WED-condition satisfeita pelo WED-state $\mathrm{S}_{\mathrm{i}}$, uma WED-transition é disparada. Uma execução bem-sucedida de uma WED-transition resulta em um novo WED-state $\mathrm{S}_{\mathrm{i}+1}$. Os resultados de cada processamento de evento em cada WED-state são armazenados por meio do conceito de banco de dados multiversão (Lomet et al., 2005).

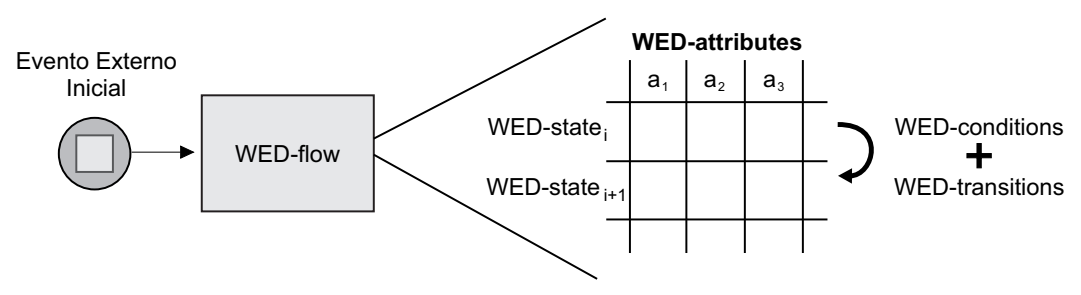

Figura 4.3: Representação WED-flow adaptado de (Ferreira et al., 2010b)

A Figura 4.4(a) ilustra os elementos WED-flow que implementam o processo de solicitação de reserva de veículo de acordo com uma notação gráfica específica. Nessa notação, um círculo indica uma WED-condition e um pentágono representa uma WED-transition. Além disso, o par (círculo e pentágono) é usado para representar um WED-trigger e os retângulos são usados para ilustrar os WED-states que constituem o caminho primário desse processo.

Uma execução esperada e bem-sucedida para esse processo resulta nos WED-states $\mathrm{S}_{0}$ a $\mathrm{S}_{6}$ ilustrados na Figura 4.4(b). Os atributos pertencentes à classe de dados necessários para descrever os estados de dados são id, cidade, data_entrega, data_devolucao, preferencias e status para a classe de dados PEDIDO; id e status para a classe de dados CLIENTE; id, categoria e status para a classe de dados VEICULO. Os valores dos atributos atualizados em cada WED-transition são sombreados na Figura 4.4(b).

Toda vez que um cliente inicia uma solicitação de reserva de veículo, um novo WED-state é criado. A abordagem WED-flow reage para esse primeiro evento ao criar uma nova instância. Nesse exemplo, o primeiro evento é capturado e armazenado no WED-state $\mathrm{S}_{0}$. O WED-state $\mathrm{S}_{0}$ tem os seguintes valores:

$\mathrm{S}_{0}=\langle\mathrm{P} 1, \mathrm{NYC}, 01 / 01,03 / 01$, COMPACTO, SOLICITADO, C4, NAO_VALIDADO, null, null, null $\rangle$ 


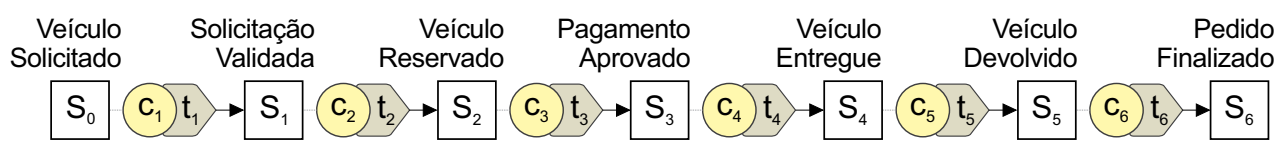

(a)

\begin{tabular}{|c|c|c|c|c|c|c|c|c|c|c|c|}
\hline & \multicolumn{6}{|c|}{ PEDIDO } & \multicolumn{2}{|r|}{ CLIENTE } & \multicolumn{3}{|c|}{ VEÍCULO } \\
\hline & Id & Cidade & $\begin{array}{c}\text { Data } \\
\text { Entrega }\end{array}$ & $\begin{array}{c}\text { Data } \\
\text { Devolução }\end{array}$ & Preferências & Status & Id & Status & Id & Categoria & Status \\
\hline $\mathrm{S}_{0}$ & $\mathrm{P} 1$ & NYC & $01 / 01$ & $03 / 01$ & Com & Solicitado & C4 & Não Validado & & & \\
\hline $\mathrm{S}_{1}$ & $\mathrm{P} 1$ & NYC & $01 / 01$ & $03 / 01$ & Compacto & Validado & C4 & Validado & & & \\
\hline $\mathrm{S}_{2}$ & $\mathrm{P} 1$ & NYC & $01 / 01$ & $03 / 01$ & Compacto & Validado & $\mathrm{C} 4$ & Validado & V1 & Compacto & Reservado \\
\hline $\mathrm{S}_{3}$ & $\mathrm{P} 1$ & NYC & $01 / 01$ & $03 / 01$ & Compacto & Aprovado & $\mathrm{C} 4$ & Validado & V1 & Compacto & Reservado \\
\hline $\mathrm{S}_{4}$ & P1 & NYC & $01 / 01$ & 03/01 & Compacto & Aprovado & C4 & Validado & V1 & Compacto & Entregue \\
\hline $\mathrm{S}_{5}$ & $\mathrm{P} 1$ & NYC & $01 / 01$ & 03/01 & Compacto & Aprovado & $\mathrm{C} 4$ & Validado & V1 & Compacto & Devolvido \\
\hline $\mathrm{S}_{6}$ & $\mathrm{P} 1$ & NYC & $01 / 01$ & 03/01 & Compacto & Finalizado & C4: & Validado & V1 & Compacto & Devolvido \\
\hline
\end{tabular}

(b)

Figura 4.4: Processo de solicitação de reserva de veículo: (a) Representação dos elementos WED-flow e (b) WED-states para o caminho primário

O WED-state $\mathrm{S}_{0}$ representa que um cliente solicitou um veículo compacto em Nova Iorque entre os dias 1 e 3 de janeiro. Em seguida, o WED-state $\mathrm{S}_{0}$ é avaliado por um conjunto de WEDconditions. Nessa avaliação, a WED-condition representada pelo círculo $c_{1}$ é satisfeita indicando que a WED-transition $t_{1}$ deve ser executada. A WED-transition $t_{1}$ é responsável por verificar os dados da solicitação, analisando também se o registro do cliente está ativo e apto para realizar uma reserva. Em uma execução normal, $t_{1}$ validará a solicitação do cliente e produzirá o WED-state $\mathrm{S}_{1}$. O WED-state $\mathrm{S}_{1}$, por sua vez, satisfaz a WED-condition $c_{2}$ que habilita o disparo da WEDtransition $t_{2}$. Essa transição é responsável por reservar um veículo entre as diversas alternativas que respeitam as preferências do cliente. Como uma consequência de uma execução bem-sucedida da WED-transition $t_{2}$, o WED-state $\mathrm{S}_{2}$ é criado. Para esse exemplo, um veículo compacto é atribuído para essa requisição conforme ilustrado na Figura 4.4(b). Em seguida, a execução das transições para verificação do método de pagamento, entrega e devolução do veículo e envio de fatura geram os WED-states $\mathrm{S}_{3}, \mathrm{~S}_{4}, \mathrm{~S}_{5}$ e $\mathrm{S}_{6}$, respectivamente. Por fim, ao alcançar o WED-state $\mathrm{S}_{6}$, a instância atinge seu estado final como ilustrado na Figura 4.4(b).

Os elementos da abordagem WED-flow são expressos de forma declarativa. Atualmente, há algumas iniciativas em andamento do grupo de pesquisa DATA para concepção e implementação dos elementos WED-flow por meio de uma extensão da SQL (do inglês, Structured Query Language). Entretanto, neste trabalho, esses elementos ilustrados na Figura 4.5 ainda são descritos de acordo com as definições apresentadas na Seção 4.1.

Na última etapa, o modelo WED-flow é traduzido em uma linguagem de especificação concreta que, por sua vez, é traduzida em programas de executáveis por meio de ferramentas automatizadas de software. Nesta etapa, destaca-se a implementação de um arcabouço discutido na Seção 6.1.

\subsection{Expressividade da abordagem WED-flow}

Uma importante característica de um modelo de processos para os PAIS é a sua capacidade de expressar os diferentes comportamentos do mundo real. Nesse contexto, os padrões de workflow descritos em (Aalst et al., 2003; Russell et al., 2006a) exercem um papel importante ao prover abs- 


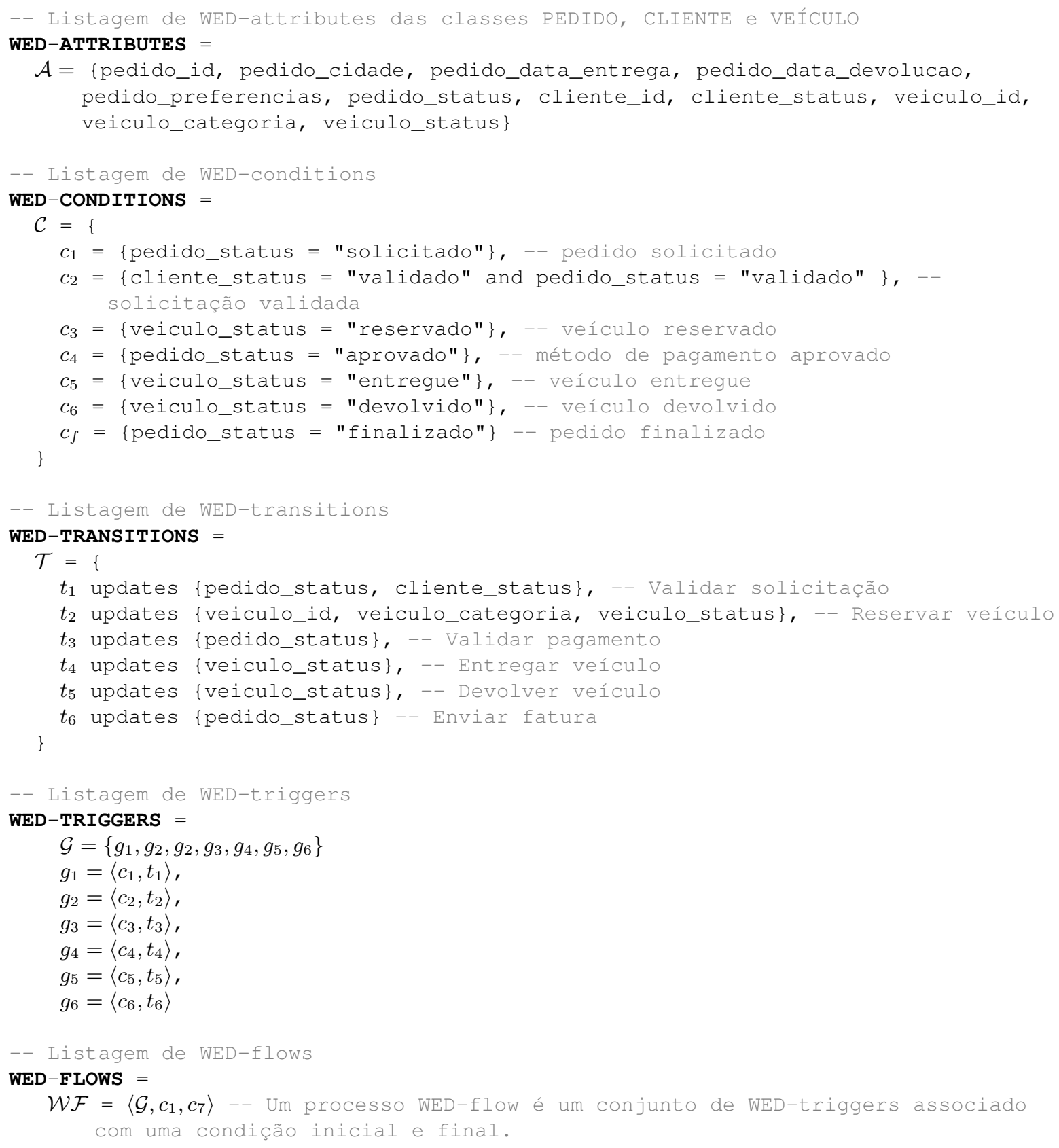

Figura 4.5: Representação textual do processo Solicitação de Reserva de Veículo de acordo com as definições WED-flow

trações independente de linguagem dos comportamentos de controle de fluxo. Os padrões expressam desde comportamentos mais simples até os mais complexos que são recorrentes na modelagem de processos. Além disso, os padrões também desempenham um papel importante na definição de requisitos que deveriam ser contemplados pelas abordagens que permitem a especificação de processos. Esses requisitos podem ser utilizados para mensurar o nível de expressividade da abordagem ao modelar um processo. Quanto maior o número de padrões contemplados, maior é o nível de expressividade da abordagem.

Como dito anteriormente, a composição das atividades das instâncias dos processos na abordagem WED-flow é determinada por gatilhos (i.e. WED-triggers) que capturam o acontecimento dos eventos materializados por estados de dados. Isso significa que os WED-triggers são disparados 
somente se suas WED-conditions associadas forem satisfeitas pelo WED-state atual. Isso habilita a abordagem WED-flow com um alto nível de expressividade, uma vez que as WED-conditions são suficientemente poderosas para descrever diferentes comportamentos dos processos.

Em (Liberato et al., 2015) foi mostrado que a abordagem WED-flow é capaz de expressar diferentes comportamentos de disjunção (split) e de junção (join) por meio de seus componentes básicos. A Figura 4.6 descreve os padrões de disjunção e junção atualmente apoiados pela abordagem WED-flow.
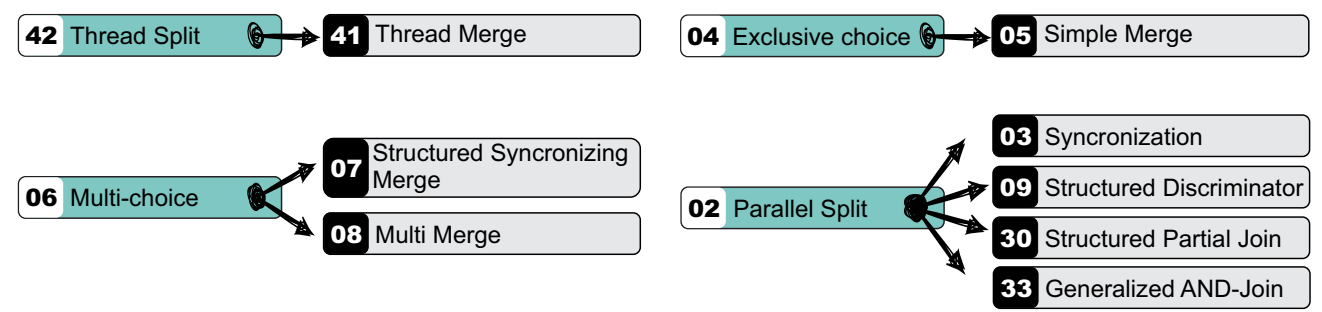

Figura 4.6: Padrões de junção e disjunção estudados em (Liberato et al., 2015)

Mais especificamente, o WED-flow é capaz de expressar uma disjunção no fluxo de atividades por meio de uma estrutura que agrupe dois ou mais WED-triggers. Nessa estrutura, cada WEDtrigger é responsável por uma ramificação na execução. A Figura 4.7(a) ilustra uma estrutura de disjunção composta por três WED-triggers que dividem o fluxo de execução em três ramificações. Nesse exemplo, o estado de dado $\mathrm{S}_{\mathrm{a}}$ pode habilitar a execução das WED-transitions $B, C$ e $D$. Caso a WED-condition $c_{b}$ seja satisfeita pelo WED-state $\mathrm{S}_{\mathrm{a}}$, a WED-transition $B$ será executada e o WED-state $\mathrm{S}_{\mathrm{b}}$ será produzido como resultado de sua execução. De forma análoga, se $\mathrm{S}_{\mathrm{a}}$ satisfizer as condições $c_{c}$ e $c_{d}$, as WED-transitions $C$ e $D$ também serão executadas e produzirão os WEDstates $\mathrm{S}_{\mathrm{c}}$ e $\mathrm{S}_{\mathrm{d}}$, respectivamente. Essa estrutura expressa uma generalização das possíveis formas de disjunção do fluxo de execução dos processos. É importante também ressaltar que a ordem da execução das transições $B, C$ e $D$ é determinada em tempo de execução.

A junção de duas ou mais ramificações no WED-flow também pode ser expressa por meio de uma estrutura genérica, como ilustrado pela Figura 4.7(b). Nesse exemplo, a WED-condition $c_{n}$ pode ser satisfeita por uma combinação dos WED-states $\mathrm{S}_{\mathrm{b}}, \mathrm{S}_{\mathrm{c}}$ e $\mathrm{S}_{\mathrm{d}}$. De forma similar à disjunção, essa estrutura de junção é uma generalização das possíveis formas de junções do fluxo de execução das atividades. Em outras palavras, ambas estruturas podem ser chamadas de polimórficas e são capazes de expressar o comportamento das diferentes disjunções e junções ilustradas na Figura 4.6 por meio de parametrizações dos seus componentes básicos.

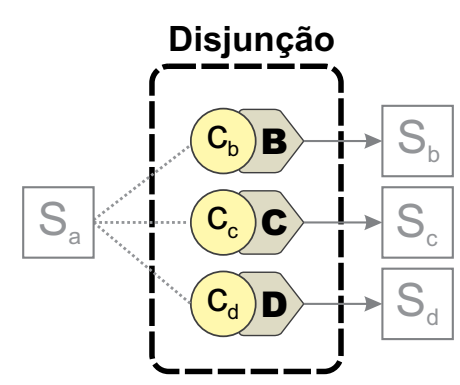

(a)

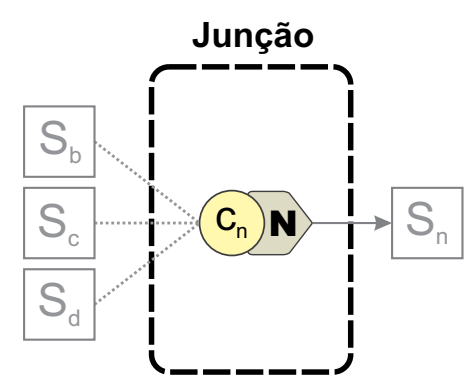

(b)

Figura 4.7: Estruturas polimórficas WED-flow para representação dos comportamentos de (a) disjunção e de (b) junção 
Uma vantagem de expressar diferentes comportamentos de disjunção e junção em estruturas polimórficas é a capacidade de adaptação do esquema do processo quando novas regras de negócio são detectadas. Por exemplo, ao alterar a WED-condition $c_{n}$ pode-se facilmente mudar de um comportamento de syncronization para structured discriminator. Mais detalhes sobre como esses padrões são expressos na abordagem WED-flow podem ser encontrados em (Liberato et al., 2015). A representação WED-flow dos demais padrões de controle de fluxo ainda carecem de estudos mais aprofundados.

Uma outra importante observação é a crítica descrita em (Bhiri et al., 2006) em que os autores afirmam que as abordagens baseadas em modelos transacionais avançados tem uma aplicabilidade limitada para apoiar aplicações devido suas estruturas de controles primitivas. Em (Liberato et al., 2015), mostra que a abordagem WED-flow pode, ao mesmo tempo, reunir importantes características transacionais e expressar diferentes comportamentos de controle de fluxo.

\subsection{Consistência da aplicação}

Uma instância de um processo baseado nos conceitos do WED-flow pode ser vista como uma transação de longa duração em execução similarmente ao apresentado em (García-Molina e Salem, 1987). No WED-flow, cada transação longa é uma composição de WED-transitions (passos SAGA), que são disparadas quando suas WED-conditions associadas são satisfeitas por WED-states. Uma mesma aplicação pode ter diferentes transações que compartilham os conjuntos de WED-conditions, WED-transitions e WED-triggers. Isso é uma vantagem, uma vez que permite o reuso em diferentes transações dos componentes básicos do WED-flow.

Similarmente a propriedade de consistência do modelo clássico de transações que assegura que o banco de dados permanece em um estado consistente antes do início da transação e após a sua conclusão (com ou sem sucesso), a abordagem WED-flow garante que uma transação é conduzida de um estado AWIC-consistente para outro estado AWIC-consistente pela execução de um conjunto de transições de estados (passos SAGA) disparadas pelo conjunto de WED-triggers atribuído ao WED-flow. Um WED-state AWIC-consistente pode ser formalmente definido como:

Definição 8. WED-state AWIC-consistente. Restrições de Integridade da Aplicação (AWICs, do inglês Application-Wide Integrity Constraints) são condições lógicas que abrangem todos os bancos de dados autônomos utilizados pela aplicação. Essas restrições também incluem as regras semânticas que expressam as regras de negócio (por exemplo, limite financeiro para operações no cartão de crédito). Uma AWIC pode ser definida por meio de predicado sobre os WED-attributes da aplicação. O conjunto $\mathcal{W}$ representa todas AWICs da aplicação, tal que $\mathcal{W} \subseteq \mathcal{C}$. Um WED-state é dito ser AWIC-consistente se ele respeita todas as AWICs definidas pela aplicação. O WED-state inicial de uma instância do WED-flow não é AWIC-consistente e o WED-state final é AWICconsistente. Se um WED-state não é AWIC-consistente, então alguma ação deve ser tomada com a intenção de prover um novo estado AWIC-consistente.

Quando um novo WED-state $s$ é gerado na aplicação por algum evento externo e $s$ não é AWIC-consistente, uma nova instância do WED-flow pode ser criada para manipular esse estado. O conjunto $\mathcal{F}_{s}$ de WED-flows capaz de tratar $s$ é definido como:

$$
\mathcal{F}_{s}=\left\{f=\left\langle\mathcal{G}_{f}, c_{i_{f}}, c_{f_{f}}\right\rangle \mid f \in F \wedge \text { satisfies } c_{i_{f}}\right\}
$$


isto é, todos os WED-flows da aplicação no qual $s$ representa um estado inicial válido. Se $\mathcal{F}_{s}=\emptyset$ então a aplicação permanecerá paralisada em $s$. Caso contrário, um WED-flow $f$ será selecionado a partir de $\mathcal{F}_{s}$ para ser instanciado, gerando uma instância $i$.

O último WED-state de uma transação definido pela WED-condition $c_{f}$ na Definição 6 é um estado AWIC-consistente. Os estados intermediários produzidos pela transação são chamados de WED-states transação-consistente. Intuitivamente, um estado transação-consistente é aquele que mantém a transação em execução. Formalmente, um WED-state transação-consistente é definido como:

Definição 9. WED-state Transação-Consistente. Assuma um WED-state $s \in S$ que pertence a uma instância $i$. Seja $f=\left(\mathcal{G}_{f}, c_{i_{f}}, c_{f_{f}}\right)$ o WED-flow associado a instância $i$. O WED-state $s$ é um transação-consistente se ele respeita pelo menos uma das seguintes propriedades:

- $\exists\left\langle c_{g}, t_{g}\right\rangle \in \mathcal{G}_{f}$, tal que $s$ satisfaz $c_{g}$. Em outras palavras, se $s$ habilita o disparo de pelo menos uma transição na instância $i$;

- Existe pelo menos uma transição em execução na instância $i$. Isso significa que, embora $s$ não pode disparar uma transição de estado, ele não será o último estado gerado na instância, pois cada uma das transições em execução, ao terminar a execução, produzirá um novo estado para $i$.

O WED-state inicial de uma instância deve ser transação-consistente. Caso contrário, o WED-flow não será capaz de evoluir esse estado para um estado AWIC-consistente.

A execução bem-sucedida de uma transação produz uma sequência de estados transação-consistente e um último estado AWIC-consistente. Entretanto, estados inconsistentes podem ser produzidos quando a transação desvia do seu caminho esperado. Um estado inconsistente habilita o travamento da transação, não permitindo que ela avance ou retroceda. Pelo ponto de vista do processo, um estado inconsistente é indesejado na execução de uma transação. Formalmente, um WED-state inconsistente é descrito como:

Definição 10. WED-state inconsistente. Um WED-state é inconsistente se ele não é AWICconsistente nem transação-consistente. Um WED-state inconsistente na instância pode ser resultado da ocorrência de um dos seguintes eventos:

- o aborto de uma WED-transition devido ao término do tempo máximo de execução;

- a interrupção de uma WED-transition devido a uma decisão tomada em tempo de execução. Por exemplo, um cancelamento solicitado pelo usuário da aplicação; e

- um erro no projeto do WED-flow.

Em resumo, uma instância WED-flow, durante sua execução, pode alcançar três classes de WED-states: AWIC-consistente, transação-consistente e inconsistente. A Figura 4.8 ilustra intuitivamente essas três classes de WED-states descritas acima. Um novo estado de dados faz com que o sistema saia do estado AWIC-consistente e uma instância é criada para tratá-lo. O objetivo final dessa instância é alcançar novamente um estado AWIC-consistente por meio de passos SAGA 


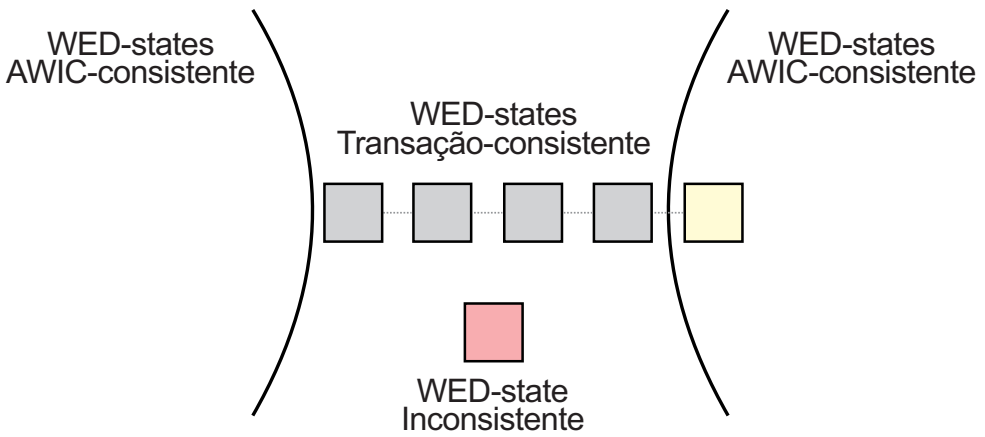

Figura 4.8: Uma instância WED-flow pode alcançar três classes de WED-states: AWIC-consistente, transação-consistente e inconsistente

que produzem estados transação-consistente. Entretanto, em algumas situações indesejadas, estados inconsistentes podem ser gerados.

Mais especificamente, os estados inconsistentes são exceções imprevistas e podem ser tratadas por algum método de recuperação descrito a seguir.

\subsection{Métodos de Recuperação}

Um caminho de recuperação é uma composição de passos de recuperação que conduzem a instância WED-flow para um estado AWIC-consistente. Quando uma instância do processo desvia do caminho primário devido a uma exceção causada por time-out, cancelamento, passo inesperado, ou até mesmo, erros de projeto, a abordagem WED-flow é capaz de prover algum método de recuperação backward ou forward para permitir que a instância alcance um estado AWIC-consistente. Exceções previstas caracterizam a ocorrência de desvios previstos dos caminho primário, isto é, aqueles desvios em que o projetista tem ciência em tempo de projeto. Exceções imprevistas podem ocorrer em qualquer ponto do caminho primário e também desviam do objetivo do processo. A principal diferença é que os eventos imprevistos são aqueles não esperados ou não modelados em tempo de projeto e devem ser tratados em tempo de execução por alguma estratégia de recuperação do WED-flow. Na Seção 4.5.1 é descrito como passos de compensação são projetados na abordagem WED-flow. Em seguida, na Seção 4.5.2 será discutido como a abordagem WED-flow trata exceções previstas. Por fim, será discutido quais as alternativas para manipular as exceções imprevistas na Seção 4.5.3.

\subsubsection{Compensações}

A abordagem WED-flow é fortemente baseada nos fundamentos do modelo SAGAS proposto em (García-Molina e Salem, 1987). Tal como em SAGAS, cada passo do processo (WED-transition) é implementado encapsulado em uma transação atômica. Além disso, para cada WED-transition, uma ação de compensação chamada WED-compensation pode ser projetada para desfazer semanticamente os seus efeitos. As WED-compensations também são encapsuladas em transações atômicas e sua execução bem-sucedida gera um novo WED-state para a instância do processo. Uma WEDcompensation é formalmente definida a seguir.

Definição 11. WED-compensation. Uma WED-compensation $t^{-1}$ é uma função de compensação $t^{-1}: \mathcal{S} \rightarrow \mathcal{S}$ atribuída para cada WED-transition $t \in \mathcal{T}$. Uma WED-compensation $t^{-1}$ é 
implementada como um passo de compensação SAGA e desfaz semanticamente os efeitos da WEDtransition $t$. A execução de $t^{-1}$ sobre um WED-state gerado pela execução de $t$ deve produzir um WED-state equivalente ao usado como entrada para a execução de $t$. Ou seja, se $t\left(s_{i}\right)=s_{i+1}$, então $t^{-1}\left(s_{i+1}\right)=s_{i}^{-1}$, sendo $s_{i}^{-1}$ equivalente a $s_{i}\left(\operatorname{com} s_{i}, s_{i+1}\right.$ e $\left.s_{i}^{-1} \in \mathcal{S}\right)$. O conjunto de todas WED-compensations definidas para a aplicação é denotado por $\mathcal{T}^{-1}$.

De acordo com a Definição 11, uma WED-compensation $t^{-1}$ atribuída para $t$ atua sobre o WED-state $s_{i+1}$ produzindo um WED-state $s_{i}^{-1}$ que deve ser equivalente a $s_{i}$. Dois WED-states são considerados equivalentes se disparam os mesmos WED-triggers. A equivalência de WED-states é formalmente definida a seguir.

Definição 12. Equivalência de WED-states. Assuma que $s_{n}$ e $s_{m}$ são WED-states, $G_{n}$ é um conjunto de WED-triggers $\left(G_{n} \subseteq G\right)$ que são habilitados por $s_{n}$, e $G_{m}$ é um conjunto de WEDtriggers $\left(G_{m} \subseteq G\right)$ que são habilitados por $s_{m}$. Os WED-states $s_{n}$ e $s_{m}$ são equivalentes (i.e. $\left.s_{n} \equiv s_{m}\right)$ se, e somente se, $G_{n}=G_{m}$.

As WED-compensations devem ser cuidadosamente projetadas para que produzam WED-states equivalentes aqueles usados na execução das WED-transitions. A Figura 4.9 ilustra a execução de um passo de compensação cujo objetivo é desfazer a reserva do veículo realizada para um veículo compacto no processo de solicitação de reserva de veículo. Na Figura 4.9(a), a WED-compensation $t_{2}^{-1}$ é ilustrada por um pentágono semelhantemente a uma WED-transition $t_{2}$, porém em direção oposta. Embora graficamente uma WED-compensation represente um retorno na execução da instância, fisicamente sempre um novo estado é produzido. Os estados de dados produzidos pela WED-transition $t_{2}$ e a WED-compensation $t_{2}^{-1}$ são detalhados na Figura 4.9(b).

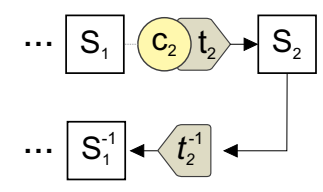

(a)

\begin{tabular}{|c|c|c|c|c|c|c|c|c|c|c|}
\hline \multicolumn{6}{|c|}{ PEDIDO } & \multicolumn{2}{|c|}{ CLIENTE } & \multicolumn{3}{|c|}{ VEÍculo } \\
\hline 1 & Cidade & $\begin{array}{c}\text { Data } \\
\text { Entrega }\end{array}$ & $\begin{array}{c}\text { Data } \\
\text { Devolução }\end{array}$ & Preferências & Status & Id & Status & Id & Categoria & Status \\
\hline & NYC & $01 / 01$ & $03 / 01$ & Compacto & Validado & C4 & Validado & $\begin{array}{l}\cdots \\
-\end{array}$ & $\begin{array}{l}\cdots \\
-\end{array}$ & $\begin{array}{l}\cdots \\
-\end{array}$ \\
\hline & NYC & $01 / 01$ & $03 / 01$ & Compacto & Validado & C4 & Validado & V1 & Compacto & Reservado \\
\hline & $\begin{array}{c}\text { NYC } \\
\ldots\end{array}$ & $\begin{array}{c}01 / 01 \\
\ldots\end{array}$ & $\begin{array}{c}03 / 01 \\
\ldots\end{array}$ & $\begin{array}{c}\text { Compacto } \\
\ldots\end{array}$ & $\begin{array}{c}\text { Validado } \\
\quad \ldots\end{array}$ & C4 & $\begin{array}{c}\text { Validado } \\
\quad \ldots\end{array}$ & $\begin{array}{l}\mathrm{V} 1 \\
\cdots\end{array}$ & Compacto & $\begin{array}{c}\text { Cancelado } \\
\ldots\end{array}$ \\
\hline
\end{tabular}

(b)

Figura 4.9: Execução da WED-compensation para o cancelamento da reserva do veículo

\subsubsection{Exceções previstas}

De acordo com as diretrizes de modelagem da abordagem WED-flow, eventos de exceções previstas podem ser modelados da mesma forma dos eventos pertencentes ao caminho primário. Dado um evento de exceção, deve-se definir qual estratégia de recuperação será adotada. Para exemplificar a escolha dessas estratégias, algumas variações do exemplo apresentado na Figura 4.4 serão 
consideradas a seguir. Primeiramente, assuma que um cliente, cuja solicitação de reserva de veículo está sendo processada, possui seus dados cadastrais incompletos. Um novo caminho do processo pode ser considerado para contemplar esse novo evento de exceção. A Figura 4.10 ilustra uma nova ordenação temporal no qual esse evento é considerado.

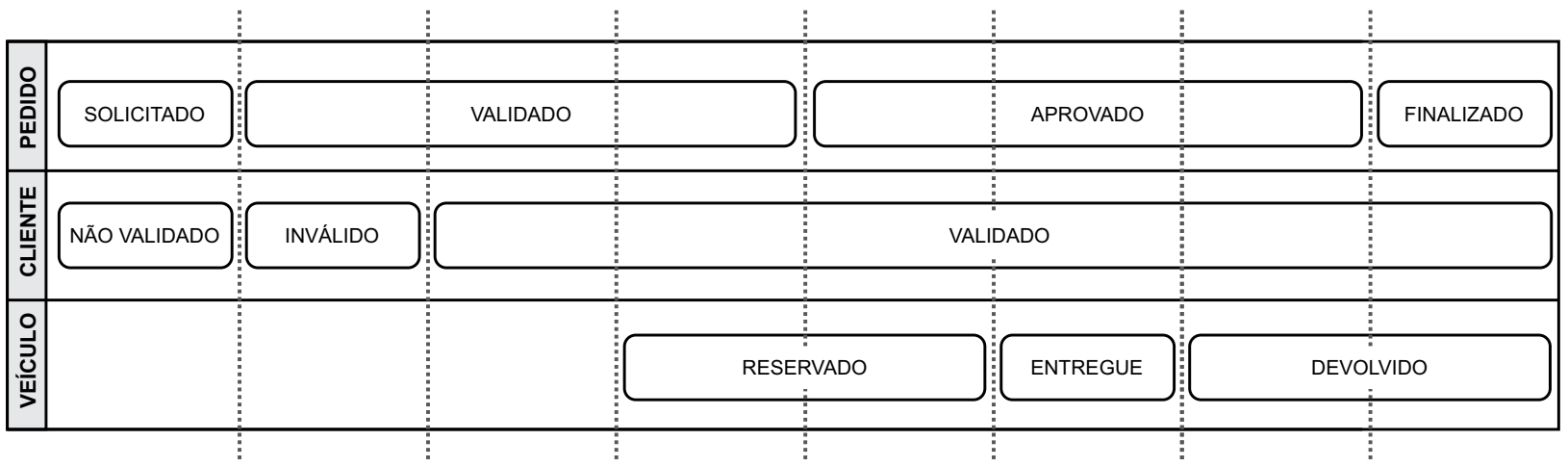

Figura 4.10: Uma nova ordenação temporal dos eventos no qual um evento de exceção é considerado

Para tratar esse novo evento representado por um novo estado de dado, primeiramente, uma nova WED-condition que seja capaz de capturá-lo deve ser descrita. Em seguida, uma ação de recuperação forward pode ser implementada por meio de uma nova WED-transition. Essa nova WED-transition é responsável pela atualização das informações inválidas do cliente e sua execução produz um novo WED-state. Nesse exemplo, a nova WED-condition é identificada por $c_{e}$ e a nova WED-transition por $t_{e}$. Ambos componentes compõem um novo WED-trigger $g_{e}$ que é inserido no esquema do processo. A Figura 4.11 ilustra esse exemplo no qual o processo de solicitação de reserva de veículo é desviado do caminho primário quando a execução da WED-transition $t_{1}$ gera um WEDstate $\mathrm{S}_{\mathrm{e}}$. Com a inserção do novo WED-trigger, a abordagem WED-flow é capaz de recuperar a instância a partir desse evento de exceção e retornar o fluxo de execução para o caminho primário.

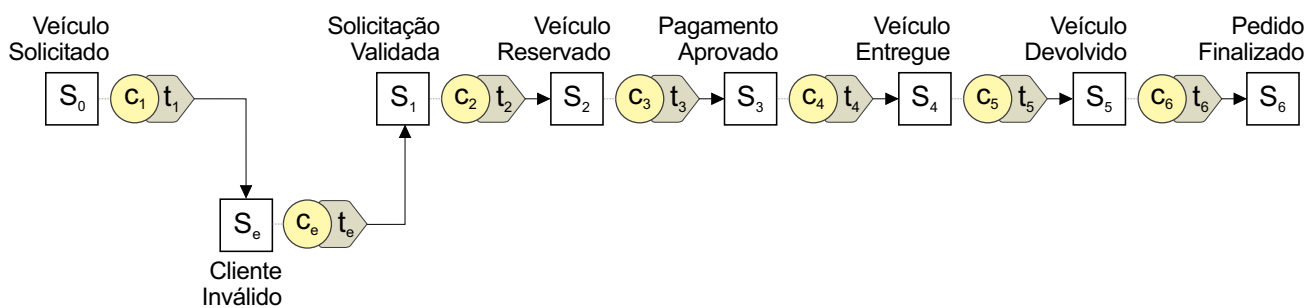

(a)

\begin{tabular}{|c|c|c|c|c|c|c|c|c|c|c|c|}
\hline & \multicolumn{6}{|c|}{ PEDIDO } & \multicolumn{2}{|r|}{ CLIENTE } & \multicolumn{3}{|c|}{ VEÍ́cULO } \\
\hline & Id & Cidade & $\begin{array}{c}\text { Data } \\
\text { Entrega }\end{array}$ & $\begin{array}{c}\text { Data } \\
\text { Devolução }\end{array}$ & Preferências & Status & Id & Status & Id & Categoria & Status \\
\hline $\mathrm{S}_{0}$ & P1 & NYC & $01 / 01$ & $03 / 01$ & Compacto & Solicitado & C4 & Não Validado & & & \\
\hline $\mathrm{S}_{\mathrm{e}}$ & P1 & NYC & $01 / 01$ & $03 / 01$ & Compacto & Validado & C4 & Inválido & & & \\
\hline $\mathrm{S}_{1}$ & P1 & NYC & $01 / 01$ & 03/01 & Compacto & Validado & C4 & Validado & & & \\
\hline $\mathrm{S}_{2}$ & P1 & NYC & $01 / 01$ & $03 / 01$ & Compacto & Validado & C4 & Validado & V1 & Compacto & Reservado \\
\hline $\mathrm{S}_{3}$ & P1 & NYC & $01 / 01$ & 03/01 & Compacto & Aprovado & C4 & Validado & V1 & Compacto & Reservado \\
\hline $\mathrm{S}_{4}$ & P1 & NYC & $01 / 01$ & 03/01 & Compacto & Aprovado & C4 & Validado & V1 & Compacto & Entregue \\
\hline $\mathrm{S}_{5}$ & P1 & NYC & $01 / 01$ & 03/01 & Compacto & Aprovado & C4 & Validado & V1 & Compacto & Devolvido \\
\hline $\mathrm{S}_{6}$ & P1 & NYC & $01 / 01$ & 03/01 & Compacto & Finalizado & $\mathrm{C} 4$ & Validado & V1 & Compacto & Devolvido \\
\hline
\end{tabular}

(b)

Figura 4.11: Passo de recuperação forward inserido para tratar um evento de exceção previsto

Em termos práticos, a recuperação forward para tratar essa exceção prevista ilustrada na Figura 4.11 pode ser executada da mesma forma que o caminho primário. Consequentemente, o 
novo caminho obtido para tratar esse evento de exceção pode ser incluído na especificação do esquema WED-flow. O tratamento de exceções de forma homogênea usando componentes básicos do WED-flow é uma vantagem sobre as demais abordagens que propõem estratégias híbridas para o tratamento de exceção como discutido na Seção 1.3. Essa vantagem está relacionada aos aspectos evolutivos e adaptativos do esquema do processo. Uma vez que os eventos de exceção e do caminho primário são tratados de forma homogênea, o esquema do processo pode ser facilmente adaptado e evoluir quando novos eventos são detectados.

Para exemplificar a recuperação backward assuma que um cliente desistiu da reserva do veículo. A Figura 4.12 ilustra uma situação no qual o cliente cancela sua reserva logo após retirar o veículo reservado. O evento de cancelamento ocorre quando uma WED-transition $t_{c}$ é executada ao invés da WED-transition $t_{5}$ do caminho primário. Isso faz com que a instância gere um WED-state $\mathrm{S}_{\mathrm{c}}$ que represente o evento de cancelamento. Para garantir a consistência da instância WED-flow, um passo de recuperação backward deve ser projetado para tratar essa exceção. Nesse exemplo, a exceção é capturada pela WED-condition $c_{c}$ e o passo de recuperação é identificado por $t_{c}^{-1}$. Note que o passo $t_{c}^{-1}$ produz o WED-state $\mathrm{S}_{4}^{-1}$ que é equivalente ao último WED-state transação-consistente executado. Isso faz com que o WED-flow determine em tempo de execução uma composição de passos de compensação formada pelas WED-compensations $t_{4}^{-1}, t_{3}^{-1}, t_{2}^{-1}$ e $t_{1}^{-1}$ que estão previamente descritos no esquema do processo. Essas WED-compensations compensam as WED-transitions $t_{4}$, $t_{3}, t_{2}$ e $t_{1}$, respectivamente. A execução é encerrada quando um WED-state AWIC-consistente é obtido.

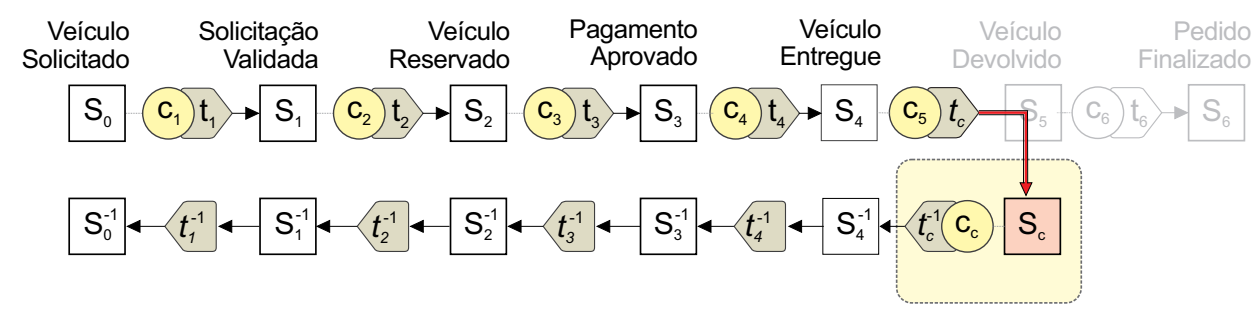

(a)

\begin{tabular}{|c|c|c|c|c|c|c|c|c|c|c|c|}
\hline \multicolumn{7}{|c|}{ PEDIDO } & \multicolumn{2}{|r|}{ CLIENTE } & \multicolumn{3}{|c|}{ VEÍCULO } \\
\hline & & Cidade & $\begin{array}{c}\text { Data } \\
\text { Entrega }\end{array}$ & $\begin{array}{c}\text { Data } \\
\text { Devolução }\end{array}$ & Preferências & Status & Id & Status & Id & Categoria & Status \\
\hline & & NYC & $01 / 01$ & $03 / 01$ & Compacto & Solicitado & C4 & Não validado & & & \\
\hline & & NYC & $01 / 01$ & $03 / 01$ & Compacto & Validado & C4 & Validado & & & \\
\hline & & NYC & $01 / 01$ & 03/01 & Compacto & Validado & $\mathrm{C} 4$ & Validado & V1 & Compacto & Reservado \\
\hline & & NYC & $01 / 01$ & $03 / 01$ & Compacto & Aprovado & C4 & Validado & V1 & Compacto & Reservado \\
\hline & & NYC & $01 / 01$ & 03/01 & Compacto & Aprovado & C4 & Validado & V1 & Compacto & Entregue \\
\hline & & NYC & $01 / 01$ & 03/01 & Compacto & Cancelar & C4 & Validado & V1 & Compacto & Entregue \\
\hline & & NYC & $01 / 01$ & $03 / 01$ & Compacto & Aprovado & C4 & Validado & V1 & Compacto & Entregue \\
\hline & & NYC & $01 / 01$ & 03/01 & Compacto & Aprovado & C4 & Validado & V1 & Compacto & Reservado \\
\hline & & NYC & $01 / 01$ & 03/01 & Compacto & Não Aprovado & C4 & Validado & V1 & Compacto & Reservado \\
\hline & & NYC & $01 / 01$ & 03/01 & Compacto & Não Aprovado & C4 & Validado & V1 & Compacto & Cancelado \\
\hline & & NYC & $01 / 01$ & 03/01 & Compacto & Cancelado & $\mathrm{C} 4$ & Validado & V1 & Compacto & Cancelado \\
\hline
\end{tabular}

(b)

Figura 4.12: Recuperação backward para tratar um evento de cancelamento

Uma das mais importantes vantagens da abordagem WED-flow em contraste com abordagens procedurais tais como Redes de Petri e Grafos é a facilidade de detectar exceções e compor caminhos de recuperação para qualquer parte do processo. Por exemplo, a Figura 4.12 ilustra o cancelamento ocorrendo logo após o veículo ter sido retirado na agência. Entretanto, cancelamentos normalmente 
podem ser disparados em qualquer parte do processo. Em abordagens procedurais, projetistas devem descrever os caminhos de recuperação necessários para cada etapa do processo. Isso, certamente, torna o tratamento de exceções complexo, prejudica a manutenibilidade e está propenso à erros. Ao contrário, ambas estratégias de recuperação da abordagem WED-flow têm significativa vantagem ao tratar as exceções como novos eventos da aplicação. Por esse motivo, a abordagem WED-flow permite o reuso de especificações de blocos (estados, condições e transições) por meio de uma composição em tempo de execução de passos de recuperação que proporcionam alta flexibilidade e desenvolvimento incremental.

\subsubsection{Exceções imprevistas}

O objetivo de um WED-flow é conduzir uma instância de um estado de dado AWIC-consistente até um outro estado AWIC-consistente. Entretanto, durante a execução, uma transição pode produzir um estado de dado intermediário que, ao ser avaliado, não satisfaz nenhuma WED-condition. Pela Definição 10, esse WED-state é dito ser inconsistente. Tal inconsistência é ocasionada por uma exceção imprevista e leva a instância do processo a ser interrompida. As instâncias interrompidas são tratadas pelo gerenciador de recuperação. A abordagem WED-flow permite duas estratégias para tratar de exceções imprevistas: (i) semiautomática e (ii) automática. Cada uma delas será descrita a seguir.

\section{Estratégia Semiautomática}

A abordagem WED-flow propõem duas formas semi-automatizadas para tratar exceções imprevistas: (i) passo de recuperação backward $\mathrm{WED}-S^{-1}$ e (ii) passo de recuperação forward WED- $S^{+a}$. Ambos são projetados e implementados em tempo de execução pelo projetista para tratar uma exceção imprevista específica de uma instância. Nas Figuras 4.13 e 4.14 são ilustrados exemplos em que estados inconsistentes são gerados pelas instâncias e são tratados pelo gerenciador de recuperação.

A Figura 4.13 ilustra um exemplo em que um WED-state inconsistente $\mathrm{S}_{\mathrm{i}}$ é gerado por uma WED-transition desconhecida. Por causa dessa inconsistência, ocorre um travamento dessa instância e ela é encaminhada para o gerenciador de recuperação do WED-flow. No gerenciador de recuperação o projetista pode analisar esse estado inconsistente e descrever em tempo de execução um passo WED- $S^{-1}$ para contornar os efeitos indesejáveis dessa exceção e retornar a instância para seu último WED-state transação-consistente. Assuma agora que o estado de inconsistência tenha sido gerado por uma falha na verificação do método de pagamento da solicitação de reserva do veículo. Isto é, ao invés da execução da WED-transition $t_{3}$ produzir um WED-state $\mathrm{S}_{3}$ que representa a aprovação do método de pagamento da solicitação, seu comportamento inesperado produziu um WED-state inconsistente. Neste exemplo, o passo WED- $S^{-1}$ compensa o efeito dessa falha produzindo um WED-state $\mathrm{S}_{2}^{-1}$. A partir deste estado, o mecanismo de execução pode compor um caminho de recuperação ao executar as WED-compensations $t_{2}^{-1}$ e $t_{1}^{-1}$. É possível também que o projetista opte por uma segunda estratégia que habilite a reexecução da WED-transition $t_{3}$ ao invés do encadeamento do compensações.

Um passo WED- $S^{-1}$ pode ser formalmente definido como:

Definição 13. WED- $S^{-1}$. Um passo de recuperação backward, denotado por WED- $S^{-1}$, é um passo SAGA especialmente definido para transformar um WED-state inconsistente de uma instância 


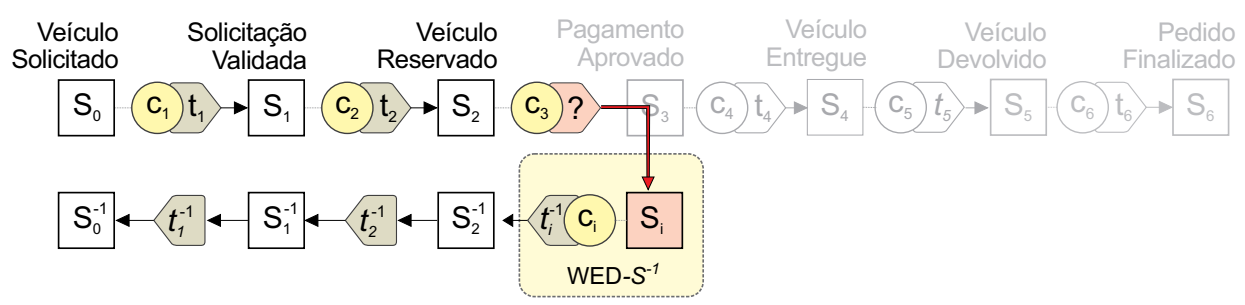

(a)

\begin{tabular}{|c|c|c|c|c|c|c|c|c|c|c|}
\hline \multicolumn{6}{|c|}{ PEDIDO } & \multicolumn{2}{|r|}{ CLIENTE } & \multicolumn{3}{|c|}{ VEÍ́culo } \\
\hline & Cidade & $\begin{array}{c}\text { Data } \\
\text { Entrega }\end{array}$ & $\begin{array}{c}\text { Data } \\
\text { Devolução }\end{array}$ & Preferências & Status & Id & Status & Id & Categoria & Status \\
\hline & NYC & $01 / 01$ & $03 / 01$ & Compacto & Solicitado & $\mathrm{C4}$ & Não validado & & & \\
\hline & NYC & $01 / 01$ & 03/01 & Compacto & Validado & C4 & Validado & & & \\
\hline 1 & NYC & $01 / 01$ & $03 / 01$ & Compacto & Validado & C4 & Validado & V1 & Compacto & Reservado \\
\hline 1 & NYC & $01 / 01$ & $03 / 01$ & Compacto & Recusado & C4 & Validado & V1 & Compacto & Reservado \\
\hline & NYC & $01 / 01$ & $03 / 01$ & Compacto & Não Aprovado & $\mathrm{C} 4$ & Validado & V1 & Compacto & Reservado \\
\hline & NYC & $01 / 01$ & 03/01 & Compacto & Não Aprovado & $\mathrm{C} 4$ & Validado & V1 & Compacto & Cancelado \\
\hline 1 & NYC & $01 / 01$ & 03/01 & Compacto & Cancelado & C4 & Validado & V1 & Compacto & Cancelado \\
\hline
\end{tabular}

(b)

Figura 4.13: Passo de recuperação backward $W E D-S^{-1}$ para uma exceção imprevista

em um novo WED-state transação-consistente, equivalente ao último estado transação-consistente da instância. Seja $s \in S$ um WED-state inconsistente de uma instância gerada por uma WEDtransition $t \in T$. O passo SAGA associado a um WED- $S^{-1}$ definido para $s$ deve executar uma ação compensatória de $t$, entre outras ações corretivas.

No segundo exemplo ilustrado na Figura 4.14, uma outra situação de inconsistência requer ser tratada pelo gerenciador de recuperação. Neste exemplo, o projetista optou por uma ação alternativa forward de contingência que reverta os efeitos do estado de inconsistência e conduza a instância interrompida novamente ao caminho primário. No WED-flow esse passo denominado como WED$S^{+a}$ é responsável por produzir um novo WED-state transação-consistente. Assuma, nesse exemplo, que a execução da WED-transition $t_{4}$, ao invés de produzir o estado que identifica a devolução do veículo, teve um comportamento imprevisto que fez com que um WED-state inconsistente tenha sido produzido. Isso ocorreu porque o veículo foi devolvido com alguma avaria. Por causa disso, esse veículo deve ser revisado por uma oficina mecânica para que a devolução seja completada. Nesse caso, o passo WED- $S^{+a}$ representa a realização do conserto do veículo e o WED-state $\mathrm{S}_{5}$ pode então ser atingido. A partir desse estado, a instância pode continuar sua execução normalmente.

Um passo WED- $S^{+a}$ pode ser formalmente definido como:

Definição 14. WED- $S^{+a}$. Um passo de recuperação forward, denotado por WED- $S^{+a}$, é um passo SAGA especialmente definido para transformar um WED-state inconsistente de uma instância em um novo WED-state transação-consistente. Ao contrário da recuperação backward, o novo estado gerado pela execução do WED- $S^{+a}$ não está relacionado com os estados anteriores da instância.

\section{Estratégia automática}

O gerenciador de recuperação também pode ser configurado para o WED-flow reagir automaticamente quando uma exceção imprevista ocorre durante a execução de uma instância. A Figura 4.15 ilustra uma exceção imprevista no qual um WED-state inconsistente $\mathrm{S}_{\mathrm{i}}$ é gerado por uma transação desconhecida. Devido ao fato que o WED-state $\mathrm{S}_{\mathrm{i}}$ é desconhecido em tempo de projeto, os 


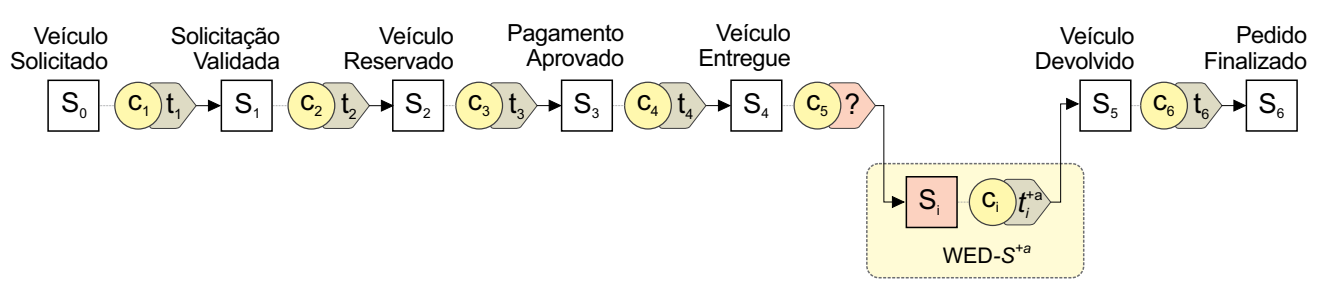

(a)

\begin{tabular}{|c|c|c|c|c|c|c|c|c|c|c|}
\hline \multicolumn{6}{|c|}{ PEDIDO } & \multicolumn{2}{|r|}{ CLIENTE } & \multicolumn{3}{|c|}{ VEÍ́culo } \\
\hline & Cidade & $\begin{array}{c}\text { Data } \\
\text { Entrega }\end{array}$ & $\begin{array}{c}\text { Data } \\
\text { Devolução }\end{array}$ & Preferências & Status & Id & Status & Id & Categoria & Status \\
\hline 1 & NYC & $01 / 01$ & $03 / 01$ & Compacto & Solicitado & C4 & Não validado & & & \\
\hline 1 & NYC & $01 / 01$ & $03 / 01$ & Compacto & Validado & $\mathrm{C} 4$ & Validado & & & \\
\hline & NYC & $01 / 01$ & $03 / 01$ & Compacto & Validado & $\mathrm{C} 4$ & Validado & V1 & Compacto & Reservado \\
\hline & NYC & $01 / 01$ & $03 / 01$ & Compacto & Aprovado & $\mathrm{C} 4$ & Validado & $\mathrm{V}_{1}$ & Compacto & Reservado \\
\hline 1 & NYC & $01 / 01$ & 03/01 & Compacto & Aprovado & $\mathrm{C} 4$ & Validado & V1 & Compacto & Entregue \\
\hline & NYC & $01 / 01$ & $03 / 01$ & Compacto & Aprovado & C4 & Validado & V1 & Compacto & Danificado \\
\hline & NYC & $01 / 01$ & $03 / 01$ & Compacto & Aprovado & $\mathrm{C} 4$ & Validado & V1 & Compacto & Devolvido \\
\hline 1 & NYC & $01 / 01$ & 03/01 & Compacto & Finalizado & $\mathrm{C4}$ & Validado & $V_{1}$ & Compacto & Devolvido \\
\hline
\end{tabular}

(b)

Figura 4.14: Passo de recuperação forward para uma exceção imprevista

seus valores também são imprevisíveis como ilustrado na Figura 4.15. Para o WED-flow, um estado de inconsistência é detectado quando um WED-state atual da instância não habilita nenhum WED-trigger. Em outras palavras, um estado de inconsistência causa o travamento da instância. Assim, o WED-flow captura exceções imprevistas ao identificar WED-states que não satisfazem nenhuma WED-condition projetada. Após esse estado ter sido detectado, o WED-flow pode automaticamente reverter o WED-state inconsistente para o último WED-state transação-consistente ao executar um passo de reversão. Um passo de reversão é possível uma vez que o histórico de execução da instância é permanentemente armazenado. Nesse exemplo, após a reversão ter sido executada, um encadeamento de compensações é executado como ilustrado na Figura 4.15. Outras estratégias de recuperação também poderiam ser configuradas para uma exceção imprevista. Por exemplo, ao invés de executar o encadeamento de compensações, uma re-execução da WED-transition $t_{5}$ poderia ser realizada.

Para realizar esse tratamento automático de exceções imprevistas é necessário assumir que os efeitos da WED-transition que produziu o estado inconsistente podem ser desprezados durante a execução da instância do processo. Desta forma, o mecanismo de recuperação do WED-flow reverte esse passo de execução conduzindo a instância para novamente para o último estado consistente. Um passo ser reversão é definido como:

Definição 15. Passo de reversão. Um passo de reversão, denotado por $r$, é uma ação de recuperação que reverte um WED-state inconsistente $s_{i}$ de uma instância WED-flow para último WED-state transação-consistente $s_{i-1}$. Ao contrário do WED- $S^{-1}$, nenhum novo estado é produzido por uma ação de reversão.

\subsection{Propriedades de consistência}

Uma vantagem da abordagem WED-flow é a preservação das propriedades de correção e consistência do sistema ao longo da execução de uma instância WED-flow (Ferreira et al., 2012). As propriedades de consistência sustentadas pelas definições WED-flow são descritas a seguir: 


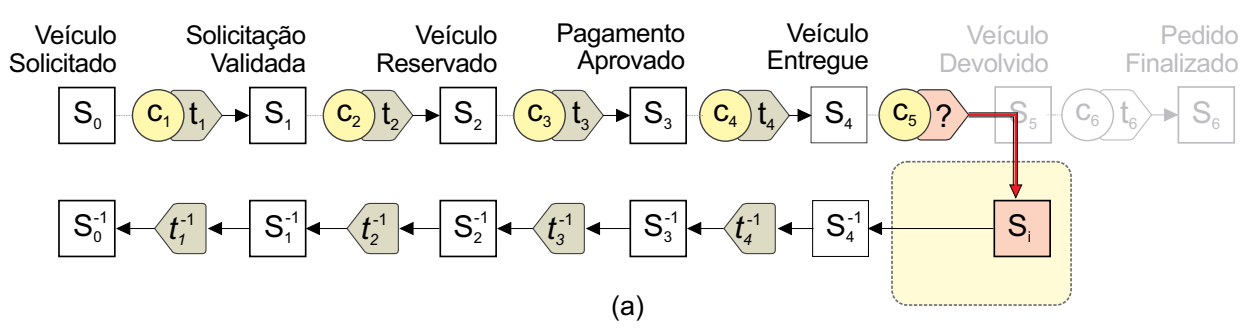

\begin{tabular}{|c|c|c|c|c|c|c|c|c|c|c|c|}
\hline & \multicolumn{6}{|c|}{ PEDIDO } & \multicolumn{2}{|r|}{ CLIENTE } & \multicolumn{3}{|c|}{ VEÍCULO } \\
\hline & & Cidade & $\begin{array}{c}\text { Data } \\
\text { Entrega }\end{array}$ & $\begin{array}{c}\text { Data } \\
\text { Devolução }\end{array}$ & Preferências & Status & Id & Status & Id & Categoria & Status \\
\hline$\partial_{0}$ & 1 & NYC & $01 / 01$ & $03 / 01$ & Compacto & Solicitado & C4 & Não validado & & & \\
\hline 5 & 1 & NYC & $01 / 01$ & $03 / 01$ & Compacto & Validado & C4 & Validado & & & \\
\hline 5 & 1 & NYC & $01 / 01$ & $03 / 01$ & Compacto & Validado & C4 & Validado & V1 & Compacto & Reservado \\
\hline 5 & 1 & NYC & $01 / 01$ & 03/01 & Compacto & Aprovado & C4 & Validado & V1 & Compacto & Reservado \\
\hline 2 & 1 & NYC & $01 / 01$ & $03 / 01$ & Compacto & Aprovado & C4 & Validado & $\mathrm{V} 1$ & Compacto & Entregue \\
\hline 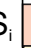 & $x$ & $x$ & $x$ & $\mathrm{x}$ & $x$ & $x$ & $\mathrm{x}$ & $x$ & $x$ & $x$ & $x$ \\
\hline & 1 & NYC & $01 / 01$ & $03 / 01$ & Compacto & Aprovado & C4 & Validado & V1 & Compacto & Entregue \\
\hline & 1 & NYC & $01 / 01$ & $03 / 01$ & Compacto & Aprovado & C4 & Validado & V1 & Compacto & Reservado \\
\hline & 1 & NYC & $01 / 01$ & $03 / 01$ & Compacto & Não Aprovado & C4 & Validado & V1 & Compacto & Reservado \\
\hline & 1 & NYC & $01 / 01$ & 03/01 & Compacto & Não Aprovado & C4 & Validado & V1 & Compacto & Cancelado \\
\hline 0 & & NYC & $01 / 01$ & 03/01 & Compacto & Cancelado & C4 & Validado & V1 & Compacto & Cancelado \\
\hline
\end{tabular}

(b)

Figura 4.15: Passo de reversão para uma exceção imprevista

Consistência do caminho primário. Assuma uma $m$-tupla $\left\langle s_{1}, s_{2}, \ldots, s_{m}\right\rangle$ como uma sequência de WED-states produzidos por uma instância WED-flow no qual nenhum estado inconsistente é gerado. Na abordagem WED-flow, uma instância é responsável por conduzir a aplicação a partir de um estado AWIC-consistente para um outro estado AWIC-consistente pela Definição 8. Isso significa dizer que uma instância é iniciada sempre que um estado Não-AWICconsistente (por exemplo, $s_{1}$ ) é criado. Ao longo de sua execução, a instância WED-flow pode criar diversos WED-states intermediários (por exemplo, $s_{1}$ até $s_{m-1}$ ) nomeados como WED-states transação-consistente (veja em Definição 9).

Consistência do caminho de recuperação. Um caminho de recuperação é uma sequência de passos SAGA que conduz o banco de dados a um estado AWIC-consistente. Se a execução de uma instância desvia do seu caminho primário (isto é, produz um estado inconsistente (Definição 10)), uma exceção imprevista é gerada. A abordagem WED-flow trata exceções em dois níveis. No nível sintático, WED-transitions são abortadas e suas atualizações são desfeitas. Essa reversão é factível porque, atualmente, as WED-transitions são implementadas como transações atômicas. Em um nível semântico, a reconciliação é alcançada por meio de passos de recuperação backward ou forward. A recuperação backward conduz a instância de um WED-state inconsistente para o último WED-state transação-consistente por meio de um passo de recuperação backward (Definição 13). Em seguida, a instância pode re-executar a partir desse estado ou compensar por meio WED-compensation (Definição 11) todos os passos que já foram executados. Em ambos os casos, um WED-state AWIC-consistente é o alvo para a recuperação backward. Um passo de recuperação forward (Definição 14) executa ações alternativas para o caminho primário que levam uma instância WED-flow de um WEDstate inconsistente para um novo WED-state transação-consistente. 
Reuso dos passos de recuperação. Como os caminhos de recuperação são composições de passos de recuperação, em que um mesmo conjunto de passos de recuperação pode ser reusado em diferentes caminhos de recuperação.

\subsection{Considerações Finais}

O WED-flow é uma abordagem transacional alternativa para modelagem e execução de processos. Sua principal característica é integrar as perspectivas de atividades, eventos e dados que permite uma modelagem flexível de processos. A principal vantagem da abordagem WED-flow é a sua capacidade de reduzir a complexidade do tratamento de exceção por meio de rotinas de recuperação backward e forward. Ambas estratégias de recuperação backward e forward tem significativas vantagens em comparação com outros PAIS, uma vez que permitem reusar passos de recuperação para compor diferentes caminhos de recuperação. Além disso, o WED-flow permite tratar cada novo evento de exceção de forma homogênea ao caminho primário por meio de especificações de blocos de componentes (eventos, estados, condições e transições) que fornecem alta flexibilidade e capacidade evolutiva para o processo.

Ambas as estratégias backward e forward podem também ser combinadas. Essa composição flexível em tempo de execução introduz um interessante desafio, ou seja, o problema da escolha do melhor caminho de recuperação a partir das várias combinações possíveis. Isso é particularmente a situação no qual diferentes caminhos de recuperação possuem diferentes custos e benefícios que podem variar dinamicamente. O método de composição ciente de custos e benefícios de passos de recuperação descrito no próximo capítulo é projetado para encontrar caminhos de recuperação que maximizam o lucro (ou minimizam o custo) de instâncias WED-flow em execução. 


\section{Capítulo 5}

\section{Método de Composição para Recuperação ciente de Custos e Benefícios}

Neste capítulo será apresentado o método de composição para recuperação ciente de custos e benefícios que combina caminhos de recuperação backward e forward. No decorrer deste capítulo, primeiramente, são discutidas algumas considerações para recuperação que incluem um cenário negócio que requer um tratamento de exceção que considere custos e benefícios na Seção 5.1. Em seguida, o mecanismo para o cálculo dos custos e benefícios é introduzido na Seção 5.2. A composição automática para recuperação na abordagem WED-flow seguida de exemplos de recuperação é discutida nas Seções 5.3 e 5.4, respectivamente. Finalmente, o algoritmo de otimização para produzir o caminho de recuperação mais lucrativo é descrito na Seção 5.5.

\subsection{Considerações para Recuperação da AWIC-Consistência}

Os cenários descritos na Seção 4.5 (caminhos de recuperação backward e forward) ilustram como a abordagem WED-flow restaura a AWIC-consistência quando a execução do caminho primário é desviada por uma falha. No entanto, a restauração da AWIC-consistência por si só pode ou não atingir o objetivo de negócios de adotar um caminho de recuperação, minimizando as perdas (maximizando lucros remanescentes) quando ocorre uma falha. Para exemplificar a abordagem proposta, serão consideradas as várias alternativas que podem ajudar uma empresa de aluguel de veículos a recuperar uma avaria de um carro.

O caminho primário da solicitação de reserva de veículo descrito na Figura 4.4 maximiza o lucro quando a execução alcança uma terminação bem-sucedida. Entretanto, o caminho primário tem também diversas potenciais ramificações para cada atividade para cobrir situações menos lucrativas tal como caminhos secundários que desviam da execução esperada devido a falhas. Neste capítulo, será usado um específico cenário de reagendamento de veículos para ilustrar as diversas possibilidades de caminhos secundários habilitados pela abordagem WED-flow. Dessa forma, considere a seguinte situação:

- Todos os veículos da categoria compacto estão atribuídos para alguma solicitação de reserva. 
- Um veículo compacto com severos problemas mecânicos tem sido identificado.

- Pelo menos uma das solicitações em que um veículo compacto foi reservado necessita ser alterada para adequar a requisição que não pode mais ser completada porque um veículo foi identificado com problemas mecânicos.

Observe que um veículo danificado ou com problemas mecânicos é um evento externo que introduz uma inconsistência para a aplicação, isto é, o invariante do número total de veículos disponível tem sido reduzido em uma unidade. Esse tipo de violação da AWIC-consistência que exige uma recuperação não trivial, uma vez que não existem registros internos de como o evento externo tenha sido originado. Tradicionalmente, a recuperação para esse tipo de evento é realizada ou atribuída para operadores humanos (por exemplo, em centros de atendimento ao cliente). Esses, por sua vez, devem normalmente executar uma árvore de decisões previamente descrita por projetistas do processo para recuperar o sistema desse tipo de inconsistência. No caso do veículo avariado, a estratégia mais intuitiva e natural é substituir o veículo com problemas por um outro veículo similar. Por outro lado, caso nenhum veículo compacto esteja disponível, o objetivo é selecionar um veículo substituto que satisfará as preferências do cliente. Algumas possibilidades de caminhos secundário incluem: (1) encontrar um veículo disponível de uma categoria superior; (2) transferir um veículo adequado de uma outra localização; (3) dar um cupom de desconto, ou créditos para serem resgatados em alguma empresa parceira (por exemplo, Uber). Atualmente, operadores de centros de atendimento ao cliente devem determinar quais dessas alternativas são adequadas, e oferecê-las aos clientes. Infelizmente, os custos relativos das várias alternativas são variáveis dinamicamente e normalmente estão indisponíveis para os operadores, o que torna a recuperação impraticável, mesmo quando a análise envolve apenas uma pequena quantidade de reservas. Consequentemente, é difícil para processos baseados em PAIS encontrar o caminho secundário que otimiza a relação custo-benefício.

Na próxima seção, será descrito como blocos de construtores WED-flow são usados para calcular os lucros e compor automaticamente caminhos secundários adequados com seus respectivos custos e benefícios, tal que seja possível escolher o caminho secundário mais lucrativo para a empresa.

\subsection{Apoio WED-flow para o Cálculo do Lucro Estimado}

O projeto e implementação da abordagem WED-flow facilita a introdução de novas características que podem ser complexas para serem manipuladas nos PAIS tradicionais. O apoio para o cálculo dos custos e benefícios dos caminhos de execução é um bom exemplo de tais características. Por uma questão de simplicidade, o termo lucro é usado para denotar a diferença entre todos os custos e benefícios produzidos por um caminho de execução. Em abordagens procedurais, o monitoramento e o cálculo dos custos e benefícios de cada caminho de recuperação é difícil. O principal problema é que ambos, custos e benefícios, podem variar dinamicamente em tempo de execução devido ao contexto de execução, as dependência entre os componentes e, frequentemente, ao estado atual do sistema. Consequentemente, o monitoramento e o cálculo do lucro é tão complexo quanto o próprio tratamento de exceção, sujeito a uma explosão combinatória quando cada caminho de recuperação é descrito explicitamente em procedimentos.

Ao contrário das abordagens procedurais, caminhos de recuperação WED-flow são constituídos dinamicamente e cada componente é disparado por um evento, implementado como uma apropriada 
alteração de WED-states. Uma vez que os WED-states contêm toda informação relevante sobre a instância WED-flow que está sendo executada, é possível calcular o lucro de cada caminho de execução (incluindo o caminho primário e os possíveis caminhos secundários) a partir de seus WEDstates. Para produção do custo ou benefício de cada atividade pertencente em um caminho de execução, o WED-state é expandido com um novo WED-attribute chamado C/R (acrônimo para Cost/Revenue).

A função $C R$ também é introduzida para o cálculo do lucro obtido para cada caminho de execução, sendo formalmente descrita a seguir:

Definição 16. CR. (Cost/Revenue) Considere uma instância WED-flow $W f_{i}$ que executa as seguintes WED-transitions $\left\langle t_{1}, t_{2}, \ldots, t_{m}\right\rangle$. Seja $h_{i}=\left\langle s_{0}, s_{1}, \ldots, s_{m}\right\rangle$ a história de execução de $W f_{i}$, formada pela sequência de WED-states produzidos pelas WED-transitions correspondentes em $W f_{i}$. Para cada $s_{j}$, o valor $v_{c r}\left(s_{j}\right)$ representa o valor (custo ou benefício) alcançado por $t_{j}$ na história de execução $h_{i}$. A função CR de $h_{i}$ é dada por:

$$
C R\left(h_{i}\right)=\sum_{j=1}^{m} v_{c r}\left(s_{j}\right)
$$

A interpretação do cálculo do lucro da função CR acima é simples quando ela começa a partir de um WED-state inicial e termina em um WED-state final, por exemplo, a partir de $\mathrm{S}_{0}$ a $\mathrm{S}_{6}$ na Figura 4.4 .

Uma generalização da Definição 16 em uma história de execução concreta $h_{i}$ é necessária para habilitar o cálculo de um lucro estimado de uma história de execução incompleta $h_{i n c}=\left\langle s_{0}, s_{1}, \ldots, s_{r}\right\rangle$, em que $r<m$. O cálculo de tais lucros estimados é realizado pela simulação da execução das WEDtransitions $\left\langle t_{r+1}, \ldots, t_{n}\right\rangle$ tal que $n \leq m$ ao continuar a execução de $W f_{i}$ a partir de $s_{r}$. A execução simulada (com entradas reais para cada WED-transition, e sem causar qualquer efeito colateral) das várias possíveis ramificações de $W f_{i}$ permite estimar seus lucros alcançáveis. Os lucros estimados habilita uma comparação ciente dos custos e benefícios que resultam em uma escolha de um caminho que maximiza o lucro para a empresa. Assume-se que existem $k$ possíveis continuações (enumerado a partir de $f_{1}$ até $f_{k}$ ) para o término de $W f_{i}$. Desta forma, é possível definir os lucros esperados de $W f_{i}$ com história de execução $h_{i}$, ao continuar a partir do WED-state atual $s_{r}$ da seguinte forma:

Definição 17. ECR. (Expected Cost/Revenue) O lucro esperado $E C R$ de $W f_{i}$ com WEDtransitions $\left\langle t_{1}, \ldots, t_{m}\right\rangle$, em uma execução incompleta $h_{i n c}=\left\langle s_{0}, s_{1}, \ldots, s_{r}\right\rangle, r<m$, é a soma dos lucros alcançados pela execução em andamento $C R\left(h_{\text {inc }}\right)$ e o máximo dos lucros estimados a partir dos caminhos hipotéticos que $W f_{i}$ pode tomar a partir do WED-state atual $s_{r}$. A escolha dos caminhos hipotéticos $\left\{f_{1}, \ldots, f_{k}\right\}$ é restringida pela disponibilidade dos valores de entrada estimados para seus WED-states. O processo de encontrar valores de entrada para um caminho hipotético será explicado adicionalmente abaixo.

$$
E C R\left(W f_{i}, h_{\text {inc }}\right)=C R\left(\left\langle s_{1}, s_{2}, \ldots, s_{r}\right\rangle\right)+\max _{j}\left\{C R\left(f_{j}=\left\langle s_{r+1}, \ldots, s_{m(j)}\right\rangle\right), 1 \leq j \leq k\right\}
$$

O WED-state de terminação de uma execução hipotética $f_{j}$ é denotado por $s_{m(j)}$, uma vez que cada execução hipotética pode terminar em qualquer WED-state com a finalidade de cálculo do 
$E C R$. Leitores familiarizados com problemas de otimização podem notar que tal definição genérica da função $E C R$ permite um número potencialmente muito grande de caminhos hipotéticos, que podem introduzir um problema computacional para encontrar o lucro máximo, uma vez que problemas de otimização frequentemente pertencem à classe de problemas NP-difíceis. Uma vez que o objetivo deste trabalho é um método automatizado de recuperação ciente dos custos e benefícios em WED-flow, o cálculo do ECR é simplificado para considerar apenas caminhos possíveis $f_{j}$ de tamanho 1, isto é, $s_{m(j)}=s_{r+1}$. Isso é um Algoritmo Guloso (Cormen et al., 2009) (Greedy Algorithm) e o acrônimo GECR (Greedy ECR) será usado para denotar o resultado otimizado do algoritmo guloso.

O algoritmo guloso é adequado quando não existem dependências entre as WED-transitions, e o espaço de otimização de cada WED-transition é convexo. Nesse caso, a soma dos lucros máximos locais (a partir de cada WED-transition) torna-se o lucro máximo global. Essa suposição é válida no exemplo de reserva de veículos em que cada WED-transition no caminho primário é independente das outras. Essa suposição também é válida em muitas aplicações práticas. Além disso, o grupo de pesquisa DATA tem explorado promissoras ideias tal como a remoção sistêmica de dependências entre componentes do workflows ao combinar componentes com dependências em um único componente. Um tratamento completo do caso geral, em que dependências podem surgir entre as WED-transitions é objeto de investigação em andamento e está além do escopo deste trabalho.

Agora, o algoritmo guloso é usado para calcular os lucros estimados do caminho primário. A Figura 5.1 inclui os custos e benefícios em uma nova coluna na tabela de WED-states (WEDattribute $\mathrm{C} / \mathrm{R}$ ), em que os lucros são calculados ao seguir o caminho primário, escolhendo a opção de mais baixo custo e/ou a opção de mais alto benefício para a WED-transition quando múltiplas escolhas são possíveis. Um bom exemplo é a WED-transition $t_{2}$ que tem como entrada um WEDstate que contém as preferências do cliente que podem resultar em múltiplas alternativas aceitáveis de veículos para a reserva. Essa WED-transition é projetada e implementada para escolher a opção de mais alto benefício entre os veículos disponíveis que satisfaz as preferencias do cliente.

Na Figura 5.1, a execução da WED-transition t 2 (Reserva do Veículo) adiciona uma renda de (\$20) de acordo com a categoria do veículo que o cliente reservou, e a WED-transition $t_{5}$ (Devolução do Veículo) inclui a depreciação estimada do veículo durante o período alugado e custos de limpeza do veículo (-\$3). Para esse exemplo de caminho primário $h_{i}$ do veículo compacto, o $G E C R\left(W f_{i}, h_{i}\right)$ resulta em um lucro de $\$ 17$.

O exemplo de caminho primário na Figura 5.1 tem um único caminho $\left\langle\mathrm{S}_{0}, \mathrm{~S}_{1}, \ldots, \mathrm{S}_{6}\right\rangle$ quando executado com sucesso até o seu final. Nas próximas seções, será descrito o uso de GECR na recuperação automática ciente de custo e benefícios automatizada incluída ao WED-flow quando suas execuções desviam do caminho primário, pela combinação automática de passos (pré-definidos) de recuperação backward e forward.

\subsection{Composição Automática para Recuperação WED-flow}

A composição automática para a recuperação a partir dos desvios do caminho primário é tratada pela abordagem WED-flow por meio de dois tipos de procedimentos de restauração da consistência: passos de recuperação backward e forward. O processo de composição dinâmica é dividido em duas partes: autogen-undo e autogen-redo, para escolher e compor passos de recuperação backward e 


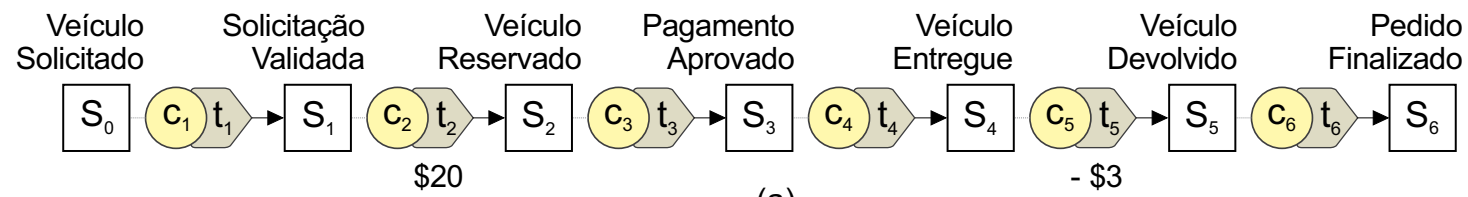

(a)

\begin{tabular}{|c|c|c|c|c|c|c|c|c|c|c|c|c|}
\hline & \multicolumn{6}{|c|}{ PEDIDO } & \multicolumn{2}{|r|}{ CLIENTE } & \multicolumn{3}{|c|}{ VEÍCULO } & \multirow[b]{2}{*}{$\mathbf{C} / \mathbf{R}$} \\
\hline & & Cidade & $\begin{array}{c}\text { Data } \\
\text { Entrega }\end{array}$ & $\begin{array}{c}\text { Data } \\
\text { Devolução }\end{array}$ & Preferências & Status & Id & Status & Id & Categoria & Status & \\
\hline & & NYC & $01 / 01$ & $03 / 01$ & Compacto & Solicitado & $\mathrm{C} 4$ & Não Validado & & & & \multirow{5}{*}{$\$ 2$} \\
\hline & & NYC & $01 / 01$ & $03 / 01$ & Compacto & Validado & $\mathrm{C} 4$ & Validado & & & & \\
\hline & & NYC & $01 / 01$ & $03 / 01$ & Compacto & Validado & C4 & Validado & V1 & Compacto & Reservado & \\
\hline & & NYC & $01 / 01$ & 03/01 & Compacto & Aprovado & C4 & Validado & V1 & Compacto & Reservado & \\
\hline & & NYC & $01 / 01$ & $03 / 01$ & Compacto & Aprovado & C4 & Validado & V1 & Compacto & Entregue & \\
\hline & & NYC & $01 / 01$ & $03 / 01$ & Compacto & Aprovado & C4 & Validado & V1 & Compacto & Devolvido & \multirow[t]{2}{*}{$-\$ 3$} \\
\hline & 1 & NYC & $01 / 01$ & 03/01 & Compacto & Finalizado & C4 & Validado & V1 & Compacto & Devolvido & \\
\hline
\end{tabular}

(b)

Figura 5.1: Solicitação de reserva de veículo incluindo os valores dos custos e benefícios

forward, respectivamente. Na Figura 5.2, um exemplo de recuperação concreto (manipular o impacto da falha mecânica do veículo que foi atribuído para uma reserva) é usado para ilustrar o processo de composição dinâmica pela combinação do autogen-undo e autogen-redo.

Quando um veículo torna-se indisponível devido a uma falha mecânica, o evento é tratado pelo processo de recuperação WED-flow em três etapas: (i) determinação da situação; (ii) autogen-undo; e (iii) autogen-redo. Na primeira etapa, uma busca para qualquer referência do veículo danificado é executada nos WED-states das instâncias WED-flow em execução. Se nenhuma referência é encontrada (veículo não é associado a nenhuma reserva), então o veículo pode ser enviado para o reparo sem quaisquer ações adicionais. Nesse exemplo, o veículo está atribuído para uma solicitação de reserva, e aguardando para ser retirado (WED-state $\mathrm{S}_{3}$ ). A recuperação é necessária uma vez que a retirada falhará, pois o veículo danificado não está mais disponível.
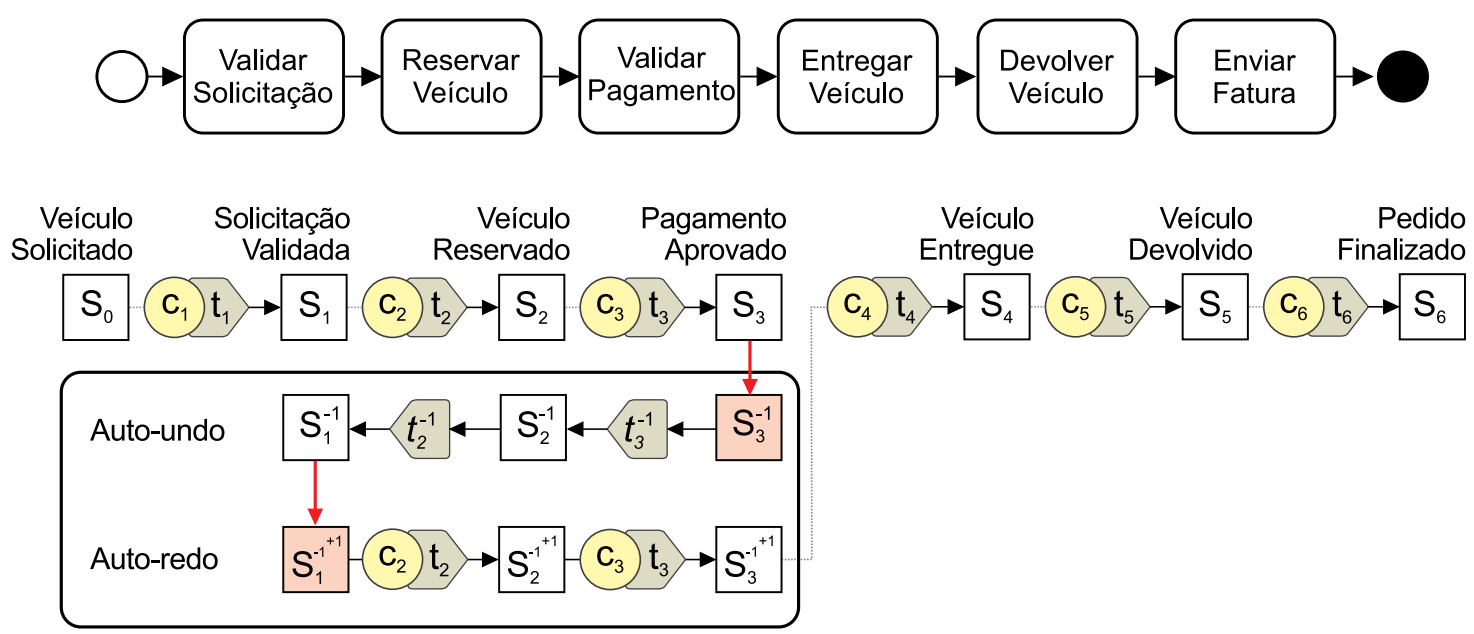

Figura 5.2: Exemplo concreto de composição automática para recuperação no WED-flow

O processo de recuperação inicia a segunda etapa ao invocar o procedimento autogen-undo para desassociar o veículo danificado. Isso é alcançado ao compensar os WED-states afetados pelo evento 
de falha. Nesse exemplo, autogen-undo inicia a partir do WED-state $\mathrm{S}_{3}$ e continua até alcançar o objetivo de desassociar o veículo ao desfazer o WED-state no qual ele foi reservado. Por causa disso, o procedimento autogen-undo invoca as WED-compensations para produzir um caminho de recuperação até o WED-state $\mathrm{S}_{1}$, chamado de ponto de parada para o método de recuperação automática.

O procedimento autogen-undo inicia a partir do WED-state atual $\left(\mathrm{S}_{3}\right)$, chamado $\mathrm{S}_{3}^{-1}$ para evitar confusão com a execução forward do caminho primário. Assume-se que em tempo de projeto de cada WED-transition $t_{i}$, uma WED-compensation correspondente $t_{i}^{-1}$ também tem sido implementada, em que semanticamente $\left(\left(t_{i} \circ t_{i}^{-1}\right)=I\right)$. O procedimento autogen-undo segue a sequência de WEDstates iniciando a partir do WED-state atual $\left(\mathrm{S}_{3}\right)$ ao invocar a WED-compensation $t_{3}^{-1}$ com $\mathrm{S}_{3}^{-1}$ como entrada. A execução bem-sucedida de $t_{3}^{-1}$ produz o WED-state $\mathrm{S}_{2}^{-1}$, que torna-se a entrada para a WED-compensation $t_{2}^{-1}$, uma vez que a WED-transition anterior foi $t_{2}$. O processo de recuperação continua até o procedimento autogen-undo produzir um WED-state equivalente ao ponto de parada $\left(\mathrm{S}_{1}\right)$, ilustrado na Figure 5.2.

Os passos básicos para o procedimento autogen-undo são os seguintes:

1. Obter o WED-state atual no momento da falha, isto é, a última entrada na base de dados dos WED-states e o ponto de partida do caminho de recuperação;

2. Encontrar o WED-state ponto de parada $s_{s p}$, o objetivo do caminho de recuperação; essa busca inicia a partir da falha que causou uma inconsistência em um dos campos de $s_{s p}$. (Na Figura 5.2 o veículo danificado que causou a atribuição inconsistente do veículo). O WEDstate que serviu como entrada para a WED-transition que produziu o campo inconsistente (Reserva do Veículo) é o ponto de parada.

3. Executar a sequência de WED-compensation, iniciando a partir de $s_{c}^{-1}$ até atingir um WEDstate equivalente a $s_{s p}$.

O procedimento autogen-undo restaura o WED-flow para um estado de consistência ao compensar os estados intermediários inconsistentes. A terceira etapa do processo de recuperação encontra uma solução alternativa para rentabilidade, por exemplo, ao retornar para o caminho primário. O terceiro estágio é implementado pelo procedimento autogen-redo, que inicia a partir do WED-state equivalente ao ponto de parada $s_{s p}\left(\mathrm{~S}_{1}^{-1}\right.$ no exemplo da Figura 5.2). Para evitar confusão com a recuperação backward, o WED-state equivalente ao ponto de parada $s_{s p}$ usado como entrada para o autogen-redo é ilustrado como $\mathrm{S}_{1}^{-1^{+1}}$ na Figura 5.2. Esse WED-state é então avaliado por todas WED-conditions para determinar quais WED-transitions podem ser executadas. No exemplo do aluguel de veículos, a WED-transition $t_{2}$ é disparada, e sua execução produz o WED-state $\mathrm{S}_{2}^{-1^{+1}}$. Em outras palavras, a execução de $t_{2}$ atribui um novo veículo para essa solicitação de reserva de acordo com os veículos disponíveis e as preferências do cliente. A seguir, o WED-state $\mathrm{S}_{2}^{-1^{+1}}$ é também avaliado por todas WED-conditions, que determina a execução da WED-transition $t_{3}$. Essa execução produz o WED-state $\mathrm{S}_{3}^{-1^{+1}}$. O procedimento autogen-redo finaliza quando um passo executado produz um estado equivalente ao WED-state atual $s_{c}$ antes do início do autogen-undo, por exemplo, ao retornar ao caminho primário. Entretanto, quando o caminho primário não é alcançado, o procedimento autogen-redo pode também ser finalizado quando um WED-state AWIC-consistente é alcançado. Um caminho secundário concreto que ilustra essa última situação é descrito na próxima seção. 
Os passos básicos para o autogen-redo podem ser descritos como:

1. Obter o WED-state equivalente ao $s_{s p}$ produzido por meio do procedimento autogen-undo; e

2. Obter o WED-state $s_{c}$ (estado atual antes do inicio do autogen-undo)

3. Executar a sequência de WED-transitions, iniciando a partir do último WED-state produzido pelo autogen-undo até alcançar um WED-state equivalente ao WED-state $s_{c}$.

O procedimento autogen-redo é encerrado uma vez que o WED-state $\mathrm{S}_{3}^{-1^{+1}}$ é equivalente ao estado atual (i.e. $\mathrm{S}_{3}$ ) no momento em que a inconsistência foi detectada. Após o WED-state $\mathrm{S}_{3}^{-1^{+1}}$ ser criado, a instância do processo pode seguir normalmente com sua execução alcançando as atividades: entregar veículo, devolver veículo e enviar fatura como ilustrado na Figura 5.2.

A combinação dos procedimentos autogen-undo e autogen-redo é capaz de encontrar caminhos secundários que não consideram o veículo compacto identificado com uma falha mecânica. Há diversas alternativas de caminhos secundários que dependem de uma combinação de fatores relacionados aos requisitos da instância do processo, dos recursos disponíveis no momento da inconsistência e dos custos de recuperação. Na seção seguinte, são descritos alguns possíveis caminhos secundários obtidos a partir das execuções dos procedimentos autogen-undo e autogen-redo.

\subsection{Exemplos de Caminhos Secundários obtidos pela Recuperação}

A fim de exemplificar as alternativas de recuperação, nesta seção, serão descritos alguns caminhos secundários que podem ser alcançados dentro do cenário de aluguéis de veículos. Nesses exemplos, todos os WED-states são numerados sequencialmente. Além disso, as linhas destacadas no histórico de execução referem-se aos passos adicionais ao caminho primário combinados para tratar a recuperação. Os custos e benefícios de cada transição de estado também são apresentados na coluna $\mathrm{C} / \mathrm{R}$.

A Figura 5.3 ilustra um caminho secundário no qual um veículo compacto previamente reservado foi cancelado e um outro veículo é automaticamente obtido pela recuperação por meio da combinação dos procedimentos autogen-undo e autogen-redo. Primeiramente, os WED-states $\mathrm{S}_{1}, \mathrm{~S}_{2}$ e $\mathrm{S}_{3}$ indicam a conclusão das atividades validar solicitação, reservar veículo e validar pagamento, respectivamente. Em seguida, o método de composição para recuperação inicia a execução para tomar as ações necessárias para tratar a inconsistência. Então, o procedimento autogen-undo produz os WED-states $\mathrm{S}_{4}$ e $\mathrm{S}_{5}$ ao compensar as atividades validar pagamento e reservar veículo. Logo após, o procedimento autogen-redo produz os WED-states $\mathrm{S}_{6}$ e $\mathrm{S}_{7}$ ao executar as WED-transitions $t_{2}$ e $t_{3}$. O mecanismo de recuperação então finaliza sua execução ao produzir o WED-state $\mathrm{S}_{7}$ que é equivalente ao WED-state atual no início do processo de recuperação (i.e. $\mathrm{S}_{3}$ ). A partir do WEDstate $\mathrm{S}_{7}$, a instância continua o seu fluxo normal de execução alcançando os WED-states $\mathrm{S}_{8}$, $\mathrm{S}_{9}$ e $\mathrm{S}_{10}$.

Embora o veículo substituto seja diferente daquele originalmente reservado, ele ainda satisfaz as preferências do cliente. Neste exemplo, um veículo econômico substitui o veículo compacto. É importante salientar que no lado direito na Figura 5.3 são descritos os custos e benefícios em cada transição de estado. Por exemplo, a instância WED-flow tem acumulado um saldo de $\$ 20$ quando o WED-state $\mathrm{S}_{3}$ é produzido. Uma vez que o veículo compacto é cancelado, um prejuízo financeiro 
é associado com a instância pela execução do procedimento autogen-undo. Em seguida, quando o procedimento autogen-redo encontra um caminho secundário ao executar as WED-transitions $t_{2} \mathrm{e}$ $t_{3}$, um novo saldo é calculado. Observe que o veículo econômico fornece um lucro menor para a empresa em comparação com o veículo compacto. A instância alcançou um saldo de $\$ 15$ ao invés dos $\$ 20$ obtidos antes do cancelamento. Logicamente, isso ocorre porque um caminho secundário tornou-se necessário devido à falha mecânica do veículo desejado (caminho primário).

\begin{tabular}{|c|c|c|c|c|c|c|c|c|c|c|c|c|}
\hline \multirow[b]{3}{*}{$\mathrm{S}_{0}$} & \multicolumn{6}{|c|}{ PEDIDO } & \multicolumn{2}{|r|}{ CLIENTE } & \multicolumn{3}{|c|}{ VEÍ́culo } & \multirow[b]{2}{*}{$C / R$} \\
\hline & Id & Cidade & $\begin{array}{c}\text { Data } \\
\text { Entrega }\end{array}$ & $\begin{array}{c}\text { Data } \\
\text { Devolução }\end{array}$ & Preferências & Status & Id & Status & Id & Categoria & Status & \\
\hline & $\mathrm{P} 1$ & NYC & $04 / 01$ & $05 / 01$ & {$[\mathrm{E}, \mathrm{C}]$} & Solicitado & $\mathrm{C} 4$ & Não validado & & & & \\
\hline $\mathrm{S}_{1}$ & P1 & NYC & $04 / 01$ & $05 / 01$ & {$[E, C]$} & Validado & $\mathrm{C} 4$ & Validado & & & & \\
\hline $\mathrm{S}_{2}$ & P1 & NYC & $04 / 01$ & $05 / 01$ & {$[E, C]$} & Validado & $\mathrm{C} 4$ & Validado & V1 & Compacto & Reservado & $\$ 20$ \\
\hline $\mathrm{S}_{3}$ & $\mathrm{P} 1$ & NYC & $04 / 01$ & $05 / 01$ & {$[E, C]$} & Aprovado & $\mathrm{C} 4$ & Validado & $\mathrm{V} 1$ & Compacto & Reservado & \\
\hline $\mathrm{S}_{4}$ & P1 & NYC & $04 / 01$ & $05 / 01$ & {$[E, C]$} & Não Aprovado & $\mathrm{C} 4$ & Validado & $\mathrm{V} 1$ & Compacto & Reservado & \\
\hline $\mathrm{S}_{5}$ & P1 & NYC & $04 / 01$ & $05 / 01$ & & Não Aprovado & $\mathrm{C} 4$ & Validado & $\mathrm{V} 1$ & Compacto & Cancelado & $-\$ 20$ \\
\hline $\mathrm{S}_{6}$ & P1 & NYC & $04 / 01$ & $05 / 01$ & {$[E, C]$} & Não Aprovado & $\mathrm{C} 4$ & Validado & V3 & Econômico & Reservado & $\$ 15$ \\
\hline $\mathrm{S}_{7}$ & P1 & NYC & $04 / 01$ & $05 / 01$ & {$[E, C]$} & Aprovado & $\mathrm{C} 4$ & Validado & V3 & Econômico & Reservado & \\
\hline $\mathrm{S}_{8}$ & P1 & NYC & $04 / 01$ & $05 / 01$ & {$[E, C]$} & Aprovado & $\mathrm{C} 4$ & Validado & V3 & Econômico & Entregue & \\
\hline $\mathrm{S}_{9}$ & P1 & NYC & $04 / 01$ & $05 / 01$ & {$[E, C]$} & Aprovado & $\mathrm{C} 4$ & Validado & V3 & Econômico & Devolvido & \\
\hline $\mathrm{S}$ & P1 & NYC & $04 / 01$ & $05 / 01$ & {$[E, C]$} & Finalizado & $\mathrm{C} 4$ & Validado & V3 & Econômico & Devolvido & \\
\hline
\end{tabular}

$[\mathrm{E}, \mathrm{C}]$ : Compacto ou Econômico

Figura 5.3: Caminho secundário: um outro veículo que satisfaz as preferências do cliente é obtido

A Figura 5.4 mostra um cenário em que um veículo de uma categoria mais alta é selecionado para substituir o veículo compacto danificado. Nesse exemplo, o cliente reservou um veículo da categoria compacto que foi substituído por um veículo da categoria premium. Considera-se para fins ilustrativos que um veículo da categoria premium é um substituto compatível para o veículo compacto. Embora essa alternativa não é tão comum em cenários de aluguel de veículos, ela pode resultar em algum lucro como ilustrado na Figura 5.4. O caminho secundário obteve $\$ 10$ ao invés dos $\$ 20$ obtidos antes do processo de recuperação.

\begin{tabular}{|c|c|c|c|c|c|c|c|c|c|c|c|}
\hline \multicolumn{6}{|c|}{ PEDIDO } & \multicolumn{2}{|r|}{ CLIENTE } & \multicolumn{3}{|c|}{ VEÍ́CULO } & \multirow[b]{2}{*}{ C/R } \\
\hline & Cidade & $\begin{array}{c}\text { Data } \\
\text { Entrega }\end{array}$ & $\begin{array}{c}\text { Data } \\
\text { Devolução }\end{array}$ & Preferê & Status & Id & Status & Id & Categoria & Status & \\
\hline & NYC & $04 / 01$ & $05 / 01$ & Compacto & Solicitado & C4 & Não validado & & & & \multirow{4}{*}{20} \\
\hline & NYC & $04 / 01$ & $05 / 01$ & Compacto & Validado & C4 & Validado & & & & \\
\hline & NYC & $04 / 01$ & $05 / 01$ & Compacto & Validado & C4 & Validado & V1 & Compacto & Reservado & \\
\hline & NYC & $04 / 01$ & $05 / 01$ & Compacto & Aprovado & C4 & Validado & V1 & Compacto & Reservado & \\
\hline & NYC & $04 / 01$ & $05 / 01$ & Compacto & Não Aprovado & C4 & Validado & V1 & Compacto & Reservado & \multirow{4}{*}{\begin{tabular}{|l}
$\$ 20$ \\
$\$ 10$
\end{tabular}} \\
\hline & NYC & $04 / 01$ & $05 / 01$ & Compacto & Não Aprovado & $\mathrm{C} 4$ & Validado & V1 & Compacto & Cancelado & \\
\hline & NYC & $04 / 01$ & $05 / 01$ & Compacto & Não Aprovado & C4 & Validado & V4 & Premium & Reservado & \\
\hline & NYC & $04 / 01$ & $05 / 01$ & Compacto & Aprovado & $\mathrm{C} 4$ & Validado & V4 & Premium & Reservado & \\
\hline & NYC & $04 / 01$ & $05 / 01$ & Compacto & Aprovado & C4 & Validado & V4 & Premium & Entregue & \\
\hline & NYC & $04 / 01$ & $05 / 01$ & Compacto & Aprovado & C4 & Validado & V4 & Premium & Devolvido & \\
\hline & NYC & $04 / 01$ & 05/01 & Compacto & Finalizado & C4 & Validado & V4 & Premium & Devolvido & \\
\hline
\end{tabular}

Figura 5.4: Caminho secundário: um veículo de uma categoria mais alta é selecionado

As Figuras 5.3 e 5.4 ilustram cenários de recuperação no qual caminhos secundários que satisfazem as preferências do cliente foram encontrados. Ao contrário dos exemplos anteriores, a Figura 5.5 ilustra um exemplo no qual nenhum veículo que satisfaça as preferências do cliente é encontrado. Mais especificadamente, o procedimento autogen-redo finaliza antecipadamente sua execução quando a WED-transition $t_{2}$ produz o WED-state $\mathbf{S}_{6}$. A terminação antes de alcançar um WED-state equivalente ao estado atual no início do processo de recuperação é um caso especial do 
procedimento autogen-redo. De acordo com a Definição 6, a abordagem WED-flow permite múltiplos estados de terminação para um processo (que são WED-states AWIC-consistentes). Nesse exemplo ilustrado pela Figura 5.5, o WED-state $\mathrm{S}_{6}$ é um estado de terminação válido para o caminho secundário sendo um WED-state AWIC-consistente a partir da perspectiva WED-flow. A partir da perspectiva do negócio, esta é uma forma inadequada e onerosa para tratar de cancelamentos. Além disso, a satisfação do cliente e sua fidelidade podem ser comprometidas se nenhuma opção de veículo for oferecida para ele.

\begin{tabular}{|c|c|c|c|c|c|c|c|c|c|c|c|c|}
\hline & \multicolumn{6}{|c|}{ PEDIDO } & \multicolumn{2}{|r|}{ CLIENTE } & \multicolumn{3}{|c|}{ VEículo } & \multirow[b]{2}{*}{ C/R } \\
\hline & Id : & Cidade & $\begin{array}{c}\text { Data } \\
\text { Entrega }\end{array}$ & $\begin{array}{c}\text { Data } \\
\text { Devolução }\end{array}$ & Preferências & Status & Id & Status & Id & Categoria & Status & \\
\hline $\mathrm{S}_{0}$ & P1 & NYC & $04 / 01$ & $05 / 01$ & Compacto & Solicitado & C4 & Não validado & & & & \multirow{4}{*}{$\$ 20$} \\
\hline $\mathrm{S}_{1}$ & P1 & NYC & 04/01 & 05/01 & Compacto & Validado & C4 & Validado & & & & \\
\hline $\mathrm{S}_{2}$ & P1 & NYC & $04 / 01$ & 05/01 & Compacto & Validado & C4 & Validado & V1 & Compacto & Reservado & \\
\hline $\mathrm{S}_{3}$ & $\mathrm{P} 1$ & NYC & $04 / 01$ & $05 / 01$ & Compacto & Aprovado & C4 & Validado & V1 & Compacto & Reservado & \\
\hline $\mathrm{S}_{4}$ & $\mathrm{P} 1$ & NYC & $04 / 01$ & $05 / 01$ & Compacto & Não Aprovado & C4 & Validado & V1 & Compacto & Reservado & \multirow{3}{*}{$-\$ 20 \mid$} \\
\hline $\mathrm{S}_{5}$ & $\mathrm{P} 1$ & NYC & $04 / 01$ & $05 / 01$ & Compacto & Não Aprovado & C4 & Validado & V1 & Compacto & Cancelado & \\
\hline$S_{6}$ & P1 & NYC & $04 / 01$ & $05 / 01$ & Compacto & Não Aprovado & C4 & Validado & V1 & Compacto & Não encontrado & \\
\hline
\end{tabular}

Figura 5.5: Caminho secundário: nenhum veículo pode ser selecionado e a reserva do cliente é cancelada

A fim de prover uma alternativa para essas situações, novas opções podem ser consideradas como ilustrado na Figure 5.6. Nesse exemplo, após o WED-state $\mathrm{S}_{6}$ ter sido criado, um passo de contingência executa uma ação alternativa para reservar um veículo compacto em uma filial da empresa $\left(S_{7}\right)$. Esse passo habilita a transferência do veículo $\left(S_{8}\right)$ até a localização desejada do cliente. Esses passos de contingência são frequentemente custosos para a empresa. Como ilustrado na Figura 5.6, a transferência de um veículo tem um custo maior do que o valor pago pelo cliente. Em outras palavras, ações de contingência são formas não lucrativas para o tratamento de exceções. Entretanto, tais ações atendem às expectativas dos clientes uma vez que eles não sofrem os efeitos colaterais do cancelamento.

\begin{tabular}{|c|c|c|c|c|c|c|c|c|c|c|c|c|}
\hline & \multicolumn{6}{|c|}{ PEDIDO } & \multicolumn{2}{|r|}{ CLIENTE } & \multicolumn{3}{|c|}{ VEículo } & \multirow[b]{2}{*}{ C/R } \\
\hline & Id & Cidade & $\begin{array}{c}\text { Data } \\
\text { Entrega }\end{array}$ & $\begin{array}{c}\text { Data } \\
\text { Devolução }\end{array}$ & Preferências & Status & Id & Status & Id & Categoria & Status & \\
\hline $\mathrm{S}_{0}$ & P1 & NYC & $04 / 01$ & $05 / 01$ & Compacto & Solicitado & C4 & Não validado & & & & \multirow{4}{*}{$\$ 20$} \\
\hline $\mathrm{S}_{1}$ & P1 & NYC & $04 / 01$ & $05 / 01$ & Compacto & Validado & C4 & Validado & & & & \\
\hline $\mathrm{S}_{2}$ & P1 & NYC & $04 / 01$ & 05/01 & Compacto & Validado & C4 & Validado & & Compacto & Reservado & \\
\hline $\mathrm{S}_{3}$ & P1 & NYC & $04 / 01$ & $05 / 01$ & Compacto & Aprovado & C4 & Validado & V1 & Compacto & Reservado & \\
\hline $\mathbf{S}_{4}$ & $P 1$ & NYC & $04 / 01$ & $05 / 01$ & Compacto & Não Aprovado & $\mathrm{C} 4$ & Validado & V1 & Compacto & Reservado & \multirow[b]{2}{*}{$-\$ 20$} \\
\hline $\mathbf{S}_{5}$ & P1 & NYC & $04 / 01$ & 05/01 & Compacto & Não Aprovado & $\mathrm{C} 4$ & Validado & $\mathrm{V} 1$ & Compacto & Cancelado & \\
\hline $\mathbf{S}_{6}$ & P1 & NYC & $04 / 01$ & $05 / 01$ & Compacto & Não Aprovado & $\mathrm{C} 4$ & Validado & V1 & Compacto & Não encontrado & \multirow{4}{*}{$\begin{array}{l}\$ 20 \\
-\$ 30\end{array}$} \\
\hline $\mathbf{S}_{7}$ & P1 & NYC & $04 / 01$ & $05 / 01$ & Compacto & Não Aprovado & $\mathrm{C} 4$ & Validado & V6 & Compacto & Res. Externa & \\
\hline $\mathbf{S}_{8}$ & P1 & NYC & $04 / 01$ & $05 / 01$ & Compacto & Não Aprovado & $\mathrm{C} 4$ & Validado & V6 & Compacto & Transferido & \\
\hline $\mathbf{S}_{9}$ & P1 & NYC & $04 / 01$ & $05 / 01$ & Compacto & Aprovado & $\mathrm{C} 4$ & Validado & V6 & Compacto & Transferido & \\
\hline$S_{10}$ & P1 & NYC & $04 / 01$ & 05/01 & Compacto & Aprovado & C4 & Validado & V6 & Compacto & Entregue & \\
\hline$S_{11}$ & P1 & NYC & $04 / 01$ & $05 / 01$ & Compacto & Aprovado & C4 & Validado & V6 & Compacto & Devolvido & \\
\hline$\partial_{12}$ & P1 & NYC & $04 / 01$ & $05 / 01$ & Compacto & Finalizado & C4 & Validado & V6 & Compacto & Devolvido & \\
\hline
\end{tabular}

Figura 5.6: Caminho secundário: um veículo compacto é transferido de uma filial

O último exemplo ilustrado na Figura 5.7 retrata um caso em que o cliente recebe um bônus por ter sua reserva cancelada. Essa bonificação refere-se a algum tipo de crédito que pode ser usado em reservas futuras ou em alguma empresa parceira (por exemplo, Uber). Essa estratégia é comumente usada por diversas empresas em caso de cancelamentos. Pelo ponto de vista do cliente, esse tipo de bonificação minimiza sua insatisfação, mas, por outro lado, aumenta os custos da empresa para 
tratar exceções.

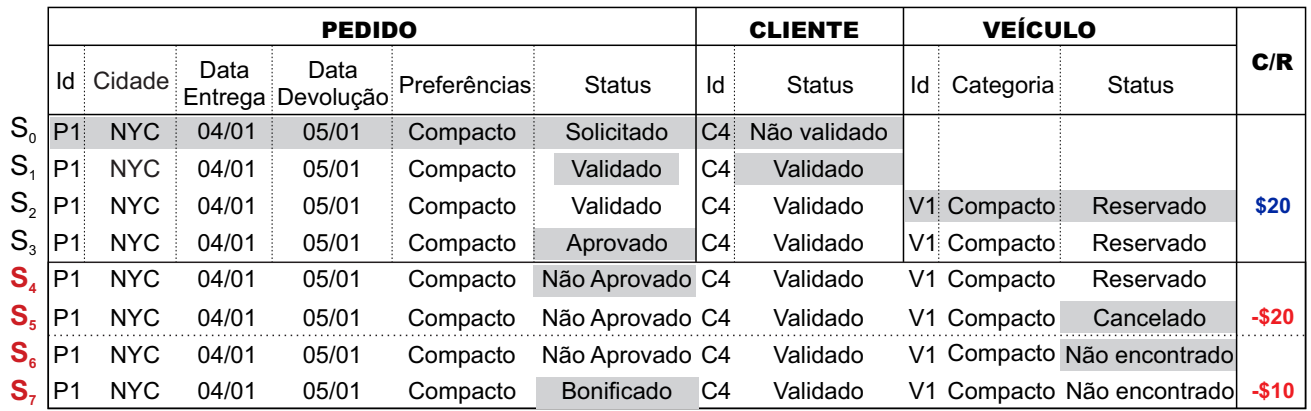

Figura 5.7: Caminho secundário: nenhum veículo é selecionado e o cliente recebe um bônus

Neste capítulo foram intuitivamente apresentados os procedimentos autogen-undo e autogenredo e como eles podem ser usados para encontrar caminhos de recuperação alternativos ao caminho primário. Além disso, destaca-se que o uso de funções que indicam o custo financeiro dos caminhos de recuperação podem ser usados para minimizar o prejuízo decorrente de situações de cancelamento.

É importante salientar que as instâncias do processo afetadas pelo cancelamento nos exemplos descritos acima possuem o mesmo estado atual meramente por uma questão de clareza. Para a abordagem WED-flow, todos os passos são sempre susceptíveis a alguma forma de recuperação. Entretanto, clientes que já estão usando o veículo alugado (i.e., já completaram a atividade entregar veículo) raramente seriam chamados para realizar a troca do seu veículo em uma questão de cancelamento. Nestes casos, a WED-compensation da atividade entregar veículo é associada com um alto custo, o que inviabiliza sua execução a partir da perspectiva do negócio.

Neste capítulo foi descrito como o método de composição para recuperação é capaz de produzir diferentes caminhos de recuperação no cenário de aluguéis de veículos. Embora nossos exemplos enfatizem o problema de reserva de veículos, os procedimentos autogen-undo e autogen-redo são aplicados em uma grande variedade de situações de inconsistências em diversos cenários de processos. Um outro exemplo comum é o cancelamento de voos devido a alguma falha mecânica ou condições do tempo desfavoráveis. Por causa da complexa engenharia dos vários passos de recuperação, sistemas de passagens aéreas normalmente não são suficientemente confiáveis para tratar esse tipo de cancelamento obrigando que essas situações sejam manipuladas com intervenções manuais no sistema. Desta forma, longas filas são formadas nos aeroportos com os passageiros que gostariam de encontrar uma alternativa para viajar entre algumas possibilidades disponíveis. A fim de resolver estes problemas, o algoritmo de otimização para encontrar o caminho secundário que maximiza o lucro baseado nos procedimentos autogen-redo e autogen-redo é descrito na próxima seção.

\subsection{Algoritmo de Otimização para produzir o Caminho Secundário mais Lucrativo}

Nesta seção, será discutido o algoritmo de otimização baseado nos procedimentos autogen-undo e autogen-redo usados para encontrar caminhos secundários, e escolher aquele que é mais lucrativo. Em seguida, os procedimentos autogen-redo e autogen-undo discutidos intuitivamente na Seção 5.3 serão detalhadamente descritos. Finalmente, será apresentado como é possível escolher o caminho mais lucrativo entre os diferentes caminhos secundários produzidos pelos procedimentos autogen- 
undo e autogen-redo.

Dada uma violação da AWIC-consistência, a principal proposta do algoritmo de otimização é encontrar um caminho secundário que minimiza os custos do tratamento de exceção. A Figura 5.8 ilustra o algoritmo de otimização que possui dois parâmetros de entrada: a história de execução $h$ que contém os caminhos de todas as instâncias em execução e a estrutura de dados assigned_item que identifica a inconsistência introduzida na aplicação. Por exemplo, assigned_item identifica o veículo danificado que não pode mais ser reservado pelos clientes. Primeiramente, o algoritmo verifica quais instâncias podem ser recuperadas para tratar a violação da AWIC-consistência identificada pelo assigned_item na linha 1. Se nenhuma instância é encontrada, nenhuma ação de recuperação é obrigatória, e consequentemente, a execução do algoritmo é finalizada na linha 3. Caso contrário, o algoritmo deve encontrar a instância que tem o caminho secundário mais lucrativo entre todas as instâncias selecionadas na linha 1. Entre as linhas 5-10, um laço de repetição itera sobre as instâncias selecionadas a fim de produzir caminhos secundários ao executar os procedimentos autogen-undo e autogen-redo. Em cada passo de iteração, o WED-state atual $s_{c}$ e o WED-state $s_{s p}$ que representa o ponto de parada são identificados para cada instância $i$. Ambos são obtidos por consultas na história de execução $h_{i}$ nas linhas 6 e 7, respectivamente. Como discutido na Seção 5.3, o ponto de parada é usado como uma condição de parada para o autogen-undo, e o estado atual é usado como uma condição de parada para o autogen-redo. Após os caminhos secundários terem sido criados para cada instância (linhas 5-10), o procedimento para o cálculo e identificação do caminho mais lucrativo é invocado na linha 11. O algoritmo de otimização é finalizado quando um caminho secundário é escolhido como o caminho mais lucrativo entre as diversas alternativas para o tratamento da violação da AWIC-consistência.

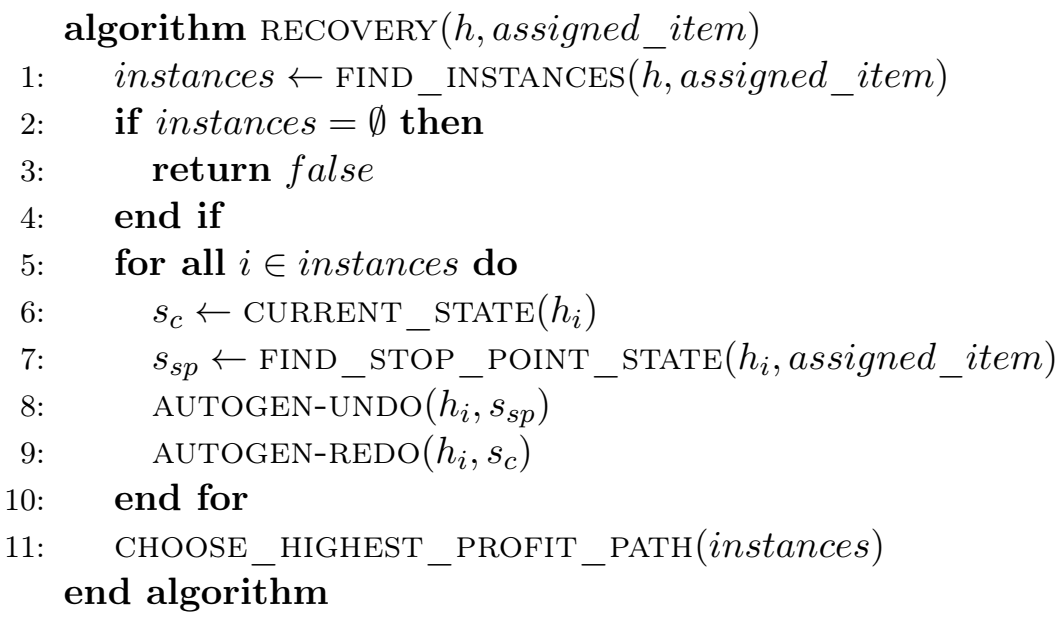

Figura 5.8: Algoritmo de otimização para encontrar o caminho secundário de maior lucro

O procedimento autogen-undo ilustrado na Figura 5.9 é responsável por recuperar cada instância a partir do estado atual até o ponto de parada. O autogen-undo executa passos de compensação para semanticamente desfazer os efeitos produzidos pela execução das WED-transitions entre $s_{s p}$ e $s_{c}$. Os parâmetros de entrada para o autogen-undo são a história de execução $h_{i}$ da instância $i$, e o WED-state ponto de parada $s_{s p}$. Primeiramente, o procedimento identifica o estado atual $s_{n c}$ ao executar uma consulta na história de execução $h_{i}$ na linha 2. Entre as linhas 3-7, um laço de repetição executa até que o WED-state $s_{n c}$ seja equivalente ao WED-state $s_{s p}$ (ponto de parada). Em cada passo de iteração, a WED-transition que produziu o WED-state $s_{n c}$ é identificada (linha 4) 
e sua WED-compensation associada é executada (linha 5), produzindo um novo WED-state $s_{n c}$. A execução termina quando o caminho de recuperação backward tem sido produzido para a instância $i$.

1: procedure AUTOGEN-UNDO $\left(h_{i}, s_{s p}\right)$

$s_{n c} \leftarrow$ CURRENT_STATE $\left(h_{i}\right)$

while $s_{n c} \not \equiv s_{s p} \overline{\text { do }}$

Seja $t$ a WED-transition que produziu $s_{n c}$

Seja $t^{-1}$ o passo de compensação para $t$

$s_{n c} \leftarrow t^{-1}\left(s_{n c}\right)$

end while

end procedure

Figura 5.9: Procedimento autogen-undo

Após a execução do autogen-undo, o procedimento autogen-redo ilustrado na Figura 5.10 é invocado. O autogen-redo é responsável por produzir um caminho secundário para cada instância envolvida no processo de recuperação. Esse procedimento tem dois parâmetros de entrada: a história de execução $h_{i}$ da instância $i$, e WED-state $s_{c}$, que foi o estado atual antes do início do autogen-undo. No primeiro passo (linha 2), o procedimento obtém o estado atual $s_{n c}$ para a instância. A principal proposta do autogen-redo é gerar um caminho secundário até que um WED-state equivalente a $s_{c}$ (retornando ao caminho primário), ou um WED-state AWIC-consistente (WED-state final) seja produzido. Ambas condições de parada são usadas pelo laço de repetição nas linhas 3-6. Em cada passo de iteração, o autogen-undo encontra uma WED-transition para ser executada ao avaliar o WED-state $s_{n c}$ com as WED-conditions da aplicação (linha 4). Na linha 5, a WED-transition associada à WED-condition satisfeita é executada, e sua execução bem-sucedida produz um novo WED-state $s_{n c}$. Após o procedimento autogen-redo executar, um caminho secundário terá sido produzido para a instância $i$. Uma vez que muitas instâncias podem estar envolvidas no processo de recuperação, é necessário encontrar qual delas produz o caminho secundário mais lucrativo como discutido a seguir.

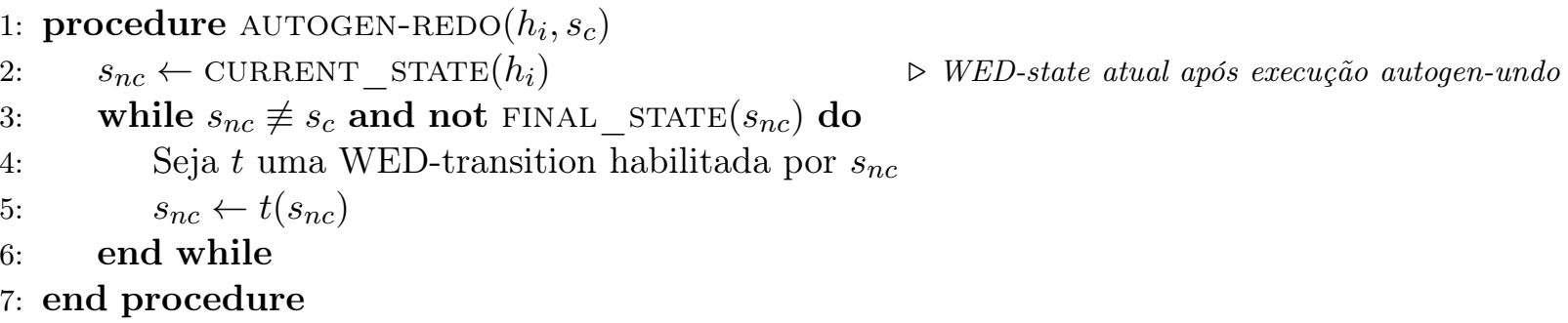

Figura 5.10: Procedimento autogen-redo

O procedimento para escolher o caminho mais lucrativo é descrito na Figura 5.11. Nas linhas 2-4, o lucro é calculado usando a função $C R$ (veja Definição 16) para cada caminho secundário obtido pelos procedimentos autogen-undo e autogen-redo. A seguir, na linha 5, a instância $k$, cujo caminho é o mais lucrativo, é identificada. A fim de evitar a exposição de seus efeitos (execução simulada), a geração de cada caminho secundário é encapsulada em uma transação atômica. Por causa disso, o caminho secundário mais lucrativo necessita ser confirmado, e todos os outros devem ser revertidos. Entre as linhas 6-12, o caminho secundário produzido pela instância $k$ é confirmado (commited) (linha 8) enquanto todos os outros caminhos secundários são abortados (linha 10).

O tempo de execução do algoritmo de otimização é caracterizado por dois fatores: (i) número de 


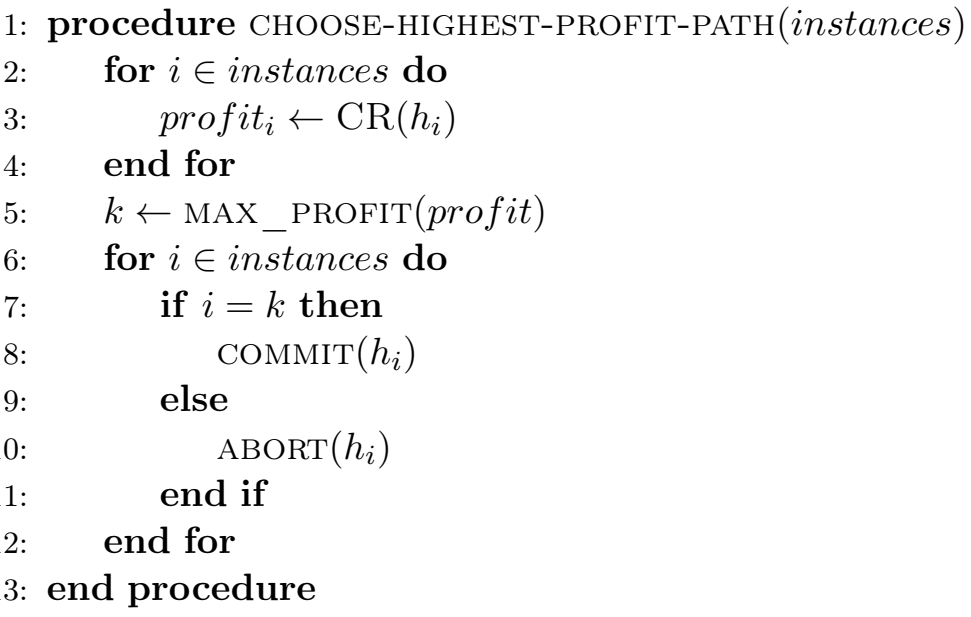

Figura 5.11: Procedimento para escolher o caminho secundário mais lucrativo

instâncias envolvidas no tratamento da inconsistência e (ii) o número de compensações e transições executadas para cada instância nos procedimentos autogen-undo e autogen-redo. Os resultados experimentais obtidos a partir de diferentes cargas submetidas ao algoritmo proposto são apresentados no próximo capítulo. 


\section{Capítulo 6}

\section{Resultados Experimentais}

Para o propósito de avaliação, o algoritmo de otimização para produzir o caminho secundário de melhor relação custo-benefício foi implementado no arcabouço da abordagem WED-flow conhecido como WED-tool (WED-tool, 2016). Neste capítulo, será descrito uma visão geral desse arcabouço, seguido pela configuração do experimento e os resultados obtidos.

\subsection{WED-tool}

A WED-tool é uma ferramenta que implementa o arcabouço WED-flow. Essa ferramenta vem sendo desenvolvida pelo grupo de pesquisa DATA do IME-USP. A WED-tool é implementada utilizando a linguagem de programação orientada a objetos Ruby ${ }^{1}$ e o arcabouço de aplicação conhecido como Ruby on Rails ${ }^{2}$. O Sistema de Gerenciamento de Banco de Dados (SGBD) PostgreSQL (PostgreSQL, 2016) é usado para armazenar a base de dados referente aos esquemas dos processos e às execuções das instâncias WED-flow. O núcleo dessa ferramenta foi apresentado em (Garcia et al., 2012a). As principais funções do núcleo são controlar a execução de processos transacionais e fornecer a estrutura necessária para apoiar a implementação do módulo de gerenciamento de recuperação.

A Figura 6.1 apresenta uma visão geral do funcionamento da WED-tool. Há basicamente três módulos implementados: configuração inicial, controle de execução e o gerenciador de recuperação. Esta seção descreve brevemente o funcionamento de cada um desses módulos.

Definição e manutenção dos esquemas dos processos. O modelo WED-flow, definido em fases anteriores da modelagem, é traduzido em uma linguagem concreta. Mais especificamente, os elementos que compõem um WED-flow, isto é, WED-attributes, WED-conditions, WEDtransitions e WED-triggers são descritos usando a sintaxe XML. Assim, um arquivo XML com esses elementos é usado como base para o módulo de configuração. Com esse arquivo, a WED-tool é capaz de criar a estrutura do banco de dados necessária para o controle da execução das instâncias. Além disso, para cada WED-transition do modelo do processo descrito no arquivo XML, o módulo de configuração gera um modelo de classe em Ruby para que o projetista possa descrever o código de cada transição. Uma descrição detalhada do XML Schema e do modelo de classes Ruby pode ser encontrada em (Garcia, 2013). Para os

\footnotetext{
${ }^{1}$ Disponível em https://www.ruby-lang.org/pt/

${ }^{2}$ Disponível em http://rubyonrails.org
} 


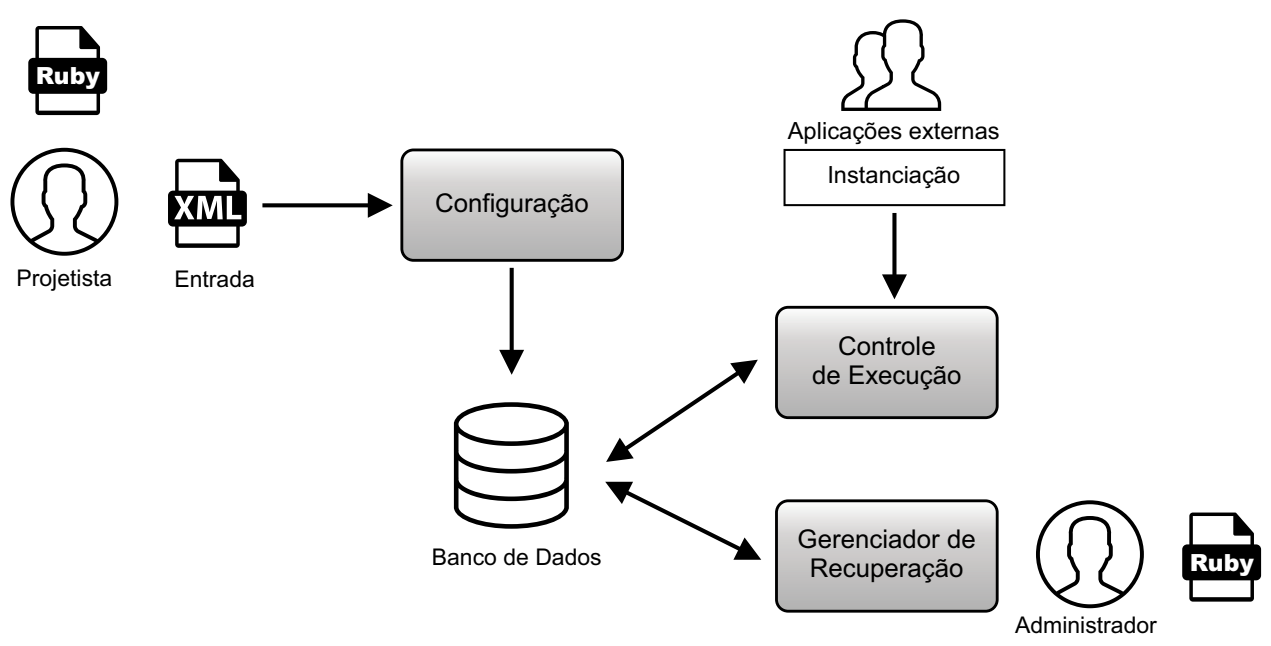

Figura 6.1: Visão geral do funcionamento da WED-tool

experimentos deste trabalho, esse módulo foi alterado para incluir a extensão dos WED-states (WED-attribute C/R) para cada WED-transition e WED-compensation.

Controle de execução. Uma vez especificado o modelo WED-flow e configurada as estruturas necessárias para o funcionamento da ferramenta, a WED-tool é capaz de instanciar e controlar a execução de processos. Para criar novas instâncias, o módulo recebe eventos externos como valores nos WED-attributes (WED-state inicial). De acordo com as definições descritas no Capítulo 4, esse WED-state não é um AWIC-consistente. Isso faz com que um WED-flow seja escolhido para tratar esse WED-state. Se esse estado satisfaz a condição inicial de algum WED-flow configurado, a WED-tool inicia uma nova instância que deverá tratá-lo. Caso contrário, esse estado é inconsistente e será tratado pelo gerenciador de recuperação.

Gerenciamento de Recuperação. Esse módulo é responsável por manipular instâncias que produzem WED-states inconsistentes. O módulo de recuperação executa ações alternativas como passos de recuperação backward e forward que conduzem a instância novamente para um AWIC-consistente. O método de composição ciente de custos e benefícios de passos de recuperação foi implementando dentro deste módulo para execução dos experimentos descritos a seguir. Os detalhes de implementação do módulo de recuperação à falhas do WED-flow é descrito em (Garcia et al., 2012b; Silva, 2013).

\subsection{Configuração dos Experimentos}

Para avaliar a execução do algoritmo de recuperação para o caminho secundário de melhor custo-benefício, um processo baseado na solicitação de reserva de veículos foi implementado. O mecanismo foi submetido a 30 cargas de 500 até 15000 instâncias. O experimento foi iniciado com uma carga de 500 instâncias e a cada execução subsequente foi adicionado 500 novas instâncias até que atingiu-se a carga final de 15000 instâncias. Por uma questão de uniformidade entre as cargas, cada instância executou de 3 a 5 passos de recuperação a partir do cancelamento. Cada carga foi submetida ao algoritmo três vezes e o tempo médio dessas execuções foi coletado.

Os experimentos foram conduzidos em um servidor executando o Sistema Operacional Ubuntu 
14.04.02 LTS $^{3}$, PostgreSQL 9.3.10 e Ruby 2.3.0 ${ }^{5}$. O servidor usado no experimento é configurado com 7 CPUs Intel Xeon 2.4GHz, 32 GB RAM e 200 GB de disco.

\subsection{Resultados}

A Figura 6.2 ilustra os resultados experimentais obtidos a partir da execução das 30 cargas. A primeira carga com 500 instâncias executou em 39,4 segundos enquanto a última carga com 15.000 instâncias obteve um tempo de execução de 5.106,8 segundos (85,2 minutos).

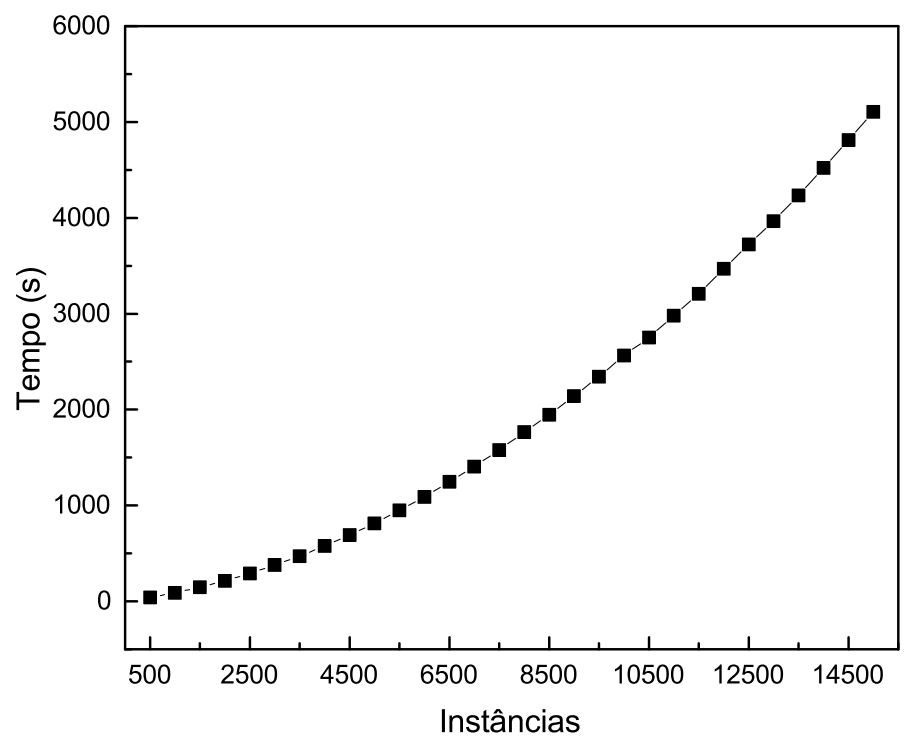

Figura 6.2: Resultados experimentais: número de instâncias versus tempo de execução (segundos)

A Figura 6.3 mostra o tempo médio gasto por instância em cada carga. O tempo médio por instância foi de 0,078 segundos para a primeira carga e de 0,34 segundos para a última carga.

\subsection{Discussão}

O principal problema dos PAIS atuais baseados em modelos de processos procedimentais em tratar exceções é sua capacidade limitada para modelagem e execução automática dos possíveis resultados e alternativas de um processo que diferem do caminho primário. Devido a essa necessidade, o tratamento de exceções tem atualmente sido realizado por intervenção de operadores humanos em centros de atendimento para resolver os efeitos colaterais dos eventos inesperados. Gradualmente, essas intervenções ad-hoc têm se tornado comuns devido ao crescimento substancial das aplicações. Como uma consequência, a manutenção dos PAIS está cada vez mais custosa e propensa a erros. Para resolver esse problema, as rotinas de recuperação propostas neste trabalho podem ser usadas em diversos processos para reduzir a intervenção de operadores humanos para manipular exceções. A Figura 6.2 ilustra o tempo médio de execução para diferentes cargas de instâncias. Este resultado

\footnotetext{
${ }^{3}$ http://www.ubuntu.com/download/server

${ }^{4}$ https://www.postgresql.org/download/

${ }^{5}$ https://www.ruby-lang.org/
} 


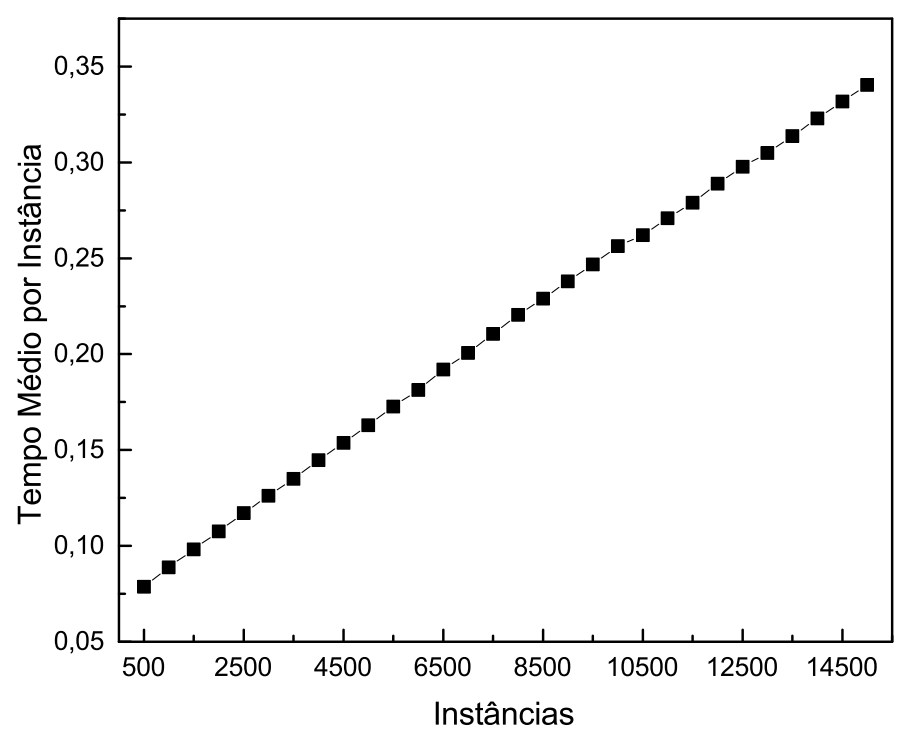

Figura 6.3: Resultados experimentais: número de instâncias versus tempo médio por instância (segundos)

indica que o algoritmo de recuperação automática para o caminho de melhor custo-benefício é adequado para ser executado em cenários de negócio reais. O tempo gasto para tratar cada instância está diretamente ligado ao número de passos de recuperação executados. Na Figura 6.3 mostra o comportamento linear do tempo médio gasto para tratar cada instância quando a carga é aumentada. Mesmo embora o tempo de resposta para um vasto conjunto de instâncias é substancial, esta proposta é capaz de reduzir significativamente a carga de trabalho em centros de atendimentos ao fornecer um mecanismo automatizado para manipular diferentes tipos de exceções ao combinar caminhos de recuperação backward e forward. Em alguns cenários de negócio, nem todas as instâncias podem ser envolvidas no cancelamento devido à aspectos semânticos. Por exemplo, clientes de alta prioridade podem não ter suas reservas canceladas se existem outros cliente de prioridade mais baixa que podem ter suas reservas canceladas, mesmo que isso signifique um maior custo para a empresa. Além disso, este algoritmo somente é disparado quando os efeitos colaterais da exceção não são autocontidos na instância em que a exceção foi detectada e, assim, afetam outras instâncias do processo. 


\section{Capítulo 7}

\section{Conclusão}

\subsection{Considerações finais}

Neste trabalho de doutorado, introduziu-se um método de composição para recuperação ciente de custos e benefícios que é capaz de encontrar e seguir caminhos alternativos que reduzam os prejuízos financeiros do tratamento de exceções. Do ponto de vista prático, esse método provê o tratamento de exceção automatizado e otimizado ao calcular os custos e benefícios de cada caminho de recuperação e escolher o caminho com a melhor relação custo-benefício disponível. Mais especificamente, o método de recuperação proposto estende a abordagem WED-flow para permitir a composição ciente de custos e benefícios de passos de recuperação transacionais backward e forward.

Diversos PAIS são baseados em modelos de processos que fornecem uma notação sólida que permite a verificação formal de propriedades de correção. Essas técnicas evitam diversos problemas estruturais graves nos modelos de processos, tais como deadlock e livelock. No entanto, esse modelos não são flexíveis suficientes para garantir uma execução robusta e confiável quando uma específica instância do processo requer desviar do comportamento esperado e definido em sua estrutura de fluxo. Devido a essa limitação, muitos PAIS são integrados com linguagens de programação procedurais, a fim de codificar rotinas específicas para o tratamento de exceção. Apesar da flexibilidade proporcionada por essas linguagens, o código do tratamento das exceção tende a crescer exponencialmente tornando-se maior do que o caminho primário por causa das muitas possibilidades de erros. Este crescimento significativo do código leva a vários problemas, tais como manutenção, teste e reutilização. Em contraste com essas abordagens, a proposta apresentada neste trabalho inclui um número reduzido de passos de recuperação que são suficientes para o gerenciamento rigoroso e eficiente do tratamento de exceções. Estes passos de recuperação, que são executados pelos procedimentos autogen-undo e autogen-redo, são homogeneamente concebido de acordo com o modelo de processos WED-flow. Isso facilita a reutilização dos passos de recuperação, minimiza o esforço envolvido na automação evolutiva, e reduz a complexidade do tratamento de exceção em ambientes dinâmicos.

Um dos requisitos para PAIS em ambientes dinâmicos é apoiar a execução de instâncias de longa duração que podem se tornar entrelaçadas ao compartilhar recursos de dados. Esse entrelaçamento gera dependências entre as instâncias que devem ser consideradas no tratamento de exceção. Nesse cenário, uma exceção pode resultar em um efeito colateral que vai além dos limites da instância do processo em que a exceção tenha sido detectada. Além disso, uma vez que pode envolver diferentes instâncias, uma exceção dentro desse cenário pode também gerar custos significativos para o negócio. 
Como discutido no Capítulo 5, o método de composição de recuperação otimizado ciente de custos e benefícios é capaz de encontrar caminhos alternativos para todas as instâncias de processo que foram afetadas pela exceção. Desta forma, a instância que minimiza as perdas financeiras decorrentes do tratamento da exceção pode ser automaticamente selecionada. Intuitivamente, quando uma exceção é detectada, o mecanismo de recuperação permite rearranjo automático do sistema, a fim de manter as instâncias dependentes consistentes. Em comparação com (Choi et al., 2002), na abordagem proposta, não há necessidade de mapear todas as dependências em tempo de projeto. Neste trabalho, observa-se que as dependências são geradas dinamicamente quando as instâncias compartilham recursos de dados durante a sua execução. Uma vez que o histórico de execução de instâncias do processo são armazenados permanentemente na forma de estados de dados, instâncias dependentes afetadas pela manipulação de exceção podem ser identificadas por meio de uma simples consulta sobre o histórico de execução, conforme mostrado na Seção 5.5.

\subsection{Sugestões para Pesquisas Futuras}

Para o prosseguimento do trabalho desenvolvido neste projeto de doutorado, há seis sugestões de pesquisa em aberto ou em andamento descritas a seguir. As quatro primeiras são propostas científicas que visam contribuições e otimizações para abordagem WED-flow. As demais propostas envolvem aspectos tecnológicos como a inclusão de ferramentas para modelagem e monitoramento da execução dos processos.

Otimização da recuperação para o caminho de melhor relação custo-benefício. Os procedimentos autogen-undo e autogen-redo são sequencialmente executados para cada instância, como descrito na Seção 5.5. Apesar disso, acredita-se que a execução desses procedimentos ainda pode ser otimizada com alternativas de computação paralela a fim de permitir que o mecanismo de recuperação encontre o caminho de melhor relação custo-benefício disponível mais rapidamente.

Ampliação da expressividade da abordagem WED-flow. Como discutido na Seção 4.3, a abordagem WED-flow é capaz de representar diferentes comportamentos de divergência (split) e convergência (join). Apesar disso, nem todas as abstrações de controle de fluxo estão claramente descritas na linguagem WED-flow. Há também comportamentos mais específicos, como milestone, que apesar de facilmente representados pela abordagem WED-flow ainda requerem uma investigação mais minuciosa. O principal desafio é representar um comportamento de controle fluxo e, ao mesmo tempo, manter a capacidade de recuperação quando alguma exceção ocorrer.

Propriedades de correção em modelos de processos WED-flow. A verificação da correção dos modelos de processos constitui de uma tarefa fundamental durante a fase de modelagem do processo. Em tempo de projeto, deve-se garantir que os modelos de processos que estão sendo descritos poderão ser corretamente executados. Por exemplo, uma instância do processo quando executado pelo PAIS não deveria ser conduzida para estados espúrios devido à erros de modelagem. Ao verificar o modelo do processo em tempo de projeto, potenciais problemas podem ser identificados antecipadamente e o modelo pode ser corrigido antes de 
sua implantação. A efetivação de técnicas para verificação de correção de esquemas de processos modelados na abordagem WED-flow ainda é uma questão de pesquisa em aberto que necessita ser melhor explorada.

Evolução e adaptação de modelos de processos WED-flow. Este trabalho tem enfoque em exceções que causam desvios do processo e requerem novos caminhos alternativos de execução. No entanto, há também a necessidade de permitir flexibilidade suficiente para tratar de novos requisitos que causem a evolução e adaptação do caminho primário. Em outras palavras, o esquema inicialmente projetado pode ser alterado para que novos requisitos sejam atendidos. Essa alteração acarreta em um problema conhecido como dynamic change bug. Devido as suas características transacionais, acredita-se que os efeitos colaterais causados por esse problema podem ser minimizados pela abordagem WED-flow

Ferramenta para modelagem visual de processos WED-flow. Atualmente, uma das iniciativas de pesquisa do grupo DATA tem sido a definição de uma linguagem declarativa baseada no padrão SQL para manipulação dos componentes fundamentais da abordagem WED-flow. Entretanto, ferramentas visuais intuitivas que permitam a modelagem dos processos ainda necessitam ser desenvolvidas.

Monitoramento de execução do processos WED-flow. Como mencionado na Seção 6.1, o núcleo e o gerenciador de recuperação do WED-flow são atualmente implementados na forma de protótipos que são usados para execução de provas de conceito, como apresentado na Seção 6.2. Apesar disso, uma ferramenta visual para o monitoramento e acompanhamento da execução dos processos também ainda necessita ser melhor implementada. 


\section{Referências Bibliográficas}

Aalst (1998) Wil M. P. van der Aalst. The application of petri nets to workflow management. Journal of circuits, systems, and computers, 8(01):21-66. Citado na pág. 9

Aalst et al. (2003) Wil M. P. van der Aalst, Arthur H. M. Ter Hofstede, Bartek Kiepuszewski e Alistair P. Barros. Workflow patterns. Distributed and Parallel Databases, 14(1):5-51. ISSN 0926-8782. Citado na pág. 11, 51

Aalst et al. (2009) Wil. M. P. van der Aalst, M. Pesic e H. Schonenberg. Declarative workflows: Balancing between flexibility and support. Computer Science - Research and Development, 23 (2):99-113. ISSN 0949-2925. Citado na pág. 9, 16, 18

Adams et al. (2007) Michael Adams, Arthur H.M. ter Hofstede, Wil M.P. van der Aalst e David Edmond. Dynamic, extensible and context-aware exception handling for workflows. Em Proceedings of the 2007 OTM Confederated International Conference on On the Move to Meaningful Internet Systems: CoopIS, DOA, ODBASE, GADA, and IS - Volume Part I, OTM'07, páginas 95-112, Berlin, Heidelberg. Springer-Verlag. ISBN 3-540-76846-7, 978-3-540-76846-3. Citado na pág. 4

Agrawal e Abbadi (1992) Divyakant Agrawal e Amr El Abbadi. Transaction management in database systems. Em Ahmed K. Elmagarmid, editor, Database Transaction Models for Advanced Applications, páginas 1-31. Morgan Kaufmann Publishers Inc., San Francisco, CA, USA. ISBN 1-55860-214-3. Citado na pág. 20

Alonso (2005) Gustavo Alonso. Transactional business processes. Em Process-Aware Information Systems, páginas 257-278. John Wiley \& Sons, Inc. ISBN 9780471741442 . Citado na pág. 32

Alonso et al. (1996) Gustavo Alonso, Divyakant Agrawal, A El Abbadi, Mohan Kamath, Roger Günthör e Chandrasekaran Mohan. Advanced transaction models in workflow contexts. Em Proceedings of the 12th International Conference on Data Engineering, páginas 574-581. IEEE. Citado na pág. 4

Angarita et al. (2015) Rafael Angarita, Marta Rukoz e Yudith Cardinale. Modeling dynamic recovery strategy for composite web services execution. World Wide Web, 19(1):89-109. ISSN 1573-1413. Citado na pág. 5

Barghouti e Kaiser (1991) Naser Saleh Barghouti e Gail E. Kaiser. Concurrency control in advanced database applications. ACM Computing Surveys, 23(3):269-317. ISSN 0360-0300. Citado na pág. 44

Bergstra et al. (2001) J. A. Bergstra, A. Ponse e Scott A. Smolka, editors. Handbook of Process Algebra. Elsevier Science, Amsterdam, The Netherlands. ISBN 0444828303. Citado na pág. 1

Bernstein et al. (1987) Philip A. Bernstein, Vassco Hadzilacos e Nathan Goodman. Concurrency Control and Recovery in Database Systems. Addison Wesley Publishing Company, Boston, MA, USA. ISBN 0-201-10715-5. Citado na pág. 21 
Bhiri et al. (2006) Sami Bhiri, Claude Godart e Olivier Perrin. Transactional patterns for reliable web services compositions. Em Proceedings of the 6th International Conference on Web Engineering, ICWE '06, páginas 137-144, New York, NY, USA. ISBN 1-59593-352-2. doi: 10.1145/1145581.1145613. Citado na pág. 4, 5, 54

Björk (1973) Lawrence A. Björk. Recovery scenario for a db/dc system. Em Proceedings of the ACM Annual Conference, ACM '73, páginas 142-146, New York, NY, USA. ACM. Citado na pág. 21

BPMN (2011) BPMN. Business process model and notation version 2.0, Jan 2011. URL http: //www.omg.org/spec/BPMN/2.0. Citado na pág. 1

Bry et al. (2006) François Bry, Michael Eckert, Paula-Lavinia Patrânjan e Inna Romanenko. Realizing business processes with eca rules: Benefits, challenges, limits. Em Proceedings of the 4th International Conference on Principles and Practice of Semantic Web Reasoning, PPSWR'06, páginas 48-62, Berlin, Heidelberg. Springer-Verlag. ISBN 3-540-39586-5, 978-3-540-39586-7. Citado na pág. $9,15,16$

Bushehrian et al. (2012) Omid Bushehrian, Salman Zare e Navid Keihani Rad. A workflow-based failure recovery in web services composition. Journal of Software Engineering and Applications, 5(2):89-95. doi: 10.4236/jsea.2012.52014. Citado na pág. 5

Cardinale et al. (2011) Yudith Cardinale, Joyce El Haddad, Maude Manouvrier e Marta Rukoz. Transactional-aware web service composition: A survey. Em Stephan Reiff-Marganiec e Marcel Tilly, editors, IGI Global-Advances in Knowledge Management (AKM) Book Series, páginas 116141. IGI Global. Citado na pág. 5

Casati et al. (1999) Fabio Casati, Stefano Ceri, Stefano Paraboschi e Guiseppe Pozzi. Specification and implementation of exceptions in workflow management systems. ACM Transactions on Database Systems (TODS), 24(3):405-451. Citado na pág. 4

Choi et al. (2002) Injun Choi, Chulsoon Park e Changwoo Lee. Task net: Transactional workflow model based on colored petri net. European Journal of Operational Research, 136(2):383-402. ISSN 0377-2217. Citado na pág. 4, 83

Cormen et al. (2009) Thomas H. Cormen, Charles E. Leiserson, Ronald L. Rivest e Clifford Stein. Greedy algorithms. Em Introduction to Algorithms, páginas 414-450. MIT Press, London, UK. Citado na pág. 68

DAGMan (2016) DAGMan. Dagman (directed acyclic graph manager) official website, 2016. URL http://research.cs.wisc.edu/htcondor/dagman/dagman.html. Citado na pág. 11

DATA (2016) DATA. Data group official website, 2016. URL http://data.ime.usp.br. Citado na pág. 46

Davies Jr (1973) Charles T. Davies Jr. Recovery semantics for a db/dc system. Em Proceedings of the ACM Annual Conference, ACM '73, páginas 136-141, New York, NY, USA. ACM. Citado na pág. 21

Davies Jr (1978) Charles T. Davies Jr. Data processing spheres of control. IBM Systems Journal, 17(2):179-198. ISSN 0018-8670. Citado na pág. 21

Dayal (1994) Umeshwar Dayal. Active Database Systems: Triggers and Rules for Advanced Database processing. Morgan Kaufmann Publishers Inc., San Francisco, CA, USA. ISBN 1558603042. Citado na pág. 15 
Dumas et al. (2005) Marlon Dumas, Wil van der Aalst e Arthur H. M. ter Hofstede, editors. Process-Aware Information Systems: Bridging People and Software through Process Technology. Wiley, New York, NY, USA. Citado na pág. 1, 8

Eder e Liebhart (1995) Johann Eder e Walter Liebhart. The workflow activity model wamo. Em Proceedings of the 3rd International Conference on Cooperative Information Systems, volume 15 of CoopIS'95, páginas 87-98, Vienna, Austria. Citado na pág. 2

Eder e Liebhart (1996) Johann Eder e Walter Liebhart. Workflow recovery. Em Proceedings of the First IFCIS International Conference on Cooperative Information Systems (CoopIS'96), páginas 124-134. IEEE. Citado na pág. 2, 3, 4

Eder e Liebhart (1998) Johann Eder e Walter Liebhart. Contributions to exception handling in workflow management. Em Proceedings EDBT Workshop on Workflow Management Systems, páginas $3-10$, Valencia, Spain. Citado na pág. 2

Elmagarmid (1992) Ahmed K. Elmagarmid, editor. Database Transaction Models for Advanced Applications. Morgan Kaufmann Publishers Inc., San Francisco, CA, USA. ISBN 1-55860-214-3. Citado na pág. 4, 20, 21

Elmasri e Navathe (1999) Ramez A. Elmasri e Shankrant B. Navathe. Fundamentals of Database Systems. Addison-Wesley Longman Publishing Co., Inc., Boston, MA, USA, 3rd ed. ISBN 0805317554. Citado na pág. 21

Ferreira et al. (2010a) João Eduardo Ferreira, Wu Qinyi, Simon Malkowski e Calton Pu. Towards flexible event-handling in workflows through data states. Em Proceedings of 6th World Congress on Services (SERVICES-1), páginas 344-351. Citado na pág. 46, 47

Ferreira et al. (2010b) João Eduardo Ferreira, Osvaldo Kotaro Takai, Simon Malkowski e Calton $\mathrm{Pu}$. Reducing exception handling complexity in business process modeling and implementation: the wed-flow approach. Em Proceedings of the International Conference on the Move to Meaningful Internet Systems - Volume Part I, OTM'10, páginas 150-167, Berlin, Heidelberg. Springer-Verlag. ISBN 3-642-16933-3, 978-3-642-16933-5. Citado na pág. vii, 6, 46, 47, 48, 50

Ferreira et al. (2012) João Eduardo Ferreira, Kelly Rosa Braghetto, Osvaldo Kotaro Takai e Calton $\mathrm{Pu}$. Transactional recovery support for robust exception handling in business process services. Em Proceedings of the 19th International Conference on Web Services (ICWS), páginas 303-310. Citado na pág. 6, 46, 47, 62

Fokkink (2000) Wan Fokkink. ntroduction to Process Algebra. Springer-Verlag Berlin Heidelberg, 1st ed. ISBN 978-3-662-04293-9. Citado na pág. 9, 12

Garcia et al. (2012a) Marcela Ortega Garcia, Kelly Rosa Braghetto, Calton Pu e João Eduardo Ferreira. An implementation of a transaction model for business process systems. Journal of Information and Data Management, 3(3):271-286. Citado na pág. 46, 78

Garcia et al. (2012b) Marcela Ortega Garcia, Pedro Paulo de S. B. da Silva, Kelly Rosa Braghetto e João Eduardo Ferreira. Wed-tool: uma ferramenta para o controle de execução de processos de negócio transacionais. Em Proceedings of the 27th Brazillian Symposium on Databases - Demos and Applications Session. Citado na pág. 79

Garcia (2013) Marcelo Ortega Garcia. Implementação do arcabouço wed-flow para controle de processos transacionais. Dissertação de Mestrado, Universidade de São Paulo, São Paulo, SP, Brasil. Citado na pág. 78

García-Molina (1983) Héctor García-Molina. Using semantic knowledge for transaction processing in a distributed database. ACM Transactions on Database Systems (TODS), 8(2):186-213. ISSN 0362-5915. Citado na pág. 44 
García-Molina e Salem (1987) Héctor García-Molina e Kenneth Salem. Sagas. ACM SIGMOD Record, 16(3):249-259. ISSN 0163-5808. Citado na pág. 4, 31, 45, 54, 56

Georgakopoulos et al. (1995) Dimitrios Georgakopoulos, Mark Hornick e Amit Sheth. An overview of workflow management: From process modeling to workflow automation infrastructure. Distributed and Parallel Databases - Special issue on software support for work flow management, 3(2):119-153. ISSN 0926-8782. Citado na pág. 3

Georgakopoulos et al. (1996) Dimitrios Georgakopoulos, Mark F. Hornick e F. Manola. Customizing transaction models and mechanisms in a programmable environment supporting reliable workflow automation. IEEE Transactions on Knowledge and Data Engineering, 8(4):630-649. ISSN 1041-4347. Citado na pág. 4

Gray (1981) Jim Gray. The transaction concept: Virtues and limitations (invited paper). Em Proceedings of the 7th International Conference on Very Large Data Bases, volume 7 of VLDB '81, páginas 144-154. VLDB Endowment. Citado na pág. 20, 23

Gray e Reuter (1992) Jim Gray e Andreas Reuter. Transaction Processing: Concepts and Techniques. Morgan Kaufmann Publishers Inc., San Francisco, CA, USA, 1st ed. ISBN 1558601902. Citado na pág. 21

Gupta et al. (2011a) Nitin Gupta, Lucja Kot, Sudip Roy, Gabriel Bender, Johannes Gehrke e Christoph Koch. Entangled queries: Enabling declarative data-driven coordination. Em Proceedings of the 2011 ACM SIGMOD International Conference on Management of Data, SIGMOD '11, páginas 673-684, New York, NY, USA. ACM. ISBN 978-1-4503-0661-4. Citado na pág. 27, 29

Gupta et al. (2011b) Nitin Gupta, Milos Nikolic, Sudip Roy, Gabriel Bender, Lucja Kot, Johannes Gehrke e Christoph Koch. Entangled transactions. VLDB Endowment, 4(11):887-898. Citado na pág. 27, 30, 44

Hagen e Alonso (2000) Claus Hagen e Gustavo Alonso. Exception handling in workflow management systems. IEEE Transactions on Software Engineering, 26(10):943-958. ISSN 0098-5589. Citado na pág. 4

Herlihy e Wing (1990) Maurice P. Herlihy e Jeannette M. Wing. Linearizability: A correctness condition for concurrent objects. ACM Transactions on Programming Languages and Systems (TOPLAS), 12(3):463-492. ISSN 0164-0925. Citado na pág. 41, 43, 45

Hoffman e Bateson (2016) K. Douglas Hoffman e John E. G. Bateson. Services Marketing: Concepts, Strategies, \& Cases. Cengage Learning, 5th ed. ISBN 9781285429786. Citado na pág. 3

Karnath e Ramamritham (1998) Mohan Karnath e Krithi Ramamritham. Failure handling and coordinated execution of concurrent workflows. Em Proceedings of 14 th International Conference on Data Engineering, páginas 334-341. Citado na pág. 4

Kot et al. (2010) Lucja Kot, Nitin Gupta, Sudip Roy, Johannes Gehrke e Christoph Koch. Beyond isolation: Research opportunities in declarative data-driven coordination. ACM SIGMOD Record, 39(1):27-32. ISSN 0163-5808. Citado na pág. 21

Lerner et al. (2010) Barbara Staudt Lerner, Stefan Christov, Leon J Osterweil, Reda Bendraou, Udo Kannengiesser e Alexander Wise. Exception handling patterns for process modeling. IEEE Transactions on Software Engineering, 36(2):162-183. Citado na pág. 4

Liberato et al. (2014) Rafael Liberato, André Luis Schwerz, Osvaldo Kotaro Takai e João Eduardo Ferreira. Gerenciador de dados compartilhados entre processos de negócio: Data-control process para wed-tool. Em VIII Workshop Brasileiro em Gestão de Processos de Negócios, volume 02 of WBPM 2014, páginas 26-33, Londrina, PR, Brasil. X Simpósio Brasileiro de Sistemas de Informação. Citado na pág. 6 
Liberato et al. (2015) Rafael Liberato, André Luis Schwerz, Calton Pu e João Eduardo Ferreira. Abordagem transacional para padrões de controle de fluxo de processos científicos e de negócios. Em XXX Simpósio Brasileiro de Banco de Dados, SBBD 2015, páginas 15-20, Petrópolis, RJ, Brasil. XXX Simpósio Brasileiro de Banco de Dados. Citado na pág. vii, 6, 53, 54

Liu et al. (1999) Ling Liu, Calton $\mathrm{Pu}$ e Wei Tang. Continual queries for internet scale eventdriven information delivery. IEEE Transactions on Knowledge and Data Engineering, 11(4): 610-628. ISSN 1041-4347. Citado na pág. 50

Lomet et al. (2005) David B. Lomet, Roger S. Barga, Mohamed F. Mokbel, German Shegalov, Rui Wang e Yunyue Zhu. Immortal db: Transaction time support for sql server. Em Proceedings of the 2005 ACM SIGMOD International Conference on Management of Data, SIGMOD '05, páginas 939-941, New York, NY, USA. ACM. ISBN 1-59593-060-4. doi: 10.1145/1066157.1066295. Citado na pág. 50

Lu e Sadiq (2007) Ruopeng Lu e Shazia Sadiq. A Survey of Comparative Business Process Modeling Approaches, páginas 82-94. BIS'07. Springer Berlin Heidelberg, Berlin, Heidelberg. ISBN 978-3-540-72034-8. Citado na pág. 15, 18

Milner et al. (1992) Robin Milner, Joachim Parrow e David Walker. A calculus of mobile processes, i. Information and Computation, 100(1):1-40. ISSN 0890-5401. doi: 10.1016/0890-5401(92) 90008-4. Citado na pág. 1, 14

Montali (2010) Marco Montali. Specification and Verification of Declarative Open Interaction Models. Springer-Verlag Berlin Heidelberg. ISBN 978-3-642-14538-4. Citado na pág. vii, 16

Montali et al. (2010) Marco Montali, Maja Pesic, Wil M. P. van der Aalst, Federico Chesani, Paola Mello e Sergio Storari. Declarative specification and verification of service choreographiess. ACM Trans. Web, 4:3:1-3:62. ISSN 1559-1131. Citado na pág. 16

Moss (1985) J. E. B. Moss. Nested Transactions: An Approach to Reliable Distributed Computing. Massachusetts Institute of Technology, Cambridge, MA, USA. ISBN 0-262-13200-1. Citado na pág. $23,32,44$

Moss (2011) J.Eliot B. Moss. Transactions, nested. Em David Padua, editor, Encyclopedia of Parallel Computing, páginas 2086-2093. Springer US. ISBN 978-0-387-09765-7. Citado na pág. 32, 33,45

Murata (1989) Tadao Murata. Petri nets: Properties, analysis and applications. Proceedings of the IEEE, 77(4):541-580. ISSN 0018-9219. doi: 10.1109/5.24143. Citado na pág. 1, 9, 11

Nodine e Zdonik (1990) Marian H. Nodine e Stanley B. Zdonik. Cooperative transaction hierarchies: A transaction model to support design applications. Em Proceedings of the 16th International Conference on Very Large Data Bases, VLDB '90, páginas 83-94, San Francisco, CA, USA. Morgan Kaufmann Publishers Inc. ISBN 1-55860-149-X. Citado na pág. 44

OASIS (2007) OASIS. Web services business process execution language version 2.0. Relatório técnico, OASIS Standard. Citado na pág. 1

Padilha et al. (2017) Bruno Padilha, André Luis Schwerz e Rafael Liberato Roberto. Wed-sql: A relational framework for design and implementation of process-aware information systems. Em Proceedings of the IEEE 37th International Conference on Distributed Computing Systems Workshops (ICDCSW'17), páginas 364-369. doi: 10.1109/ICDCSW.2017.46. Citado na pág. 6

Pegasus (2016) Pegasus. Pegasus workflow management system official website, 2016. URL http://pegasus.isi.edu. Citado na pág. 11, 12 
Pesic (2008) M. Pesic. Constraint-Based Workflow Management Systems: Shifting Control to Users. Tese de Doutorado, Eindhoven University of Technology. Citado na pág. ix, 17

Pesic et al. (2007) M. Pesic, M. H. Schonenberg, N. Sidorova e W. M. P. Van Der Aalst. Constraintbased workflow models: Change made easy. Em Proceedings of the 2007 OTM Confederated International Conference on On the Move to Meaningful Internet Systems: CoopIS, DOA, ODBASE, GADA, and IS - Volume Part I, OTM'07, páginas 77-94, Berlin, Heidelberg. Springer-Verlag. ISBN 3-540-76846-7, 978-3-540-76846-3. Citado na pág. 16

Pnueli (1977) Amir Pnueli. The temporal logic of programs. Em Proceedings of the 18th Annual Symposium on Foundations of Computer Science, SFCS '77, páginas 46-57, Washington, DC, USA. IEEE Computer Society. Citado na pág. 18

PostgreSQL (2016) PostgreSQL. Postgresql official website, 2016. URL https://www.postgresql. org. Citado na pág. 78

Ramamritham e Pu (1995) Krithi Ramamritham e Calton Pu. A formal characterization of epsilon serializability. IEEE Transactions on Knowledge and Data Engineering, 7(6):997-1007. ISSN 1041-4347. Citado na pág. 44

Reichert e Weber (2012) Manfred Reichert e Barbara Weber. Enabling flexibility in processaware information systems: challenges, methods, technologies. Springer-Verlag Berlin Heidelberg, 1 ed. Citado na pág. $1,2,8,9,16,17,19$

Reuter et al. (1997) Andreas Reuter, Kerstin Schneider e Friedemann Schwenkreis. Contracts revisited. Em Sushil Jajodia e Larry Kerschberg, editors, Advanced Transaction Models and Architectures, páginas 127-151. Springer US. ISBN 978-1-4613-7851-8. Citado na pág. 4

Russell et al. (2006a) Nick Russell, Arthur H. M. ter Hofstede, Wil M. P. van der Aalst e Nataliya Mulyar. Workflow control-flow patterns: A revised view. Relatório Técnico BPM-06-22, BPM Center. Citado na pág. 51

Russell et al. (2006b) Nick Russell, Wil M.P. van der Aalst e Arthur H. M. Ter Hofstede. Workflow Exception Patterns, páginas 288-302. CAiSE'06. Springer Berlin Heidelberg, Berlin, Heidelberg. ISBN 978-3-540-34653-1. doi: 10.1007/11767138_20. Citado na pág. 4

Salem et al. (1994) Kenneth Salem, HÃ@cctor GarcÃa-Molina e Jeannie Shands. Altruistic locking. ACM Transactions on Database Systems (TODS), 19(1):117-165. ISSN 0362-5915. Citado na pág. 25,44

Schwerz et al. (2018) André Luis Schwerz, Rafael Liberato, Calton Pu e João Eduardo Ferreira. Robust and reliable process-aware information system. Artigo Aceito para Publicação, 2018. Citado na pág. 6

Sheth e Rusinkiewicz (1993) Amit Sheth e Marek Rusinkiewicz. On transactional workflows. Data Engineering Bulletin, 16(2):20-25. Citado na pág. 4

Silva (2013) Pedro Paulo Souza Bento da Silva. Uma abordagem transacional para o tratamento de excecuções em processos de negócio. Dissertação de Mestrado, Universidade de São Paulo, São Paulo, SP, Brasil. Citado na pág. 46, 79

Sun et al. (2011) Chang-ai Sun, Elie el Khoury e Marco Aiello. Transaction management in serviceoriented systems: Requirements and a proposal. IEEE Transactions on Services Computing, 4 (2):167-180. ISSN 1939-1374. Citado na pág. 5

Taverna (2016) Taverna. Taverna workflow system official website, 2016. URL http://taverna. incubator.apache.org. Citado na pág. 11 
Weber et al. (2006) Barbara Weber, Manfred Reichert e Werner Wild. Case-Base Maintenance for CCBR-Based Process Evolution, páginas 106-120. Springer Berlin Heidelberg, Berlin, Heidelberg. ISBN 978-3-540-36846-5. Citado na pág. 8

WED-flow (2016) WED-flow. Wed-flow official website, 2016. URL http://data.ime.usp.br/ wed-flow. Citado na pág. 46

WED-tool (2016) WED-tool. Wed-tool official website, 2016. URL http://data.ime.usp.br/ wedflow/wed-tool.html. Citado na pág. 78

Weihl (1988) William Edward Weihl. Commutativity-based concurrency control for abstract data types. Em Proceedings of the 21th Annual Hawaii International Conference on Software Track, páginas 205-214, Los Alamitos, CA, USA. IEEE. ISBN 0-8186-0842-0. Citado na pág. 44

Weikum e Schek (1992) Gerhard Weikum e Hans-Jörg Schek. Concepts and applications of multilevel transactions and open nested transactions. Em Ahmed K. Elmagarmid, editor, Database Transaction Models for Advanced Applications, páginas 515-553. Morgan Kaufmann Publishers Inc., San Francisco, CA, USA. ISBN 1-55860-214-3. Citado na pág. 32, 33, 45

Weske (2007) Mathias Weske. Business Process Management: Concepts, Languages, Architectures. Springer-Verlag New York, Inc., Secaucus, NJ, USA. ISBN 3540735216. Citado na pág. 1, 8, 9, 10, 11,12

Wächter e Reuter (1992) Helmut Wächter e Andreas Reuter. The contract model. Em Ahmed K. Elmagarmid, editor, Database Transaction Models for Advanced Applications, páginas 219-263. Morgan Kaufmann Publishers Inc., San Francisco, CA, USA. ISBN 1-55860-214-3. Citado na pág. $4,35,36,41,45$

Zhang et al. (1994) Aidong Zhang, Marian Nodine, Bharat Bhargava e Omran Bukhres. Ensuring relaxed atomicity for flexible transactions in multidatabase systems. SIGMOD Record, 23(2):6778. ISSN 0163-5808. Citado na pág. 4 